University of Louisville

ThinkIR: The University of Louisville's Institutional Repository

Electronic Theses and Dissertations

8-2009

\title{
"Metaphors we teach by": representations of disciplinary and teacherly identity.
}

Stephen Edwin Neaderhiser 1978-

University of Louisville

Follow this and additional works at: https://ir.library.louisville.edu/etd

\section{Recommended Citation}

Neaderhiser, Stephen Edwin 1978-, "'Metaphors we teach by": representations of disciplinary and teacherly identity." (2009). Electronic Theses and Dissertations. Paper 1044.

https://doi.org/10.18297/etd/1044

This Doctoral Dissertation is brought to you for free and open access by ThinkIR: The University of Louisville's Institutional Repository. It has been accepted for inclusion in Electronic Theses and Dissertations by an authorized administrator of ThinkIR: The University of Louisville's Institutional Repository. This title appears here courtesy of the author, who has retained all other copyrights. For more information, please contact thinkir@louisville.edu. 
"METAPHORS WE TEACH BY":

REPRESENTATIONS OF DISCIPLINARY AND TEACHERLY IDENTITY

By

Stephen Edwin Neaderhiser

B.A., University of Kansas, 2002

M.A., University of Kansas, 2004

\author{
A Dissertation \\ Submitted to the Faculty of the \\ Graduate School of the University of Louisville \\ In Partial Fulfillment of the Requirements \\ for the Degree of
}

Doctor of Philosophy

Department of English

University of Louisville

Louisville, Kentucky

August 2009 


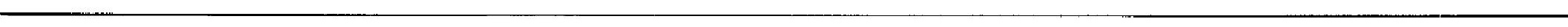


Copyright 2009 by Stephen E. Neaderhiser

All rights reserved 
"METAPHORS WE TEACH BY":

REPRESENTATIONS OF DISCIPLINARY AND TEACHERLY IDENTITY

By

Stephen Edwin Neaderhiser

B.A., University of Kansas, 2002

M.A., University of Kansas, 2004

A Dissertation Approved on

August 3, 2009

by the following Dissertation Committee:

\author{
Dissertation Director, Karen Kopelson \\ Associate Professor of English
}

Joanna Wolfe
Associate Professor of English

Susan Ryan

Associate Professor of English

Bruce Horner

Professor of English

Frank Farmer

Associate Professor of English, University of Kansas 


\section{DEDICATION}

This dissertation is dedicated to Bill Neaderhiser.

"I wish I was a little rock, Just sittin' on a hill.

Doin' nothin' all day long, Except for sittin' still.

I wouldn't eat, I wouldn't sleep, I wouldn't even wash.

I'd just sit and rest myself, A million years, by gosh." 


\section{ACKNOWLEDGEMENTS}

I would like to thank my dissertation committee and the other faculty members at both UofL and KU for their guidance and encouragement. In particular, I am extremely thankful for the help and support I received from my dissertation director, Dr. Karen Kopelson. She has been an instrumental part of my graduate work since I first began at the University of Louisville, and she has been there to help give shape to this ambitious project I started so many years ago. She has given meticulous and thoughtful feedback not only on my writing, but also my teaching and professional development throughout my entire career at UofL. I'm happy to call her my mentor as well as my friend. I must also thank Dr. Joanna Wolfe for her expertise as it factored into this project as well as my other scholarly, published efforts. Her patience with my constant questions made it easy and comfortable for me to turn to her with any concerns I had, from IRB issues to data representation. And so much of my scholarly work would never have gone far without

Dr. Frank Farmer, who has observed my development as a scholar and as a teacher since I first began. He inspired me to think about the pedagogical and theoretical issues of the field, and the class that he and Dr. Amy Devitt co-taught provided the initial inspiration for this project. He has also always been there through the rocky moments of my graduate career - I will never forget his presence as a part of my progress, and I am proud cardcarrying Bakhtinian, thanks to him. I also greatly appreciate Dr. Bruce Horner's commitment to my dissertation with his incisive feedback that so often made me realize the other perspectives I had previously left unconsidered as I put together my arguments. 
Dr. Horner gave me a new awareness of audience, and I thank him for his interest and willingness to challenge me as I prepared this dissertation. I would also like to thank Dr. Susan Ryan, who offered her time and effort to ensure my dissertation's successful completion. She not only became an integral part of my dissertation committee, she also reminded me of the value and importance of professionalism that is so important to academic work - even that work that never appears on the page.

In addition to my committee, I would like to thank Dr. Carol Mattingly, who, in addition to being the first faculty member to welcome me into UofL before I arrived, also provided me with many enriching opportunities as part of the Writing Centers Research Project that continue to benefit my scholarly development. Additionally, the courses that I took from Dr. Bronwyn Williams and Dr. Mary Rosner were instrumental to my graduate career, and gave me valuable ways to think about the work that I do as part of the field of Rhetoric and Composition. I would also like to thank Dr. Marjorie Swann, who first pointed me in the direction of Rhetoric and Composition as a field of graduate study, and Dr. James Hartman, whose seminar on metaphor theory was the most influential class I never took.

I also want to thank my partner Angela, for listening to endless amounts of rambling thoughts on metaphor while also teaching me to play tennis and ice skate, sharing laughter with me, and giving me something to look forward to. And, finally, I must thank my friends from Alter-Ego and Id for keeping things in perspective and giving me so many entertaining (and sometimes explosive) stories to tell. 


\section{ABSTRACT \\ "METAPHORS WE TEACH BY": \\ REPRESENTATIONS OF DISCIPLINARY AND TEACHERLY IDENTITY \\ Stephen Edwin Neaderhiser}

August 3, 2009

This dissertation is a theoretical examination and textual analysis of the metaphors used to describe the act of writing and the teaching of writing. Within Rhetoric and Composition, there are specific conceptual metaphors that are instrumental to how teachers and compositionists describe the how writing development occurs, and what role teachers have in encouraging that development. This dissertation excavates the metaphoric interaction that has helped to shape the discipline of Rhetoric and Composition. I argue that the metaphors of writing run the risk of becoming "blackboxed," uncritically accepted (or resisted), which can lead to an unbalanced interactive relationship between members of Rhetoric and Composition and the metaphors they use to teach writing. In this dissertation, I use a synthesis of metaphor theory to understand the interactive potential of the conceptual metaphors used to describe and teach writing, in a progressively narrowed perspective that addresses the identities metaphorically available to both the discipline at large as well as the individual teachers within Rhetoric and Composition. 
This dissertation is divided into four chapters. Chapter I reviews the theoretical views of metaphor that guide this project. This chapter also provides insight into how metaphors become morally defined, as well as (dangerously) disregarded when deemed "dead.” Chapter II examines the conceptual metaphor of WRITING-IS-PROCESS. This chapter charts the 40-year lifespan of PROCESS, providing snapshots representing the many shifts and reinvigorations that characterize the continued vitality and power of the metaphor as part of the identities available to teachers and scholars of writing. Chapter III narrows the focus further to examine the metaphors dominant within the genre of the teacher narrative. In such narratives, the teacherly experience is metaphorized through three key conceptual metaphors: TEACHING-IS-STORY, TEACHING-IS-COMMUNITY, and TEACHING-IS-CONVERSATION. These metaphors can characterize teacherly experience in productive ways, but they can also, when not fully attended to, create a narrative trajectory that depicts the teacherly identity unproductively. Chapter IV focuses localized teacherly identity within statements of teaching philosophy. This chapter draws from collected teaching statements to identify the metaphoric trends in identity construction as engaged by both novice and more experienced members of Rhetoric and Composition. 


\section{TABLE OF CONTENTS}

PAGE

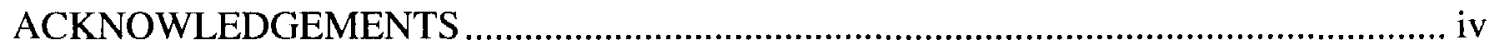

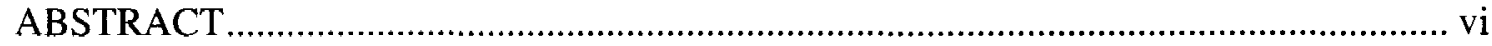

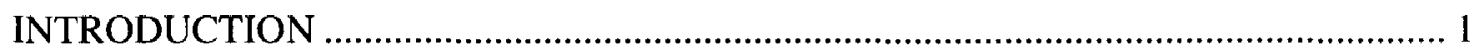

\section{CHAPTER}

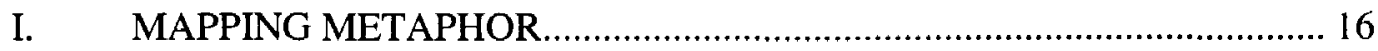

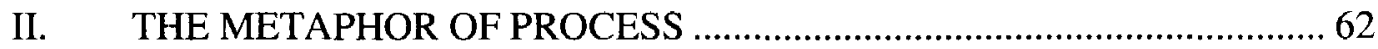

III. SHAPING OUR STORIES AS THEY SHAPE US: METAPHOR AND THE TEACHER NARRATIVE............................................................. 122

IV. INVENTING A TEACHERLY IDENTITY: TEACHING STATEMENTS AND METAPHORIC IDENTITY ……………………... 171

CONCLUSION

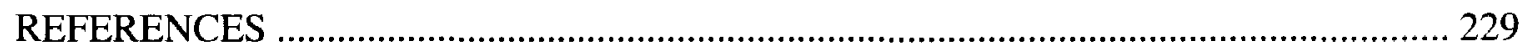

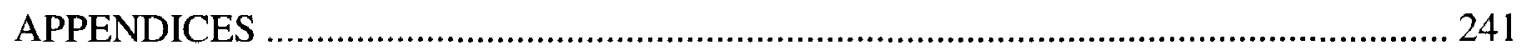

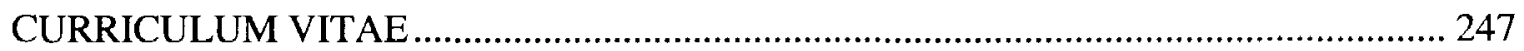




\section{INTRODUCTION}

\section{TRAWLING FOR METAPHOR}

What is a metaphor? It's for whatever you want it to be. James Hartman

There are so many entry points available for a discussion of the metaphors fundamental to the field of Rhetoric and Composition. Forty years ago, the books and writings of Donald Murray, Peter Elbow, and those who followed them helped to form one of the most dominant metaphors of the discipline, packaged into the mantra "Writing is process." Two thousand years before that, Aristotle first provided the Western conceptualization of metaphor, as part of the figurative lexicon ornamenting poetic discourse. In 1980, George Lakoff and Mark Johnson, building on (while departing from) a tradition of theory and conversation on the topic of metaphor, asserted that metaphors were not simply figurative tropes, but were the very foundation of how we perceive, conceive of, and shape human experience and the world in which we live. And, throughout the decades since the establishment of Rhetoric and Composition as a discipline (and even before, in other discussions of writing), the metaphors for the act of writing and its transmission through teaching and learning have evolved to become a part of our everyday scholarly and teacherly discourse.

The metaphors that exist and proliferate within the field of Rhetoric and Composition have an instrumental, fundamental role in the (continued) shaping of disciplinary and teacherly identity. Many of the metaphors used make sense of the 
experience of the writer and/or teacher might be quickly and easily recognizable to many members of the disciplinary community, metaphors such as the "banking concept" of teaching (Freire), the "ongoing conversation" of writing and/or academia (Burke), the "contact zone" of the classroom (Pratt). As metaphors such as these are introduced into scholarship, their metaphoric extensions become absorbed into the scholarly and pedagogical discussions within the field. They become more than metaphoric exemplifications of a concept; the burgeoning metaphoric framework actually has the ability to merge with the concept. In this way, the metaphors of Rhetoric and Composition become active agents in the shaping of pedagogical philosophies shared by the community at large, as well as those held by individual teachers within that community.

George Lakoff and Mark Johnson's contribution to metaphor theory stands as a primary point of influence within this project. In their book, Metaphors We Live By, they make the assertion that metaphors not only allow us to explain the human experience, but that these metaphors integrate into conceptual systems that define how the human experience is experienced. These systems, grounded in metaphoric extension, "govern our everyday functioning," they argue, so that "the way we think, what we experience, and what we do every day is very much a matter of metaphor" (3). In order to identify these overarching metaphoric structures, Lakoff and Johnson provide the term “conceptual metaphor.” By looking at several conceptual metaphors, such as TIME-ISMONEY, LIFE-IS-JOURNEY, and LOVE-IS-WAR, they establish a theoretical model for understanding how metaphoric meaning becomes part of conceptual, cognitive systems of human experience. 
When we look at the more narrowed discourse community of Rhetoric and Composition (as opposed to the entirety of human discourse), we find many instances of conceptual metaphor. For example, the act of participating in scholarly writing for academic purposes, metaphorically described as joining an "ongoing conversation," plays a large role in the way members of Rhetoric and Composition see their own roles as researchers and disciplinary scholars as well as in how teachers of composition present the act of writing to students (Murphy; Olson; Geisler; Bruffee; Trimbur; Davidson \& Crateau; Lunsford). However, the use of the conceptual metaphor of CONVERSATION goes well beyond being a figurative device to exemplify a single point. The act of writing, as well as the arena(s) of which that writing is a part, becomes that conversation, as members of the community begin to apply the conceptual filter of the larger metaphor to the many aspects of writing. The resulting conceptual metaphor (CONVERSATION) becomes inherent to the way members of the disciplinary community understand the very nature of the field, as well as their own placement and agency within the field as individual teachers and scholars.

Lakoff and Johnson demonstrate how the conceptual metaphor is an integral part of human language and the shaping of human experience. However, this is not the only aspect of metaphor theory that informs this project. In addition to the notion of metaphoric conceptual frameworks, the actual process of transformation affecting the ongoing evolutionary impact of the metaphors themselves highlights the continual metaphoricity within Rhetoric and Composition. For many scholars of metaphor, a defining characteristic of metaphor is its mutability - its ability to shape meaning (as Lakoff and Johnson suggest) while having the potential to be (re)shaped by the 
introduction of new connections and associations. These new connections extend beyond the individual components being metaphorically linked ("academia" and "conversation," for example, or "writing" and "process), and these metaphoric extensions stimulate new discovery and generated meaning through a recognition of both similarities and differences within the metaphor (Richards; Black; Linzey; Ricœur; Derrida). In this process, the metaphor transforms both of the elements within, as the commonplaces that are associated with each element merge, mesh, and meld together. Thus, the metaphor becomes something more, and different, than its parts. Combining these theories of metaphoric extension and meaning with Lakoff and Johnson's theories, we see the conceptual metaphor as an ever-evolving, shifting structure - a living concept that exists within a discourse community in an almost symbiotic relationship of mutual transformation.

Within Rhetoric and Composition, we can see this transformative process. Participants of the field become engaged in the process of picking up metaphors, trying them out, and adding new meaning to them. We can also see, through this engagement, how in some cases one teacher's metaphor can become another teacher's poison. Metaphors that were once introduced to produce positive and constructive meaning take on new commonplaces, while also dredging up old associations, so far that they can turn into counterproductive conceptual frameworks that have a direct impact on the identities of members of the disciplinary community. An example of this (which originally served as my own entry point into the study of metaphor and teacherly identity) can be found in the use of parenting (or, more often, specifically mothering) metaphors for the composition teacher and classroom environment. Early uses of these metaphors sought to 
empower the teacher by metaphorically associating the teacher with concepts of emotional and developmental nurturance. The composition teacher, often working in English departments dominated by (male) literature professors, was cast as being more emotionally connected to the student, as a (metaphoric) mother connected to her child in stark contrast to the oft-caricatured image of the authoritative and emotionally-distant "father figure" of English Literature professors (Culley \& Portuges; Hays; Morgan; Hill; Graham \& Goubil-Gambrell).

As the metaphor of "teacher as mother" became integrated into the scholarly and pedagogical identity, however, some composition teachers and scholars began to recognize problematic, essentializing commonplaces being carried across the metaphorical divide. The field of Rhetoric and Composition became identified as "women's work," in turn transforming the teacher into an embodiment of diminished, feminized authority (Holbrook). Teacher/scholars began to resist the metaphoric establishment of the teacherly identity as being essentially or inherently feminized by attempting to reformulate the "motherteacher" identity through a more fluid selfawareness (Schell; Harlow; Reichert; Ballif), while at the same time new teachers attempting to employ the "original version" of the metaphor discovered other mutations of the metaphor through their students reactions, which refigured the teacher as a "smothermother" or "bitch-mother" (Bell \& Nugent), a "controlling mother, a destructive Kali" (Hill), or just simply a “"feminist' or 'bitch"” (Ede). The evolutionary transformation of this conceptual metaphor, then, is locked in a struggle between engaged interactivity and assumptive acceptance resulting in negative repercussions. 
Oftentimes, when metaphors become counterproductive it is because the conceptual metaphor has been "black-boxed" as an accepted element within the community and conversation. Bruno Latour, in his discussion of the rhetoric of science and technology, introduces this metaphor of the "black box" in his book, Science in Action: "The word black box is used by cyberneticians whenever a piece of machinery or a set of commands is too complex. In its place they draw a little box" (3). Latour's (metaphorized) black box represents technologies that cannot be "opened," or no longer necessitate exploration or debate over their use and value - the user does not need to understand how the black box works, only that it does work. This same concept can be applied to the metaphors available to members/teachers within Rhetoric and Composition. Once those metaphors are accepted as conceptual constants within the philosophies and identities of teachers, they can become black boxes - with it no longer being necessary to engage the inner complexities, transmutations, and permutations of these metaphors, these opaque conceptual containers to be "fitted" into their teacherly identity as-is. The unintended result, however, is that the teacher's agentive and engaged participation in the shaping of his or her own metaphoric identity diminishes, just as Latour's impenetrably black-boxed technologies inhibit the user's ability to be a full actant with agency over the use of those technologies.

This dissertation seeks to open some of the metaphorical black boxes within the field of Rhetoric and Composition, to examine the metaphors that have shaped and defined (and continue to mold) our disciplinary discourse and the identities of the members within the discipline. Most important to this project is the fact that the individual teacherly identity is at stake. As teachers enter the discipline, they are exposed 
to the conceptual metaphors that will help them understand their own positionality as part of the discipline. The entrants have the opportunity to either engage those metaphors or accept them uncritically as black boxes, to be added to their repertoire - "tools" in their toolboxes or "costumes" in their teaching closets - as they seek to fashion their own unique identities while still connecting to established disciplinary concepts. The levels of agency available to them as they construct their pedagogical philosophies and identities is contingent on their reception, replication, and (at times) revivification of conceptual metaphors that in turn have already had a role in shaping the identity of Rhetoric and Composition writ large.

My research in metaphor theory and its specific application to an analysis of the metaphors of Rhetoric and Composition offers examples of how the teacherly identity, as well as the disciplinary identity, is reliant on our relationships with those metaphors. It is not enough to simply identify all of the conceptual metaphors at play within Rhetoric and Composition (as daunting and unfeasible of a project that might be). Nor is it enough to acknowledge that we, not just as members of Rhetoric and Composition but also as human beings, "use metaphors a lot." A firmly-set awareness of the interactivity involved with the metaphors of the discourse community must be established, one that addresses the levels of engagement available to teachers. While more experienced members of the field may see the conceptual metaphors that circulate through the disciplinary conversations as common knowledge, or just "dead(ened) metaphors," the new members who regularly enter the discipline and its conversations are learning these metaphoric concepts often for the first time. If we dismiss the conceptual metaphors as static, no longer evolving, then we not only imperil our disciplinary progress, but we also do a 
disservice to new members of the community who will observe WRITING-IS-PROCESS and other conceptual metaphors as black boxes that "just work."

This is not to say that scholars in Rhetoric and Composition are not aware of metaphors, as some writers have offered or engaged with certain conceptual metaphors in order to shape how the discipline views pedagogy and writing (Murray; Elbow; Pratt; Shor; Lunsford; Bruffee; Trimbur). However, beyond this, much of the scholarship either offers highly specialized or personalized metaphors of the teacherly identity, or addresses metaphor as part of a sort of "replacement" strategy. In the former case, the writer's metaphors are often ones that are relevant only to their particular teacherly situations, thus having the likelihood of being relatively inaccessible to the reader as he or she considers his or her own teacherly identity: the teacher as a "Dostoevskian novelist" (Lensmire), as counterpart to a Shakespearean villain (Klein), or as a postmodernist, feminist embodiment of Lyotardian difference (Ballif, Davis, \& Mountford). In the latter case, the writer offers a critique in order to supplant a metaphor already present within the field which they consider to be insufficient, problematic, or even all-out destructive (Ballif, "What Is It"; Holbrook; Tobin, "Reading"; Hashimoto; Welch, "Resisting"; Convery). In many of these cases, the potential far-reaching permutations of the metaphor go relatively unacknowledged, so that if the metaphor is to be effective, it can only be enacted or employed in the specific teaching context by which the writer offered it (even if that context could be replicated by another teacher). In both cases, the metaphor becomes prematurely black-boxed. ${ }^{1}$ As a result, future teachers, attempting to engage these various metaphors as part of their own pedagogical identities and philosophies, stand the chance of becoming quite shocked and dismayed to discover that the "black 
box" has obfuscated the necessary adjustments to their assumptions that must be made in order to properly assume these metaphoric identities for themselves (Payne; Reichert; Tobin, "Process"; Tassoni \& Thelin; K. Johnson).

While these types of scholarship definitely exhibit levels of metaphoric engagement congruent with the goals of my project, their focus on specific iterations of metaphoric teacherly identities often is grounded in assumptions that frame metaphor as a stable, static entity. By contrast, my project treats metaphor as a dynamic element that receives regular input from engaged members of the community that is in turn further influenced by newly "upgraded" versions of the metaphor. Additionally, my project endeavors to address conceptual metaphors that often go unacknowledged or underexamined as metaphors intrinsic to the teacherly identity, as black-boxed entities that do not require metaphoric engagement themselves. Simply identifying or attempting to "control" metaphors ignores the reality that conceptual metaphors and the meaning associated with them cannot be eradicated. Metaphors can, however, be redirected by initiating a reinvigorated engagement by members of the community who have a broadened awareness of the underlying conceptual metaphoric system. Accordingly, my project focuses on excavating the layers of engagement present, available, or possible for the various conceptual metaphors under study.

In order to proceed with a strong common ground by which we can understand the theoretical underpinnings of metaphor when applied to the different areas of Rhetoric and Composition and identity discussed in this project, Chapter I presents a historical chronicle and theoretical overview of the study of metaphor, dating back to Aristotle's lexical identification of metaphora. Specifically, I explore the key elements of metaphor 
theory that factor into the later chapters, such as the different levels of perceived "literality" associated with metaphoric use by different theorists, as well as the foundational work in conceptual metaphor theory as provided by George Lakoff and his collaborators Mark Johnson and Mark Turner. Additionally, in this chapter I introduce the notion of interactional metaphor, as developed by I.A. Richards and Max Black, which emphasizes the receptive and interactive potential of the metaphoric associations attributed to metaphor that allow metaphoric meaning to extend and evolve. An amalgamation of interactional and conceptual metaphor theories allows me to establish how a metaphor's associations, as they evolve and spread out to other related metaphoric expressions, become a way to observe how people interact with even a nascent conceptual metaphor as it begins to establish prominence.

In Chapter II, I address the specific conceptual metaphor of WRITING-IS-PROCESS, in its many incarnations. First introduced by writers like Donald Murray and Peter Elbow, the shift from "product" to "process" to describe the act and teaching of writing represented a significant shift in how members of Rhetoric and Composition constructed their teacherly identities, not to mention the overall identity of the discipline. Discussions of "process" as a pedagogical and disciplinary imperative have been well-worn over the past 40 years, but one element that is surprisingly unexamined is the concept's metaphoric implications as an evolving concept. I explore these implications, through the many commonplaces and related metaphoric concepts associated with this metaphor for writing. I follow these different threads to trace the lifespan of the ProcEss metaphor, pointing to the many interactive moments through its "life" that show how the metaphor becomes further developed, extended, and even resisted. Through these moments, I argue 
that the metaphor has continued to maintain its metaphoric power, especially if we consider the new generations of scholars and teachers discovering WRITING-IS-PROCESS "anew," working their way through the implications of the metaphor as it applies to their own teacherly identities, thus activating an engaged "revitalizing" of its various components.

Chapter III focuses on the stories teachers tell, as part of the conversations that make up the scholarly and teacherly body of knowledge within the discipline of Rhetoric and Composition. Scholars and teachers have argued that the sharing of teacher stories contribute to the shaping of our field, by providing support and uniquely personal perspectives on the teacherly experience. I couldn't agree more, but I find one of the most powerful and frequently used metaphors within the teacher narrative, TEACHING-ISSTORY, to be also the one most frequently "black-boxed" or uncritically accepted. The metaphoric STORYING of the teacherly experience within the teacher narrative, however, is highly contingent on the confluent use of other conceptual metaphors (which I identify as TEACHING-IS-COMMUNITY and TEACHING-IS-CONVERSATION) that can potentially mitigate its more restrictive elements while amplifying its constructive aspects. By examining a large body of teacher narratives drawn from many textual sources, I argue that the convergence of these metaphors within the genre of teacher narrative, as well as how teacher/narrators actively engage with them, shows how the teacherly experience, leading to the teacherly identity, is metaphorically shaped as part of the larger disciplinary, communal identity.

Chapter IV narrows the focus of my metaphorical examination even further, examining localized instances of individual teachers' metaphoric engagement as they 
describe their pedagogical philosophies in order to represent particular teacherly identities. The teaching statement, as a unique document that exists as a pedagogical "occluded genre" (by extension of the notion as offered by John Swales), provides the teacher/writer the opportunity to employ the guiding metaphors of the field in order to present the teacher/writer as an integrated participating member of both the field and conversations of Rhetoric and Composition. By analyzing the statements of teaching philosophy gathered from composition teachers from all levels, from incoming graduate student teachers to retired professors, I explore the specific metaphors that prevail in various representations of teaching identities. In addition to identifying these prevalent metaphors as seen in the words of "real teachers," I address the varying levels of metaphoric engagement apparent at different stages of experience with and exposure to these disciplinary conceptual metaphors. I also use the results of this study to identify some of the more dangerous pitfalls that can arise when certain metaphors are assimilated into the teacherly identity without critical consideration, resulting in a potentially unproductive figuration of the student as a passive, "unengaged" recipient of the teacher's metaphoric identity.

In the conclusion, I reiterate how the metaphoric engagement within the disciplinary texts and conversations of Rhetoric and Composition reflects the shaping of the teacherly identity by a dynamic relationship between the members and the "descriptive" metaphors of the discipline. As part of my concluding thoughts, I argue that this project, which does on occasion point out the possible dangers implicit to certain metaphoric use, is not intended to inspire a distrust of metaphor. Instead, we can locate the disciplinary and teacherly identities of Rhetoric and Composition within these 
metaphors, and through a study of the field's metaphors we can better identify the directions and paths by which we would like those metaphors to proceed. An emphasis on critical consideration of the metaphors used to describe teaching, both in the classroom and in the identities we represent as a community, is a concern not only for reflective teachers seeking to develop productive roles for teaching, but also for incoming teachers being exposed to the continuously sedimented layers of metaphoric meaning that more established or experienced teachers might come to accept as "black-boxed." In addition to exploring some of the final implications for a project such as this, I also briefly consider the ways that such a study could be further developed, both through studying the metaphoric identities of students and through examining a postulated conceptual metaphor that rarely receives much attention: the TEACHER-AS-TEACHER, embodying the sometimes unattainable ideals from both in- and outside of the discipline for what it means to be "A Teacher."

This dissertation does not attempt to give an exhaustive list of all the metaphors within Rhetoric and Composition. Instead, it reveals how metaphor is in a dynamic relationship with the field, one that affects disciplinary and teacherly identities as well as the very same metaphors being used to describe them. My focus on the metaphors we teach by demonstrates how metaphors are intrinsically connected to the teacherly identity, even when a teacher or writer doesn't intentionally invoke their metaphoricity, through the analysis of increasingly narrowed textual samples - from the overall scholarship, to the specific genre of teacher narrative, and then to the individualized and localized descriptions of identity found in teaching statements. Metaphors do not appear prêt-à-porter, fully ready for use as part of teacherly identity and experience; instead, 
they are involved in a dynamic exchange - between reader and creator, between metaphoric and literal association, and between generational iterations of the structures that underlie the larger conceptual metaphors of Rhetoric and Composition. In the chapters that follow, I offer a mapping of some of these exchanges. 


\section{Notes}

${ }^{1}$ Even Peter Elbow, in his seminal text Writing without Teachers (wherein the metaphor of WRITING-ISPROCESS gained much of its ground), warned that his use of metaphors of "growth" to describe the writing process shouldn't be taken any further than he prescribes, thus suggesting an attempt to restrict the future engaged development of the metaphor (23). 


\section{CHAPTER I}

\section{MAPPING METAPHOR}

To what extent does this way of talking reflect a set of 'natural facts,' and to what extent does it reflect the facts of a particular disciplinary culture? And is it just a way of talking? Is it not also a way of thinking, a way of seeing, and a way of doing science?

Evelyn Fox Keller, Refiguring Life

Some metaphors now current have been twisted out of their original meaning without those who use them even being aware of the fact. [...] A writer who stopped to think what he was saying would avoid perverting the original phrase.

George Orwell, "Politics and the English Language"

There are many examples of metaphoric activity to be found within the field of Rhetoric and Composition. In the scholarship, we find the introduction and promotion of metaphors intended to enhance a productive understanding of topics, as well as the identification and resistance to metaphors seen as dangerous to the representation of writing, teachers, or the discipline as a whole. Within personal accounts from teachers of writing, the examples of metaphoric identities, activities, and perspectives are plentiful too many to count, it seems. However, the understanding of what these metaphors represent - what they "mean," what level of influence they have, and how they can be controlled - varies to a great degree. Philip Eubanks, in his 2001 article "Understanding Metaphors for Writing," notes some of the presuppositions or assumptions that he might make regarding the disciplinary view of metaphor, including that "metaphor is more than decoration" and that "readers already understand and agree about the substantive, ethical, 
far-reaching nature of metaphor" (92-93). He goes on to say that "though we may be agreed, we are not finished" (93). I would agree that we are "not finished" with metaphor, by any means, but I would not be so sure that the discipline is in agreement about the nature of metaphor.

To show the variance in the range of trust and differing "agreement" within Rhetoric and Composition in regards to metaphor and its role as part of the disciplinary discourse, I would offer three examples from the past 30 years of scholarship. In 1981 , Ann Berthoff examined metaphoric portrayals of "writing as a process," arguing that metaphors must be controlled in use, because of their inherent potential for instability (Making 6). Beginning in the 1990s, writers began to question with increased scrutiny the continued relevance of "process" pedagogy, suggesting that its life as an influential model for the discipline had come to an end and therefore it needed to be replaced (Kent, "Paralogic"; Olson). Quite recently, JoAnne and Leonard Podis revisited the metaphor of parenthood (a metaphor highly critiqued in the 1980s and 1990s), stating that "in loco parentis is a deeply embedded but often overlooked principle within the teaching of composition [...] likely to remain an influential pedagogical model" ("Pedagogical" 122). While Eubanks (and others approaching metaphor in Rhetoric and Composition) might presuppose a general consensus on the role of metaphoric activity, these examples and many like them betray widely varying levels of trust in metaphor and its relationship to "reality," as well as differing views on the potential activity, lifespan, and relevance of metaphors.

My dissertation revolves around the idea that the metaphors of Rhetoric and Composition are not only descriptive of the goals and identities of teachers and scholars 
within the discipline, but that they are also active in the shaping of those very same goals and identities. In this chapter, I provide a theoretical overview of metaphor, in order to establish a metaphoric groundwork for the chapters that follow, wherein metaphor plays a critical role as both a shaped and shaping influence on the conceptualizations of disciplinary and teacherly identity within the field of Rhetoric and Composition. This discussion, however, is not structured to offer a single theorist's perspective on metaphor. There are several contesting views on metaphor within both historical and current scholarship, ranging from cognitive models, to literary interpretive applications, to sociolinguistic explorations. I would argue that, while many of these theories stand up against each other to offer contrasting explanations for what metaphor $i s$ and what metaphor does, a more productive application can be found through a synthesis of varied theories of metaphor. To enact this synthesis, I address four key points of metaphor theory that are instrumental to the continued discussion of metaphor that in part defines this dissertation.

In the first section, I present the "beginning of metaphor," as well as an account that examines the divide between literal and figurative language. While some (like Eubanks) may assume that "we" accept and agree that metaphor acts as something more than figurative language, the question of metaphor's position within the spectrum of linguistic usage has been debated for centuries, and I would argue that along with this spectrum comes a "morality of metaphor" wherein both individuals and metaphor are "judged" according to their uses and abuses within rhetorical situations. The second section then turns to the work of George Lakoff and his collaborators, whose work has introduced and developed the modern notion of the conceptual metaphor. This figuration 
of metaphor offers a way to understand metaphor as a part of language, while still providing a nuanced distinction between metaphoric and literal meaning. Not only does Lakoff et al.'s notion of the conceptual metaphor attempt to circumvent issues of morality, by arguing the conceptual inherency of metaphor within language, it also allows us to examine how instances of metaphoric activity belie larger conceptual systems that influence and shape a discourse community.

Thirdly, I examine the evolution of metaphors - specifically how this evolution fits together with an understanding of conceptual metaphor. Through the work of scholars such as I.A. Richards and Max Black, we can understand how meaning is generated in a way that goes beyond "metaphoric substitution." Black's theory of interactive metaphor (inspired by Richards) allows us to see the inherent engagement that occurs within the metaphoric activity of discourse participants, and how that engagement further develops the metaphor. Finally, I address the issue of the "dead" metaphor. A topic touched on by nearly every approach to metaphor, dead(ened), dormant, or frozen metaphors are those that are seen to be inactive - no longer generating new metaphoric meaning or inspiring engagement. While I concede that there might be dead metaphors within human discourse, I argue in this section that there are often cases wherein a (conceptual) metaphor is active in influence and potential engagement even when it has been declared "dead." This practice of accepting certain conceptual metaphors as deadened often produces one of two different results: uncritical acceptance of the metaphor without interrogation of its influences (which I refer to in the introduction by way of Bruno Latour's "black box" metaphor), or the dismissal of the metaphor as no longer stimulating influential discourse. 
In the upcoming chapters, I provide an increasingly narrowed exploration of metaphoric activity within the disciplinary and teacherly identities of Rhetoric and Composition, as found in the scholarship, stories, and personal representations of the discipline's membership - those individuals whose identities as teachers and scholars of writing are intimately connected to the metaphors available to them, as well as those they might be inspired to dream up themselves. Therefore, it is important to understand the role of metaphor as part of this project, not only in how metaphors are used, shaped, and developed by members of Rhetoric and Composition, but also in how metaphors in turn shape the disciplinary and teacherly conceptions of identity that are available to those members. When a metaphor is invoked, its implications and future activity are contingent on the ways that these teachers and scholars can (and/or do) engage with the meaningmaking metaphoric process. Equally, the different metaphors of writing and teaching, as they proliferate within the field of Rhetoric and Composition, have a way of exerting an influence over what sort of meaning can be made. What develops from the following sections of this chapter, then, is a map (or at least a legend) with which we can chart the trajectories of the metaphors of writing and teaching, as well as the paths by which those metaphors become conceptual forces that influence our identities as members of Rhetoric and Composition.

\section{Metaphora: Foundations for Moral Usage}

When charting the history of metaphor, we can start with Aristotle. In fact, according to Andrew Ortony, "any serious study of metaphor is almost obliged to start with the works of Aristotle" (3). Aristotle was arguably the first to identify and examine metaphor, classifying the distinctive trope metaphora as separate from literal meaning, an 
instrument of "exotic" usage: "By 'exotic' I mean loan-words, metaphors, lengthenings, and all divergence from the standard" (Poetics 22, 1458 21-3). ${ }^{1}$ For Aristotle, metaphora represents a deviation from normal usage, a classification that includes not only a modern understanding of metaphor, but also metonymy, analogy, and imported foreign words. ${ }^{2}$ In his Rhetoric, Aristotle refers to Homer's epic poetry to provide the metaphoric expression, "Achilles is a lion," stating that metaphoric connection is made through the similarities shared by both Achilles and the beast: "because both are courageous, [the poet] transfers the sense and calls Achilles a lion" (Rhetoric III.iv.1). This example, "Achilles is a lion," is one that has echoed through metaphor scholarship since Aristotle, for its apparently clear distinction of what makes a metaphor and what effect metaphor therefore has. However, by examining this example as well as Aristotle's other comments on metaphor, we begin to see the groundwork for one very specific use of metaphor, of metaphora. Not only is this the foundation for the substitution theory of metaphor (problematically limiting the efficacy and bounds of metaphor), Aristotle's figuration of metaphor sets the first spectrum by which a "moral" use of metaphor is being prescribed. Aristotle's classification of metaphora qualifies it specifically as a literary trope, and one that holds within it several other tropes that, while varying in the method, are still of the same genus. As stated in his definition of metaphora, metaphors are a part of nonstandard usage for Aristotle - not part of regular language. Such a definition by nature would include many different devices and tropes, which Aristotle identifies as all being part of metaphor. Not only do metaphors such as "Achilles is a lion" fit into this framework, but also similes and any "application of a word that belongs to another thing: either from genus to species, species to genus, species to species, or by analogy" (Poetics 
$\left.21,1457^{\mathrm{b}} 6-9\right)$. Examples might include referring to Ares' shield as a wine bowl, or even simply the Homeric line "ten thousand noble deeds has Odysseus accomplished." While this line seems an awkward fit for metaphoric classification, Aristotle argues that "ten thousand is many, and the poet has used it here instead of "many" (Poetics 21, 1457 $7^{\mathrm{b}} 12$ 13). In other words, "ten thousand" stands as an exaggerated replacement of "many" to paint a poetically grandiose picture of Odysseus's numerous deeds.

For the figurative, "non-standard" devices grouped into the trope of metaphora, Aristotle views their key and primary use within the realm of literature, more specifically poetry. In his Rhetoric, where he points out the inclusion of simile as part of metaphor, he states that such figurative language (of simile and by extension metaphora) "is also useful in prose, but should be less frequently used, for there is something poetical about it" (Rhetoric III.iv.2). ${ }^{3}$ This assertion, and its implications, establishes a long-standing perspective of metaphor that only recently (relatively speaking) has shifted: metaphor exists as a figurative device, for literary application first and foremost.

This leads to a second point of Aristotle's classification of metaphor, which comes from how he views the actual integration of metaphora into linguistic usage. As noted, Aristotle considers metaphors to belong to the realm of literature, by nature. Connected to this, while Aristotle does incorporate metaphor to a framework of lexis, or the naming that comes with language, he sees it neither as something that can be done by all people, nor something that can be taught as part of language use. Mastery of "good metaphors" is a sign of genius - something that cannot be passed on to someone else. The entirety of Aristotle's examples of metaphora comes from literary masters such as Euripides, Aeschylus, and Homer, and he states that "the greatest asset is a capacity for 
metaphor. This alone cannot be acquired from another, and is a sign of natural gifts" (Poetics $\left.23,1459^{\mathrm{a}} 5-7\right) .{ }^{4}$ This is a quality of metaphor that is particularly salient to the notion, as I have suggested, of a "morality of metaphor." Within such a moral usage, mastery of metaphor is something reserved, naturally, for those who have the appropriate "moral fiber" for it. ${ }^{5}$ Aristotle argued the use of metaphor as being "unseemly" when used for philosophical or rhetorical purposes by individuals such as Gorgias, who he accuses of being "too lofty and theatrical" in his rhetorical usage of metaphor, thus being "too much like poetry" (Rhetoric III.iii.4).

Aristotle, providing the earliest example of theorized metaphor, firmly establishes it as a trope grounded in substitutions, wherein the metaphoric element of a statement is one that could equally be replaced by another word or phrase, a "standard" or literal one which would hold equal meaning. In the earlier example of "Achilles is a lion," Achilles's attributes of courage and ferocity are brought to the forefront by associating him with a lion. One could just as easily state that "Achilles is a brave and ferocious warrior," according to this substitutive perspective. As I have also mentioned, though, Aristotle's consideration of metaphora carries with it a moral element, within which metaphor is positioned not only in relation to lexis, but also in relation to "good" and "bad" usage. Metaphor is something to be consciously and carefully used; it is separate from the rest of language, restricted to only a select group of individuals using it for figurative, poetic purposes. While Aristotle's figuration may be more cautious than anything, merely providing a warning regarding the moral hazards associated to potential abuses of figurative language, it isn't surprising that even other writers that followed 
much later, such as John Locke or George Orwell, would develop a distrust for metaphoric usage, on moral(izing) grounds.

\section{Ab/use and (Dis)Trust in Metaphor}

In 1690, John Locke echoes Aristotle's moral placement of metaphor, although much more vehemently. In "An Essay Concerning Human Understanding," Locke argues firmly for the avoidance of metaphoric usage in rhetoric, stating that "all the artificial and figurative application of words $[\ldots]$ are for nothing else but to insinuate wrong ideas, move the passions, and thereby mislead the judgment; and so indeed are perfect cheats" (3.10:34, 146). As did Aristotle, Locke sees the space of (public) rhetoric as being inappropriate for figurative language; although his reasoning is similar, his heightened call for the avoidance of metaphor in public speaking and writing emphasizes even more so the judgment to be placed on "the abuse of language" (as the section in his is titled). Locke's intention is to prescribe a method of discourse that centers on the purest ability to communicate "truth" (or, perhaps for our purposes, "literality") that eschews the "wit and fancy [that] find easier entertainment in the world than dry truth and real knowledge" (ibid.). George Orwell echoes this same complaint 250 years later, in "Politics and the English Language”: “[Metaphors] will construct your sentences for you - even think your thoughts for you, to a certain extent - and at need they will perform the important service of partially concealing your meaning even from yourself" (95).

What Locke and Orwell fear, what they are emphasizing through their discussions of the "abuse" of language (Orwell, too, labels it as such in his first paragraph), is the underlying obscuring of a natural, pure and true meaning that can be enforced in an individual's use of language and communication. Orwell states, in response to those who 
don't get fired up about linguistic abuse, that "underneath this [apathy] lies the halfconscious belief that language is a natural growth and not an instrument which we shape for our own purposes" (84). Equally, as noted with Locke already, it is the untrustworthy, unstable, and misleading nature of metaphor (or lack thereof) with which he has a problem. However, in both cases, even as Locke and Orwell demonize figurative, metaphoric language, their treatises are filled with metaphor. For Locke, confusion and misunderstood ideas are equated to centaurs, and catachresis is metaphorized as monstrous chimeras roaming through the mind. Orwell's polemic depicts language as an architectural nightmare, "a prefabricated henhouse" with dissolving "concrete illustrations" $(87,92)$. According to Paul de Man, who examines Locke's attempt to outline the "abuses of language" enacted through figuration, any attempt to restrict metaphor to a single definition is an attempt to control an uncontrollable thing, "for at no point in course of the demonstration can the empirical entity [language] be sheltered from tropological defiguration" (20). Locke's own endeavors to warn against the evils of metaphor are determined, and undermined, by the very metaphors he seeks to control.

One lesson to learn from this is the challenge, or perhaps even the inability, to venture a definition of metaphor without speaking metaphorically: "the use and the abuse of language cannot be separated from each other" (de Man 19). Equally, though, we still see through examples such as these, hearkening back to the first generation of Aristotle's theorized metaphora, a moral judgment being applied to metaphor - not specifically the entire use of metaphor, but the uninformed, unpracticed, and uncritical (ab)use of metaphor. Those who abuse language place too much faith and trust into metaphor, allowing it too much control over the meaning they seek to generate. 


\section{Amoral Metaphor as Footsoldier of Language}

While traditions holding metaphor as substitutive and morally suspect have stemmed from Aristotle's original characterization of metaphora, a more recent perspective on metaphor has moved it to the opposite end of the spectrum. Instead of being a clearly delineated and separate device reserved for the literary elite, metaphor has been seen as the whole of language itself. In "On Truth and Falsity in their Extramoral Sense," Nietzsche reserves this position for metaphor, arguing that all language is metaphoric, in the sense that language itself is arbitrarily connected to "real things" - a tree is by no means inherently connected to the word "tree." In fact, Nietzsche charts language's metaphoric relationship to three degrees, starting with the stimulus of the nerves by reality: "A nerve-stimulus, first transformed into a percept! First metaphor! The percept again copied into a sound! Second metaphor!" (4). ${ }^{7}$ These metaphors - the perception and creation of a sound to identify and codify reality - create an illusion of reality, when language is seen to encapsulate the unique and identifying nature of reality.

Thus, Nietzsche asks, what is truth? (or, what is literal truth?) Nothing more than "a mobile army of metaphors, metonymies, anthropomorphisms; in short a sum of human relations which became poetically and rhetorically intensified, metamorphosed, adorned, and after long usage $[\ldots]$ canonic and binding" (5). And, this assertion is one which we have come to understand and accept on some level. We can see language as this "mobile army of metaphors," constantly pressing forward in communication, and truth (or literality) as an illusion based on these multitudes of metaphors, solidified into a pretense of realistic representation. We can place this stand on "truth" and "lies" against the Lockean/Orwellian exempla provided earlier, as they depict metaphor as "deceptive" 
language: Nietzsche's stance suggests that all language is already lying, making truth itself a toothless tiger, so to speak.

However, one of the greatest problems with this approach is the fact that we still have the "literal" to contend with, regardless of how much Nietzsche would reject the idea of any "truth" that is not contingent on the metaphors which have become "canonic and binding." We may be able to acknowledge that the term "lion" is language's metaphoric answer to identifying the fierce, maned big cat represented through history, from the Iliad to The Wizard of $O_{z}$, but when we see the phrase, "Achilles is a lion," we still make the necessary "carrying over" of metaphoric understanding that includes understanding that Achilles is not a lion, but that the metaphoric expression is being used to understand the leonine qualities that Achilles embodies.

To be fair to Nietzsche, this is not what he is focusing on. He is less concerned with the figurative use of language than with the way that all language is constructed through metaphoric associations between the experience of perception and the "naming" of truth and reality. Lawrence Hinman defends Nietzsche's stance on the metaphoricity of language, stating that "in asserting the primacy of the metaphorical in these Nietzschean senses, we are in effect claiming that there is no privileged, literal link between language and reality" (199). I find this statement, as it represents Nietzsche's position, problematic even while I agree with it to a degree. To begin with, we can agree that there is no "privileged, literal link" that connects an utterance with the concrete object or experience in reality. As Nietzsche puts it, "Nature knows of no forms and ideas, and therefore knows no species but only an $x$, to us inaccessible and indefinable" (5). It is only through our application of what Nietzsche calls the metaphoric perception 
that we can vainly attempt to access and define Nature (or "truth"). However, what Hinman calls Nietzsche's assertion of the "primacy of the metaphorical" has created complications, regarding how we may understand metaphor outside of the fundamentally metaphoric nature of language itself.

We can classify these two attempts to theorize metaphor according to the activity they attribute to metaphor, as well as the potential drawbacks that come from their polarizing positioning within the spectrum of metaphor's moral usage. In the Aristotelian (substitution) sense, metaphor acts as a trope, for literary and descriptive use, thus allowing for a sensibility of metaphor's figurative power. However, its implications involve a clear delineation of how and when metaphor can be used, and by whom. Metaphor is something separate from "proper" language use that exists as a (potentially) moral compass - either elevated above normal, quotidian language as a device for masterful ornamentation, or as a subversive and deceptive force that lurks beneath language, undermining pure communication. On the other hand, Nietzsche's position offers a way to understand the relationship between language and reality. Metaphor is depicted as a largely inactive linguistic phenomenon, language being the aggregation of "worn-out metaphors": "coins which have their obverse effaced and now are no longer of account as coins but merely as metal" $(5){ }^{8}$ As an aspect of all language, metaphor then is also, according to this perspective, an extramoral or nonmoral (depending on the translation) phenomenon - language by its very nature misleads from reality. However, this view does not fully explain or take into account the actual metaphors on which we often rely that $d o$ draw a distinction between literality and figuration. 
The position of metaphor, in relation to literality as well as morality, is a key element of metaphoric understanding when considering the use of metaphor within Rhetoric and Composition. Either side of the spectrum, as outlined here, potentially leads to an underestimation of metaphoric impact. Not only does an adherence to the figurative-only nature of metaphor, as established by Aristotle, lead to a dismissive or "light" use of metaphor, but the moral code that develops around its "proper" usage (we may ask who decides what is "proper"?) allows for there to be a generated sense of distrust for metaphor. This is the type of distrust that I find echoed in concerns such as Berthoff's, with the "instability" of metaphor: "any analogy can be faulty or misleading if it is carried too far" (6). However, on the other hand, I would argue that the "primacy of metaphor" that Nietzsche establishes potentially diminishes the understanding of metaphor as a powerful tool in language. When everything is metaphor, what isn't? Or, more to the point, if everything is metaphor, you run up against the challenge of proving why any single metaphor is special in its activity within language and communication. Thus, while it is valuable to understand the inner workings of this spectrum of literal/figurative, moral/amoral language, it is necessary to move beyond this binary - not so much "transcend" it, but rather reconceive the framework under which metaphor operates.

\section{Living by Metaphor}

George Lakoff and Mark Johnson's 1980 book, Metaphors We Live By, sets the stage for a conducive exploration of conceptual metaphor, which envisions metaphor as being something more, or at least different, from the foundations set by either Aristotle or Nietzsche. Lakoff and Johnson's main thesis is indicated by the very title of the book. In 
their argument, we do indeed live by metaphors, not even at an always-conscious and active level, but through penetrating levels of conceptual, metaphoric systems that provide the foundation not simply for language, but also for how we perceive reality and continue to express it through language. By identifying several instances of normallyconsidered "standard language usage" that in fact stem from and are inspired by metaphors, Lakoff and Johnson direct our attention to the underlying conceptual metaphors represented throughout language.

Lakoff and Johnson argue that our metaphoric interaction may not always be at a conscious level, but that it is still active in layers of conceptual metaphor structures that underlie our use of language to not only describe reality, but construct and shape the reality as we perceive it. ${ }^{9}$ As Johnson points out in a later book, The Body in the Mind, metaphors represent schemata, "primary means by which we construct or constitute order and not mere passive receptacles into which experience is poured" (30). To establish their theory, they provide numerous examples of metaphors that have permeated language as more than a simple phrase describing one thing as another, not only to bolster their theoretical argument, but also to attempt to identify some of the prevailing conceptual metaphoric structures at play in language and culture. One such example is that of TIMEIS-MONEY. ${ }^{10}$ We can envision this statement being barked out at a workplace, encouraging (or demanding) that employees work harder, more efficiently, to make the most out of every moment of time in order to make more money. Lakoff and Johnson argue that while this statement may have come into being through our relation to a capitalist and industrialist society, the metaphor goes far beyond that, setting up the conceptual structure of time as actual units of money. TIME-IS-MONEY then becomes 
evident in other uses of language, in which the reference is strictly to time, without conscious reference to the originating statement and metaphor. Thus, we "waste" time and "spend" time; we'll "give you five minutes" and question whether an activity is "worth our time." Thus, not only is TIME-IS-MONEY (as the overarching conceptual metaphor) apparent in the initial metaphor, but also in the way we describe and perceive our use of time, to the extent even that Daylight Savings is expressed as "losing" and "gaining" hours of time in a commodified manner.

Lakoff and Johnson make an important point when they introduce the example of TIME-IS-MONEY as a conceptual metaphor that illustrates the systemacity of metaphor in human experience. They state that TIME-IS-MONEY and its related metaphors are metaphorical since we are using our everyday experiences with money, limited resources, and valuable commodities to conceptualize time. This isn't a necessary way for human beings to conceptualize time; it is tied to our culture [Western, or more specifically English-speaking, culture]. There are cultures where time is none of these things. (8-9)

As opposed to the Nietzschean notion that language is based on metaphoric extensions, Lakoff and Johnson are pointing out that the concept of time has already been established in language - even in the Nietzschean sense, if we so choose. It has been said by many people that "time" is a human concept, in the sense that we have superimposed our own concept of the passage of time onto the natural occurrence of time. However, after the fact, the metaphoric conceptualization of time as money has come into play at a cultural level in the English language, as evinced by the conceptual framework provided by the metaphor TIME-IS-MONEY.

The metaphoric exploration that Lakoff and Johnson undertake does not directly address Nietzsche's assertions as to the nature of language as perceptual metaphors. Just 
as Nietzsche is more focused on discussing the metaphoric "falsity" of language than the figurative character of metaphor, Lakoff and Johnson focus their efforts on examining the conceptual nature of metaphor in conjunction with language. However, quite early in their discussion, they state that "metaphor is pervasive in everyday life, not just in language but in thought and action" (3). Instead of situating metaphor as the entirety of language, cum Nietzsche, they turn to the conceptual systems that, in turn, frame language and culture as well as "what we perceive, how we get around in the world, and how we relate to other people" (ibid.). Furthermore, both in Metaphors We Live By, as well as Lakoff's later collaboration with Mark Johnson, More than Cool Reason, there are discussions of the differences between metaphoric and literal language. ${ }^{11}$ This perspective does not immediately attempt to negate Nietzsche's stance on the inherent metaphoricity of language as a perceptual experience (although it does implicitly position Lakoff and his collaborators as believers in some sort of "literal" language), but what it does do is shift the location of metaphor's importance and primary relevance from language to conceptual systems.

According to this approach, it may very well be accepted that all language is metaphoric, relying on Nietzsche's discussion of perceptual metaphors constructing the basis of language. However, Lakoff et al.'s discussion of conceptual metaphors encourage us to understand a difference between a language being metaphoric and the metaphors we use within that language. Both qualities may apply, without contradicting each other. Zoltán Kövecses, following Lakoff's lead, suggests that

metaphor is a

- linguistic

- conceptual

- social-cultural 
- neural

- bodily

phenomenon, and [...] it exists on all of these different levels at the same time. (8-9)

The idea that metaphor can be all of these things, existing simultaneously, does more than simply allow us to explore individual and conceptual metaphors separately from the "inherent" metaphoricity of language itself. As Kövecses notes, metaphor also stands as a social-cultural phenomenon - existing within what I would consider a contextual relationship to the culture and discourse within which a metaphor has arisen. This element becomes particularly important for my project, as the (conceptual) metaphors of which I will be exploring not only frame the possible realities of disciplinary identity within Rhetoric and Composition, but are often contextually relevant specifically within the framework of Rhetoric and Composition. In the next chapter, for example, I examine the conceptual metaphor WRITING-IS-PROCESS. At first glance, the conceptual background for this metaphor may appear deceptively simple, emphasizing the developmental or stage-oriented method of any activity, thus calling on conceptual ideas going well beyond the discipline of Rhetoric and Composition. However, while this stands as one factor in the creation of and continued interaction with WRITING-ISPROCESS, the metaphor also exists on a level specifically tied to the culture and discourse of the field. All of levels of metaphoricity are important, and relevant, to an exploration of metaphor in general, as well as for this project. They may at times influence each other, and they can also be separated on occasion for a closer investigation.

\section{The Interactivity of Metaphor}

It is through the initial figuration of the conceptual metaphor, as introduced by Lakoff and Johnson and further elaborated in their later works, that my project gains its 
relevance. The idea that metaphors not only reflect our interaction with the world, but also shape that world, on both macro- and microcosmic levels, sheds light on how the metaphors of the field of Rhetoric and Composition are encoded into the discourse of the discipline and then perpetuated by new generations of scholars and teachers. However, just as other scholars and writers such as Nietzsche and Aristotle had specific foci in mind when discussing metaphor, Lakoff and Johnson's work only goes so far. The identification of the conceptual metaphors that frame our communication and relationship with the world is important, but their discussion of these metaphors often stops there, at the "identifying" stage. To fully flesh out a theory of metaphor that gives conceptual metaphors at primary importance, we must consider how these metaphors are "activated" and interacted with as part of conversation and human relations. To do that, I turn to the work of I.A. Richards and Max Black, who both offer certain insights into the inner workings of metaphor.

One of I.A. Richard's chief contributions to the conversations on metaphor theory comes by way of terminology. In The Philosophy of Rhetoric, Richards points out that one of the greatest challenges in examining metaphor resides in how the two "halves" of a metaphor (as well as the sum of these parts) are distinguished:

For the whole task is to compare the different relations which, in different cases, these two members of a metaphor hold to one another, and we are confused at the start if we do not know which of the two we are talking about. At present we have only some clumsy descriptive phrases with which to separate them. 'The original idea' and 'the borrowed one'; 'what is really being said or thought of' and 'what it is compared to'; 'the underlying idea' and 'the imagined nature'; 'the principal subject' and 'what it resembles' or, still more confusing, simply 'the meaning' and 'the metaphor' or 'the idea' and 'its image.' (96) 
This certainly is problematic for any discussion of metaphor, and it is interesting to note the different examples Richards gives of how people have attempted to address these different metaphoric elements. The role of metaphor in any given scholar's conception can often be uncovered by examining the terms that scholar uses to identify the two components of a metaphor. As an example, "the original idea" and "the borrowed one" clearly point to a conception of metaphor in a substitutive faculty wherein the metaphoric activity is chiefly constructed through the "borrowing" of meaning - it is hardly meant to be a permanent arrangement, or one that is anything more than a fleeting transposition of figurative meaning.

To remedy this problem, Richards proposes the use of the terms "tenor" and "vehicle" for the two halves of a metaphor. For Richards, the tenor of a metaphoric expression would be, in simplest terms (and with all awareness of the obvious implied complications), the "literal" element being metaphorized, while the vehicle points to the "figurative" element being introduced. However, considering his earlier point about the confusion surrounding the terminology attached to metaphors, in which bipartite figurations such as "the original idea" and "the borrowed one" imply a restrictive understanding of metaphoric expression and the terms like "the meaning" and "the metaphor" lend to vague understanding, Richards takes great effort to clarify how the tenor and vehicle create meaning. He states that it is vital to understand how "the copresence of the vehicle and tenor results in a meaning [...] which is not attainable without their interaction" (100, my emphasis). It is through this interaction, capable only through the combination of vehicle and tenor, that a metaphor draws its power. This point is vital in pulling metaphor away from the simple role of replacement ascribed to it by 
substitution theory, while also separating it from the overarching, and dangerously dissolutive, draw of a Nietzschean notion of "everything is metaphor." When interaction is emphasized, the words being used almost become inconsequential - the importance is instead placed on how we interpret these words. As Richards states later, "it is not etymology but how we take the words which settles these questions [of metaphoric meaning]" (121, author's emphasis).

It is this point of interaction that Max Black takes up as a major element of metaphoric exploration in his book, Models and Metaphors. Richards argues that metaphor places two different things, the vehicle and the tenor, up against each other, and that it is through the mind's activity upon being confronted with this catachrestic moment that meaning is connected. Black states that "in this 'connection' resides the secret and the mystery of metaphor" (39). To elaborate on his point, Black introduces a new metaphoric exemplum: "Man is a wolf." 12 In this example, he identifies the principal subject (or, using Richards' terminology, the tenor) to be "Man," and the subsidiary subject to be "Wolf." These two subjects represent more than a singular instance for each - it isn't just a specific "man" being referred to here, nor a specific "wolf." Instead, it is, in each case, the concept encapsulated by the word that is being activated. This is a key element in Black's main claims regarding metaphor. He states that "these subjects are often best regarded as 'systems of things,' rather than 'things'” (44). He later clarifies this explanation by refining the definition of these "systems of things" to "systems of associated commonplaces." These "systems of associated commonplaces" allow for the interactivity within metaphoric expressions. With the example of "Man is a wolf," a "wolf-system of related commonplaces" has been invoked in reference to "Man." Thus, 
"the effect, then, of (metaphorically) calling a man a 'wolf' is to invoke a wolf-system of related commonplaces. If the man is a wolf, he preys upon other animals, is fierce, hungry, engaged in constant struggle, a scavenger, and so on" (41). The wolf-like characteristics of "Man" are highlighted by the metaphor, by the confluence of the vehicle and tenor. The person receiving the metaphor becomes part of the interactive process - the commonplaces he or she may hold in reference to wolves are called up to make the proper associations. ${ }^{13}$

These "associated commonplaces" would include, according to Black, what a layperson (rather than an expert on wolves) would say when asked about what he or she knew about wolves. In addition, however, this set of commonplaces "may include halftruths or downright mistakes (as when a whale is classified as a fish)" (40). The ability of the metaphor to be successful is not based on "truths" or facts about wolves - instead, it is only important that these associations, these commonplaces, be "readily and freely evoked" (ibid.). Therefore, when presented with "Man is a wolf," not only would we be able to call upon the commonplaces that depict the wild and predatory nature of wolves, but we would also have at our disposal the older superstitions regarding the nocturnally supernatural characteristics associated with wolves. ${ }^{14}$ Black does struggle with the issue of what constitutes this set of commonplaces, as he acknowledges that "a metaphor that works in one society may seem preposterous in another" (ibid.). He is aware that an interactional theory of metaphor operates under the assumption of some level of commonality, of commonly shared awarenesses (not so much "beliefs" or "truths," as he notes that not all commonplaces are either of those). However, he argues that the interactive exchange between metaphoric interlocutors must by very nature of being a 
communicative act be capable of allowing a shared acceptance of these awarenesses. This does not constitute agreement, but at least acknowledgement. However, as Paul Ricour notes in The Rule of Metaphor, the complication is how these commonplaces are somehow predetermined, without accounting for difference in linguistic (or cultural) communities, that "to return to a system of associated commonplaces is to address oneself to connotations that are already established" (88). While Black does not, even for himself, completely come up with a satisfactory answer (beyond suggesting that perhaps in some cases commonplaces might be replaced by "deviant implications established ad hoc by the writer" [44]), I would argue that there is something metaphorically valuable that comes actually from the dissimilarity of meaning, of commonplaces as they are exchanged. Richards, in noting this issue through other terms, turns the focus towards the actual elements of metaphoric association, rather than the individuals in the exchange:

In general, there are very few metaphors in which disparities between tenor and vehicle are not as much operative as the similarities. Some similarity will commonly be the ostensive ground of the shift, but the peculiar modification of the tenor which the vehicle brings about is even more the work of their unlikenesses than of their likenesses. (127)

The inclusion of catachrestic meaning, highlighting the disharmonious, tensive, and conflicting commonplaces potentially available within a metaphoric exchange, can produce a stronger sense of metaphoric discovery and interaction within an engaged moment. This sense has much in parallel with Bakhtin's notion of heteroglossia, which relies on the recognition of differences between ideological positions to create internally persuasive discourse. While, ultimately, Black's own justification of the commonplace might hang in ambiguity, I would suggest that the commonplace, contradictory to its own name, is more reliant on these notions of catachrestic conflict in creating metaphoric 
meaning. It can be more dangerous, I would argue, to have absolute acceptance of commonplaces, as such a situation would need no metaphoric engagement whatsoever. Thus, as each individual, regardless of community affiliation, will bring their own set of accepted, "associated commonplaces" into the metaphoric exchange, the metaphoric engagement and interactive potential of metaphor is continually provoked and necessitated.

As a model for understanding metaphor, Black's interaction theory (inspired by I.A. Richards) accounts not only for the ways that the tenor, or "principal subject," is metaphorized by the vehicle, but also how the vehicle is metaphorized through the process as well. This interactive exchange of commonplaces is not one-way. Not only is "Man" affected by a "wolf-system of commonplaces," but equally so is "wolf" transformed by a "man-system of commonplaces." As Black states, "if to call a man a wolf is to put him in a special light, we must not forget that the metaphor makes the wolf seem more human than he otherwise would" (44). Neither element of the metaphoric expression leaves the union completely unaltered, due to the interactivity between these two sets of commonplaces.

This discussion, of the sets of commonplaces involved in any metaphoric interaction, leads to another problematic weakness with Black's argument as he lets it stand, but it also allows a way to bring together Lakoff and Johnson's theories on metaphor with those of Richards and Black. Black notes that one of the chief objections to an interactional theory of metaphor is that "some of the 'associated commonplaces' themselves suffer metaphorical change of meaning in the process of transfer" (42). In other words, not only may "Man" and/or "wolf" become metaphorically altered by the 
interactive exchange, but the commonplaces associated with each concept ("Man," "wolf") may change simply by being placed up against the other system of commonplaces. He answers this by stating that not "all changes of meaning in the 'associated commonplaces' must be counted as metaphorical shifts. Many of them are best described as extensions of meaning, because they do not involve apprehended connections between two systems of concepts" (ibid.). Thus, Black is arguing that the associated commonplaces that exchange between "Man" and "wolf" are partial in nature, without there being impactful metaphoric activity in all of the commonplaces introduced to the metaphoric expression. Instead, some commonplaces are simply "extended" across the metaphoric divide.

Thus, let us examine this by altering Black's original metaphor to state, "Man is a wolf, with shaggy mane and bared teeth." The shaggy hair of a mane, and bared teeth, are commonplaces that may initially be associated with wolves, but according to Black's argument, here they are only extensions of meaning, bolstering the metaphor. A man may have a mane of hair, and even a human smile is nothing more than a baring of the teeth. If we take Black's stance on this, then, these descriptive elements are merely extended between two analogous commonplaces held by both "Man" and "wolf." In fact, this is exactly what Black suggests, as he parenthetically comments that "it is easy enough to mutter 'analogy,' but closer examination soon shows all kinds of 'grounds' for shifts of meaning with context - and even no ground at all, sometimes" (42-43). By the second part of Black's line here, though, we note that even he is not fully satisfied with this suggestion. Perhaps analogy does not suffice in answering how meaning is extended between the two metaphoric elements, he ventures. ${ }^{15}$ According to Richards, as 
previously noted, while "some similarity" might initiate the metaphoric connection (which admittedly seems dangerously close to a substitution/comparison view of metaphor), it is the catachrestic association of "unlikeness" that strengthens the metaphoric expression. The "similarities" to which Richards refers seem to be the same as the commonplaces that Black argues simply get carried through as "extended meaning." While catachresis certainly plays an crucial role in metaphoric meaning, Richards' dismissal of any prolonged nature of similarity as an aspect of metaphor implies what I would see as a connection to Black's struggling attempt to answer for the ways in which extended meaning and metaphoric meaning come together within metaphor.

I would argue that the fact that some of the commonplaces in a metaphoric expression "suffer metaphorical change" is just as vital to an interactional view of metaphor as the ones Black has already pointed out. This is a point in which I see a convergence between Lakoff and Johnson's work and Black's. Black has previously outlined, basically, two sets or systems of commonplaces in the metaphor "Man is a wolf": the "wolf-system of related commonplaces" and, conversely, a "man-system" of commonplaces. To this I would add a third system of commonplaces: the "man/wolf system," or, MAN-IS-WOLF - the conceptual metaphor that spawns from the metaphoric association of the two subjects, as Lakoff and Johnson would identify it. In the original metaphoric expression, both "man" and "wolf" are influenced by each other's commonplaces, and in turn the expression extends into this third set of commonplaces, the conceptual metaphor, to be used in other situations in which "man" is given wolfish characteristics (or wolves given man-like ones). Thus, to shift to Lakoff and Johnson's 
example of the original metaphor "time is money," both "time" (which at this point we may identify as the tenor) and "money" (the vehicle) are shifted, influenced, affected by the commonplaces of the other element, and the association between the two, initiated by their metaphorically-shifted commonplaces and bolstered by the "extended meaning" shared between the two subjects, creates the conceptual TIME-IS-MONEY. Although this metaphor might be seen as one-sided, in which "time" is primarily the metaphorized element in Lakoff and Johnson's examples (it is, of course, time that gets "spent," "wasted," etc.), the interactivity that takes place between "time" and "money" brings the two commonplaces, of time and money, so closely that they become conceptually intertwined. It may be hard at times not to conceive of time in monetary terms, but we can still note that time isn't "literally" a money - the connection of the two commonplaces has thus created a new set of commonplaces, a new conceptual system in which time indeed is money, or Man is a wolf. ${ }^{16}$

\section{The Lifespan of Metaphor}

The theories of Lakoff and Johnson, paired with those of Max Black, provide us with a powerful way to understand metaphor as a powerful, shaping, interactive force in language and discourse. As is the case with many theoretical perspectives on metaphor, however, much of their work is done "in retrospect": whether using the examples of TIME-IS-MONEY or "Man is a wolf," any discussion of metaphoric interaction is being done after the fact, when the metaphor(s) are already identified and accepted as suitable examples. What is lacking, then, from these discussions is an example of such metaphoric interaction and conceptual establishment in action. We can hypothesize about how the interaction takes place, but we lack a view of such a trajectory, from the point of 
discursive introduction to the establishment of a metaphor as a model that allows for a conceptualization of reality.

In his essay, “Toward a Life-Span Account of Metaphor,” Tim Linzey offers such a perspective, on the trajectory of a metaphor's interaction. He uses an actual example of a metaphor that came out of a training program he conducted for educational psychologists. To offer the different perspective on the first-time experience of an individual visiting a psychologist, Linzey suggested to his class the metaphor of "psychologist is a psychic seer." Linzey charts the development of this metaphor through four stages, starting with what he calls the "gee-whiz stage":

The utterance positioned the group members as playful participants of a simple word game, inviting them to make quite extravagant claims about the similarities between the practices of psychologists and psychics: the reading of body language, the use of intuitions and hunches, the capacities for these hunches about the client to be self-confirming, and so on. (199)

Linzey points to the playfulness in this stage. A novel, new metaphor excites the discourse community's senses, and encourages them to play around with the idea: in what ways is the metaphor accurate? What are the metaphoric implications of connecting these two roles? What are the disconnects between the two metaphoric halves; how is the metaphor complicated? The focus of this stimulation and exploration, Linzey notes, is the vehicle of the metaphoric expression (although he does not use those terms). The group of students were focused on seeing the attributes of "psychic," how they applied to "psychologist," and how these attributes survived a metaphoric reversal: "If psychologists are psychics, then psychics are psychologists."17 Linzey sees this stage as one in which play is encouraged but not trust or faith in the metaphor, and attributes this lack of trust to the metaphor's "initial lack of explanatory force" (ibid.). The metaphor, 
being newly introduced into the discourse at hand, still has some "proving" to do before it can be an accepted mode of metaphorizing the "tenor" of discussion - psychologists.

The second stage, according to Linzey, focuses on how the members of the community transform the initial metaphor into a simile suitable for other uses within the same conversation. "Participants," he states, "discussed the similarity between the "cold reading' skills of the psychic and their own limited ability at interpreting their first-time clients" (200). This goes beyond simply changing the metaphor from "psychologist is a psychic seer" to "psychologist is like a psychic seer." In the "simile stage," we are seeing the birth of the conceptual metaphor through its first uses, such as the metaphorizing of a first-time client interaction by using psychic terms of "cold reading." At this point, the "gee-whiz" novelty of the metaphor has passed, and the playfulness of the first stage is fading. Instead, members of the conversation are seeing the applicability of the metaphor to other situations, and seeing how it can relate to other conversations within the community. The trustworthiness of the metaphor increases, and Linzey notes that in this stage, the metaphor is "marked by an increase in the heuristic force" (ibid.).

Linzey describes the next stage as a "modeling phase," in which the simile becomes situated within specific conversations in the community to interrogate a specific issue. With the metaphor "psychologist is psychic seer," the issue was "investigating the disempowerment of naïve clients."18 Through the discussion that followed, the metaphor became the primary model to view this extended issue, which was not initially associated with the initial metaphoric introduction. In a sense that bordered on scientific discovery, Linzey describes the exploration of this issue in conjunction with the model of "psychologist as psychic seer." He states that his students" "interrogation of the metaphor 
had generated certain problem-based hypotheses that directed the subsequent professional ethics conversation." It is during the discussion of this stage that Linzey's statements belie a certain level of distrust for metaphor and its conceptual power. He states that the modeling stage of metaphor "provokes us into stretching the conceptual terms of discourse and thereby allows the generation of problems for legitimate research" (201-2). While Linzey exhibits a bit of discomfort in metaphor's tendency to "stretch conceptual terms of discourse," what he is pointing to here is the creation of the conceptual metaphor, which of course leads to a reconceptualizing, on some degree, of the initial discourse at hand - the "tenor," if you will. Also, at this stage, Linzey notes that the heuristic potential of the metaphor drops quickly, as the stimulation of discovery decreases, but at the same time the "fiduciary force of the model is increased" (202). The ability to use the metaphor as a way to explain situations beyond the original use of the expression becomes more stabilized, more "trustworthy." 19

Finally, Linzey points to "metaphoric assumption" as being the last stage of a metaphor's life-span. It is at this point that the metaphor "achieve[s] the status of an unstated set of metaphoric ontological assumptions" (ibid.). Linzey's class, he states, never reached this stage with the metaphor "psychologist is psychic seer." ${ }^{20}$ However, he goes on to discuss this stage, and what it entails in the development of a metaphor. This is the point, by his standards, that the metaphor becomes part of "literal language" - dead. Certainly, the "set of assumptions" continue to exist, but the metaphoric expression has lost its panache. Its ability to excite the senses, and to cast things in a new light, has dissipated, while at the same time its reliability as a commonplace within the discourse has been firmly asserted. Linzey refers to metaphors in this stage as being "in their most 
mature form" (203), and it seems clear from his discussion that he sees metaphors at this stage as having one foot in the grave, with the other foot on a banana peel. There's no new development to be had for such metaphors. While these metaphors may be verging on death, and their subsequent entombment as part of literal language and conceptual assumptions (by his standards), Linzey argues that it is at this point that they exhibit their highest levels of "cognitive significance" (202). They may no longer have a high level of discovery, of heuristic potential, but they "make sense" within the discourse of the community to a high degree, and they are "trustworthy."

Linzey's depiction of the progression of a metaphor from newly-introduced to established and assumptive provides a valuable way to map the development of a conceptual metaphor, even though he does not strictly discuss it in those terms. Lakoff and Johnson's theory of conceptual metaphor, with the insertion of Black's interactive theory of metaphor, help us to see the ways that conceptual metaphors are integrated into the discourse of a given culture, but they do not provide helpful, hard-set examples of the interaction and establishment of these metaphors. Linzey's mapping of the single metaphor "psychologist is psychic seer" gives a model we can follow, as well as modify and build upon based upon our understandings of Lakoff and Johnson, Black, and others. However, I also see an opportune moment of catachrestic meaning that arises at this point. Linzey's argument is based on his own metaphorization of metaphoric LIFE. As he explores the moments of engaged metaphoric activity exhibited in the example of "psychologist as psychic seer," he presents us with the metaphoric model of what he suggests is a metaphor's typical "life-span." His argument is thus hinged, at least partially, on the idea that a metaphor, when reaching its "fullest maturity," becomes 
(nearly, if not fully) "dead." However, the commonplaces that I myself import into this metaphoric association include a disruption: I do not see metaphor necessarily leading to its own death. While his metaphorized "life-span" would imply some point when that life must end, I would argue that if a metaphor achieves a level of "metaphoric assumption," it can hardly be seen as dead. As it becomes part of the conceptualization of a discourse community's reality, that metaphor (now a conceptual metaphor) retains a high level of liveliness. ${ }^{21}$ The commonplaces that have carried over, for example between "psychic" to "psychologist" take on a life of their own, beyond the initial metaphoric expression - this much Linzey notes himself when he describes the "modeling" and "metaphoric assumptions" stages - and they will continue to influence the directions in which the conversations of that community will follow.

This adjusted way of looking at Linzey's proposed "life-span" for metaphor is what we see, for example, in Evelyn Fox Keller's monograph, Refiguring Life, as she describes how metaphoric concepts of biological and genetic sciences both signaled and led to paradigmatic (conceptual) shifts in the nature of how scientific inquiry was performed and made meaningful within those discourse communities. While I do reserve more of Keller's examination for Chapter II, I find it valuable to this present discussion to note her portrayal of the metaphoric shift in scientific discourse that occurred after World War II. Keller describes how the field of molecular biology, working under a conceptual metaphor of "gene action" that saw genetic activity as unidirectional and based on "master genes" translating and delegating "duties," experienced first an influence and then later a full shift to a metaphoric discourse as offered and used by "cyberscience," with models of "networks and organizational complexity, borrowed from cyberscience by 
theoretically minded biologists" (89). However, cyberscience, itself shaped by the militarized discourse following the war, had picked up these metaphors from older, premolecular, biological models - intentionally discarded by molecular biologists as "conspicuously teleological" and no longer productive to biological science (88). But these metaphors were not just drawn from biology to be returned later. They had (much along Linzey's timeline) gone through a metaphoric livelihood within organicist (premolecular) biology, and while they were discarded by the community as "dead" or unproductive, they were discovered and reinvigorated by others - in new contexts, for new purposes. In addition, though, these metaphoric concepts returned to biology, "revitalized" and capable of inspiring new levels of interactivity. I would argue (as does Keller) that the metaphors did not shift so drastically that they do not still hold some of the original sense (what Max Black might think of as the "original" set of commonplaces) associated with them. Instead, the evolutionary, progressive development of the conceptual metaphors, now on loan from cyberscience, became imbued with new meanings in addition to those older ones, and this accretion of meaning allowed for the metaphors to reenter the community discourse with new potential for stimulated, engaged activity.

\section{A Defense against the Death of Metaphor}

As a final note regarding metaphor, I would like to address the issue of the "dead metaphor" more fully. Linzey is not the only writer to invoke the notion of a metaphor's death. Just as Ortony pointed out the inevitability of any survey of metaphor theory to begin with Aristotle, it seems that every scholar intent on plumbing the depths of metaphor has something to say about dead metaphors. Discussions about dead metaphors 
just might be the most metaphoric of all the contemplations put forth by metaphor theorists. Scholars invoke all sorts of metaphors to describe how unmetaphorical dead metaphors are: dictionaries are graveyards, literal users of metaphors are murderers, metaphor theorists are "metamorticians," and dead metaphors themselves are described as frozen, senile, or corpses. Most often, what theorists do say dismisses the value and importance of dead metaphors, or even need to consider dead metaphors as part of the metaphoric system. Michael Silk, for example, argues for a very strict view of what is a metaphor, refusing to include terms from "common usage" and privileging literary examples. He states that "in current English, chairs have 'legs' and to speak of the leg of a chair involves no trope; but when Gerard Manley Hopkins says, of God, 'Over again I feel thy finger', there is a trope" (123, author's emphasis). ${ }^{22}$ Silk adopts a particularly Aristotelian approach, emphasizing the deviance of language when identifying metaphors - the "leg" of a chair is part of normal ("standard") language, part of regular life, whereas the usage of language that deviates from the standard through inventive (literary) means indicates the masterful use of tropes (metaphora, metaphor). A common, "deadened" metaphor, such as the leg of a chair, "does not feel deviant, therefore cannot be a trope" (ibid.). Donald Davidson echoes this argument, stating that "once upon a time, I suppose, rivers and bottles did not, as they do now, literally have mouths. Thinking of present usage, it doesn't matter whether we take the word 'mouth' to be ambiguous because it applies to entrances to rivers and openings of bottles as well as to animal apertures" (35). Thus, according to this idea, these metaphors have lost any "deviance," or "ambiguity," that warrant an interactive exploration of metaphoric meaning. "Legs," "mouths," and other long-past metaphors have simply become part of the literal use of language. 
Even though Silk's argument for what may be considered a metaphor smacks of Aristotelian substitution theory, the placement of dead metaphors as being part of literal language actually aligns more with Nietzsche's "mobile army of metaphors" that create the whole of language. John Searle, while not going as far as Silk in dismissing the value of dead metaphors, submits that dead metaphors can and do become literal through continual use, "but their continual use is a clue that they satisfy some semantic need" (88). In fact, in his essay "White Mythology," Derrida identifies this very tendency to fill a "semantic need" as being characteristic of the "metaphoric condition," stating that every metaphor "carries its own death within itself" (271). This suggestion, of course, allows scholars to avoid dealing with the messy details of dead metaphors, and it also helps to establish a firmer, clearer line between metaphoricity and literality - a threshold between life and death.

Even Max Black, in his essay "More about Metaphor," shows little interest in pursuing the interactive potential of dead metaphors. His only real concern is with the labels "dead" and "live" being applied to metaphors. He states that to use the term "dead metaphor" is "no more helpful than, say, treating a corpse as a special case of a person: A so-called dead metaphor is not a metaphor at all, but merely an expression that no longer has a pregnant metaphorical use" (25). Black instead proposes the labels "active," "dormant," and "extinct" to distinguish the varying levels of activity inherent to different metaphors. "Dormant" metaphors may be ones which are relatively easy to revive, in his opinion, whereas "extinct" metaphors are beyond any help. However, he is fine with letting sleeping metaphors lie, proclaiming that he "shall be concerned hereafter only with metaphors needing no artificial respiration, recognized by the speaker and hearer as 
authentically 'vital' or active" (ibid.). Black's interest is with active metaphors, whose use is consciously acted upon by the speaker and consciously received by the hearer. This is in fact a common element to many scholars' opinions on dead metaphors: if they are no longer consciously recognized as "pregnant" with metaphoric implications, they are not worth examining. ${ }^{23}$ It is worth noting, however, that I.A. Richards, who inspired Black's development of an interactive theory of metaphor, takes a more generous position towards these supposed "extinct" or dead metaphors. ${ }^{24}$ While Black has no interest in metaphors need "artificial respiration," Richards argues that "however stone dead such metaphors seem, we can easily wake them up" (101). He gives the example of "strong light" - while "strong" may seem to be a fairly straightforward literal qualifier for "light," Richards suggests that a light's "strength" comes through an original metaphoric association. Davidson may consider this as yet another example of "once upon a time," like a bottle or river's mouth, but using "strong" to describe the intensity of light gives a different interactive quality than, say, simply saying "bright." It may be the case that such a metaphor does require resuscitation to allow it to be excavated for metaphoric meaning, but according to Richards, the simple fact that upon revival it does recall its metaphoricity firmly plants it within the field of metaphoric value and interest.

Aside from simply dismissing dead metaphors as being not worth exploring, another way scholars deal with metaphors "past their prime" is by re-categorizing them as something else: idioms. Again returning to Max Black, we find this justification for dismissal in action. In "More about Metaphor," Black brings up the example of "falling in love," stating that such a phrase would not immediately present itself as a metaphor, to a reader. He states that "it is doubtful whether this expression was ever more than a case 
of catachresis (using an idiom to fill a gap in the lexicon)" $(25) .{ }^{25}$ Thus, Black declares "falling in love," and all other idioms, to be irrelevant to the exploration of metaphoric meaning. Davidson gives a similar response regarding idiomatic sayings, although he does allow that such sayings may have, at some point, been metaphoric (as with dead metaphors):

'He was burned up' is genuinely ambiguous [...], but although the slangish idiom is no doubt the corpse of a metaphor, 'He was burned up' now suggests no more than he was very angry. When the metaphor was active, we would have pictured fire in the eyes or smoke coming out of the ears. (36)

Davidson admits that an idiom may be the lifeless husk of a metaphor, but that this is inconsequential to a modern reader's understanding of the phrase. Accordingly, the use of "He was burned up" (or, by extension, "falling in love" and other idioms) has lost its metaphoric immediacy and thus cannot be counted in the ranks of metaphor (except, perhaps, the ranks of Nietzsche's metaphoric army that is all of language).

I would argue, against Davidson (and even Black in this case), that idioms such as these $d o$ fit into the schemata of metaphoric influence. While idiom as a trope may be considered separate from metaphoric tropism, these examples represent a case of metaphoric activity that perhaps may be less "novel" to those individuals whose cultural and experiential commonplaces and awarenesses already "accept" the idiom(s) in question, but they still are capable of inspiring metaphoric understanding when used and engaged by individuals approaching them for the first time, or from different discursive communities. Nelson Goodman uses the term "frozen metaphor" instead of "dead metaphor" to discuss metaphors past their prime, and makes the point that "a frozen metaphor has lost the vigor of youth, but remains a metaphor. [...] What vanishes is not 
its veracity but its vivacity" (68). Whether as a "frozen" metaphor, a "dead" metaphor, or an idiom (debatable as this last one might be), the emphasis seems to be on how acceptable the metaphoric meaning of the expression has become to the contextual and cultural awarenesses available to a particular group of readers or hearers. Zdravko Radman identifies this moment, the deadening of a metaphor, as the moment that "they lose their Verfremdungseffekt, their puzzling novelty" (152). These metaphors might attain a nearly clichéd status - in common use to such a point that they stand as a commonplace of sorts, thus not considered novel or unique. We must not forget, however, that the Verfremdungseffekt of a metaphor is always present, even if dormant the intersections of the varying, oftentimes conflicting commonplaces (or, if we would rather, "awarenesses") that individuals from different discourse communities carry with them reignite this effect, as these new metaphoric interlocutors grapple with making meaning.

Even in the case of a homogenous group, wherein a metaphor's "puzzling novelty" has faded, there are methods of revival. One way that the resuscitation of these "less novel" metaphors occurs is exactly through the exercises so many metaphor theorists engage in. By calling up these metaphors, and excavating their metaphoric meaning, we can not only discover their original roots, but we can see how they have laid the foundations for layers upon layers of additional meaning. ${ }^{26} \mathrm{We}$ are able to see where these metaphors have taken us, and how they have shaped our conceptions of literality, both by intertwining with literal language and by standing alone as metaphoric exempla. In fact, by looking back to Lakoff and Johnson's Metaphors We Live By, we discover that so many of the examples they give, pointing to the presence of conceptual metaphors, are 
indeed what other theorists would qualify as dead metaphors, idioms, or simply clichés. "Wasting" and "spending" time have clearly become a part of the way we use language, and people may have trouble immediately accepting that they exist in some metaphoric context. As an acquaintance of mine, whose background is in accounting and business management, told me, "But time is money." Time quite literally has an effect on monetary gains in certain contexts, and so the idea that TIME-IS-MONEY exists only in a metaphoric sense just isn't true to her. Even if the original use of the phrase was metaphoric, in this case the metaphor has become a literal truth, a dead metaphor. This is where we find the unconscious use of metaphors to be most prevalent: in the dead metaphors people use that, even without them putting much thought into their word choice, connect to a higher order of metaphoric engagement. By noting that people use words like "spend" and "gain" to describe their relationship to time, we are able to see the inherently metaphoric system that has shaped a conceptual link between TIME and MONEY. Tim Linzey, in his account of the lifespan of a metaphor, concludes by declaring that the levels of "discovery" and "trust" that are held in potential at the beginning and end stages of a metaphor's life are inversely proportionate: "In their most mature form, metaphoric assumptions exert virtually no heuristic force on the conversational community. The fiduciary force, or trust, in the cognitive content of the new metaphor is minimal" (203). The "trustworthiness" of a new metaphor is suspect, in Linzey's eyes, and the ability of an old, established, or "deadened" metaphor to excite and stimulate discovery is nil. I would argue that Linzey, and the other scholars who declare that novelty and "discovery" are vital to identifying the livelihood of a metaphor, is qualifying these aspects of discovery and trustworthiness too strictly, confining them to too rigid of 
a conception. When we think how Lakoff and Johnson's identification of conceptual metaphors (which carry out the process of affirming what Linzey considers "metaphoric assumptions") have stimulated an exploration of discourse to see the bonds that connect these metaphoric associations to reality, we see a very high level of discovery. ${ }^{27}$

Not only can the "heuristic force" of a metaphor be reinvigorated by a metaphoric exploration, but it can also be reinforced by its rediscovery by new generations of users. Members of a community, well-rehearsed in the language and metaphors of the discourse, may find some metaphoric expressions to be tired, worn out, idiomatic or cliché. However, when a new member enters the group and begins to learn the language of the community, they are being exposed to these metaphors for the first time, and will perceive them with new vitality. Radman calls upon this experience as he reflects on his interaction with those clichéd or idiomatic phrases, "deadened" metaphors that exist in languages foreign to him:

For instance, le coucher du soleil (sunset) is certainly a profound literal or metaphorically dead expression for all native speakers of the French language, as are the German über die Bühne bringen (to settle or solve) and entgegenkommen (to make concessions). Similarly, Sack-gasse (blind alley) or Doktor-vater (mentor or tutor) are illustrative but are, strictly speaking, not literal. For that reason, I could hardly accept the claim of the metaphorical death of these conventional expressions. As a speaker whose mother tongue is neither French nor German, I was amazed by the suggestiveness of these simple habitual phrases the first time I encountered them, and for me they still resist the deadly effect of conventionalization. (154)

For Radman, the experience of discovering the idiomatic phrases of a foreign language was just as metaphorically stimulating as when they were first introduced. Equally, initiate members of any discourse community may be struck by the Verfremdungseffekt, the "making strange," of a previously-perceived dead metaphor. Their experiences in 
these new discourses will be tinted and hued by their understanding of the metaphors that may have long-since been disregarded by veteran members of the community.

Aside from the discovery potential that does come with the "revival" of these dead metaphors, there is still another way to refute the arguments that "dead" metaphors are no longer part of the metaphoric assembly. Turning back to I.A. Richards, we can recall that a fundamental aspect of his argument was that the vehicle and tenor both construct the metaphoric expression - it is not simply the vehicle, what some people would simply call the "metaphor" of the phrase, which gives an expression its metaphoric impetus, but actually the engagement of the two elements together. Thus, in an example such as "John is a cold person," it could be argued that "cold" is no longer metaphoric, much as Davidson argues that "He was burned up" no longer invokes metaphoric visions of steam coming out of the ears. "Cold," according to this argument, exists as an accepted literal way of explaining John (and is cited in dictionaries as such). However, it is not "cold," as the vehicle, that defines the entire metaphoric expression here, and so to quickly disregard it as dead is inappropriate and inadequate to an understanding of the metaphoric workings of the statement. "Cold" acts, in conjunction with the sentence "John is a person," to indicate a larger system that metaphorizes the personalities and attitudes of people through temperature. "John warmly greeted his guests," "Sally is an ice queen," and even "He was burned up" are all within this same system, and while these examples may contain varying levels of accepted metaphoric activity individually, they hardly suggest a "dead” metaphoric structure. The larger conceptual metaphor, PEOPLEARE-TEMPERATURE-GAUGES, is quite active. 
The convergence of theories on metaphor as represented in this chapter acts to synthesize and generate a productive and capable model (or, at some points, models) for understanding the presence and activity of metaphor within Rhetoric and Composition. As previously mentioned, one common objection to Lakoff and Johnson's Metaphors We Live $B y$ is that it is primarily a text that identifies metaphors, but stops short of fully exploring how they come to pass or what keeps them from assuming the status of "dead metaphor." By incorporating Black's theory of interactive metaphor, we can see how the different elements of metaphoric expressions gain agency, creating new paths both through catachresis and through similarity. These pathways between commonplaces shape and form the conceptual groundwork, the foundations, for the larger metaphoric structures which Lakoff and Johnson discuss. Even in those cases when the commonplaces are "not so common," the metaphoric engagement that comes from difference, from dissimilarity, produces meaning within the metaphoric systems that further fuel their interactive potential.

Specifically for this dissertation, these theories together allow us to point to the metaphors as they are initially encoded into the discourse of Rhetoric and Composition. Going further than mere identification, however, we can then interrogate how the continued interactivity between tenor and vehicle, as well as the interactivity between members of the composition community and the conceptual metaphors of the field, continue to shape and reflect our ideals and goals as a discipline, while also directing which paths we may follow in telling our stories and shaping our pedagogical philosophies. In the next chapter, I explore one of the most prominent metaphors within the field of Rhetoric and Composition, that of WRITING-IS-PROCESS. By charting its own 
process, from initial inception to establishment as metaphoric assumption, we can see how the conceptual metaphor of PROCESS continues to influence and guide the discipline - not as a static concept, but as one that continues to receive engaged meaning from new sources and revitalized metaphoric association. 


\section{Notes}

${ }^{1}$ While Aristotle is considered the first to identify metaphoric language, this is not to say that metaphoric language, or rather an understanding of the use of figurative language, began with him. Homer, in the eighth century $\mathrm{BC}$, was employing metaphor much in the same way that we find basic metaphors in modern usage, and Homeric metaphors from the Iliad and Odyssey are used as chief exempla by Aristotle.

${ }^{2}$ As an interesting note, the term metaphora which Aristotle coins to encompass "non-standard" usage comes from the Greek words meta and phorein, which together mean "to transfer or carry across." Thus, this term which would evolve into the modern word "metaphor" is itself a metaphor.

${ }^{3}$ This point, that simile is metaphor, is one that has been debated and discussed by many scholars, perhaps more than any of the other tropes Aristotle includes in metaphora. While many have noted that such devices like metonymy share characteristics but are distinctly different from metaphor, simile has enjoyed a spirited discussion in scholarly works, in regards to its relation to metaphor. Max Black suggests that metaphors could be seen as "condensed or elliptical simile[s]" (35), implying that simile inhabits a higher status than metaphor, while Paul Ricour's treatment of metaphor elevates it much above simile, which he finds to be a more simplistic use of figurative language that relies too heavily on literal meaning.

${ }^{4}$ Granted, the metaphoric examples Aristotle provides of literary masters come from his discussion of literature, in Poetics - however, he makes a point of stating that metaphors are exactly suited for both epic and iambic verse, as their deviation from ordinary, non-literary speech indicates their special usage.

${ }^{5}$ As Quintilian later put it, vir bonus dicendi peritus: "a good man speaking well" (Institutio X.I.1)

6 "eisin gar kai metaphorai aprepeis, [...] de dia to semnon agan kai tragikon": though John Henry Freese, in the cited translation, chooses to translate Aristotle's words semnon agan kai tragikon as "dignified and tragic," a more apt translation emphasizes the lofty and performative impact of metaphor when used in rhetoric. Aristotle is making a distinction between genres - literary drama (tragedy) and rhetorical discourse - that is based on performative elements rather than subjective roles.

${ }^{7}$ Such an argument does seem to rely on a type of Platonic ideal of form which can only be (imperfectly) expressed metaphorically in human discourse.

${ }^{8}$ Granted, to state that Nietzsche is arguing that metaphors are largely inactive may seem a misrepresentation. Indeed, Nietzsche's argument does point out that there is an active engagement with metaphor at the moment of per/conception. His stance, however, is more centrally focused on how metaphors become the foundations of language, no longer actively conceived of as metaphors, thus it is exactly their lack of activity as metaphors that grounds his argument.

${ }^{9}$ Thus, interestingly, this suggests a reversal of Nietzsche's theory: while Nietzsche argues that language is shaped by a metaphoric understanding of reality, Lakoff and Johnson suggest that reality can also be shaped by our (sometimes unconscious) metaphoric understanding of language.

${ }^{10}$ In Lakoff's work, with Johnson and others, the overarching conceptual metaphors are textually differentiated by individual uses of metaphors by means of small-caps. Thus, TIME-IS-MONEY is distinguished from the singular metaphoric phrase "time is money." To maintain a level of coherence and to allow readers to understand similar distinctions, I will use the same convention for identifying larger conceptual metaphors.

${ }^{11}$ In More than Cool Reason, Lakoff and Turner have an entire section devoted to "What Is Not Metaphorical."

${ }^{12}$ Black's example of "man is a wolf" could perhaps be seen as a modernized update of Aristotle's "Achilles is a lion." 
${ }^{13}$ Black points out that this is key aspect in showing how metaphor is culturally-specific - as different cultures may view "wolves" in different ways may have an entirely different reading of the metaphor: "Men who take wolves to be reincarnations of dead humans will give the statement "Man is a wolf" an interpretation different from the one I have been assuming" (40).

${ }^{14}$ These commonplaces continue to evolve, retaining older attributes while at the same time gaining new ones. Thus, not only would a "wolf-system of commonplaces" still carry "metaphoric residue" from older superstitions, but it would also include newer perceptions of wolves, such as the increasingly endangered status of wolf populations.

${ }^{15}$ Black is not the only one unsatisfied with his conclusion. Other scholars have attempted to delineate the differences between "metaphoric shift" and "extension of meaning," most often coming to a similar conclusion as Black, that the two concepts are difficult to clearly identify independent of each other (Myers, 1964; Crosthwaite, 1985). There are extreme examples that resist Black, however, such as J. Srzednicki, who goes further than most by arguing for a clear and distinct separation of the two actions, proclaiming that a metaphor and an extension of meaning are absolutely different and cannot, except under "special circumstances" (which he does not explain), be found within the same expression (237).

${ }^{16}$ This argument can even be extended to Aristotle's prototypical metaphoric example, "Achilles is a lion." Even though Aristotle wasn't thinking of metaphora in conceptual terms, this metaphor clearly involves commonplaces, extending into a created conceptual metaphor of PEOPLE-ARE-LIONS (since not only are (male) epic heroes associated with lions, but also villains, women, and children). Moreover, while the metaphor began as part of the Homeric tradition of epic poetry, its conceptual power is evidenced crossgenerically, so that it appears in other classical texts, while always being part of the cultural, poetic inheritance.

${ }^{17}$ Although Linzey doesn't acknowledge it, we can see that some of the metaphoric connections being recognized between "psychologist" and "psychic seer" certainly come from their related etymological past, rooted in the same origin word.

${ }^{18}$ The issue explored by Linzey's class, through the metaphor "psychologist is psychic seer," further points to Black's comments about the interaction of the commonplaces within a metaphoric expression. As Black stated, not only are "accurate" or "true" commonplaces carried through by metaphoric association, but also perceptions, misperceptions, and assumptions. Some would argue against strictly perceiving people who go to psychics as "naive," however it is clear that this is an assumption that came as part of Linzey's class's associated commonplaces, as the class underwent the throes of metaphoric interaction.

${ }^{19}$ Linzey characterizes this stage of heightened metaphoric trustworthiness or "stability" as exhibiting a higher "fiduciary" force - a specifically financial trustworthiness. It's worth noting here the apparent draw to explain metaphor through particularly financial conceptualizations. In addition to Linzey, Nietzsche describes the metaphors that comprise of all language as being coins with their faces worn away, thus no longer of monetary value. Also, while Lakoff and Johnson don't specifically associate metaphor with monetary qualities, many of their key examples to foreground their assertions involve money: TIME-ISMONEY, or, in Lakoff's later solo article "Metaphor, Morality, and Politics," "moral action [...] conceptualized in terms of financial transaction" (179). I might suggest that the transactional nature of metaphor (perhaps one of the only aspects of metaphor that all theorists might agree on, in one way or another) creates a strong sense of similarity with the transactional commonplaces often associated to money.

${ }^{20}$ I believe that Linzey gives neither the metaphor nor his students enough credit in this regard. He notes that "the group began to consider its own professional language from a somewhat revised point of view. [...] Terms like informed consent and coercion reentered the reformed conversational context in a much more circumscribed form" (ibid.). Unfortunately, we don't have any other account of the conversations and language from that class to see any ways that the metaphor may have spawned multiple occurrences of a 
conceptual metaphor, but it does seem like the metaphor of "psychologist is psychic" has become an influential part of these students' conceptualization of their community, of the field of psychology.

${ }^{21}$ As I reread my words, I wonder if I haven't simply engaged my own interactive shaping of Linzey's offered conceptual metaphor to redirect it, as I recognize the catachresis: in my resistance to a metaphor's "life-span" having a definitive end, my descriptive justification appears to refigure METAPHOR-As-LIVINGENTITY just with a new stage: a "transcendent," "heavenly" afterlife as a conceptual metaphor?

22 When stating his argument, Silk uses as his support metaphors which come solely from literary exempla: Virgil, Sophocles, Shakespeare, Yeats, Eliot, and others.

${ }^{23}$ Black's interest in those metaphors "pregnant" with meaning exposes one of the problems that many metaphor theorists do not acknowledge, which is their assumptions regarding the cultural contexts that they are working under - they quite often present their metaphoric considerations presupposing a homogenous linguistic community. Black, of course, does state that the incorporation of commonplaces by nature allows for multiple community perspectives to affect metaphoric meaning, but he does not answer the question of who decides metaphoric "authenticity."

${ }^{24}$ Richards finds, just as Black does, the labeling of "live" and "dead" metaphors to be problematic: "This favourite old distinction between dead and living metaphors (itself a two-fold metaphor) is, indeed, a device which is very often a hindrance to the play of sagacity and discernment throughout the subject" (102).

${ }^{25}$ Black finds it necessary to give a parenthetical definition of catachresis, invoking idioms, and opening up his rationalization to other perspectives on catachrestic engagement. However, Richards points to catachresis as one element that plays a functional role in the creation of metaphoric meaning, and even Black himself points out that the differences between two subjects of a metaphoric expression are vital to the interactive nature of metaphor.

${ }^{26}$ I realize that even the metaphors $I$ use, when talking about "excavating" the "roots" and "foundations" of metaphors, trace back to an assumption that metaphoricians are archaeologists, digging up the remains of dead metaphors. It's ever so hard to resist the draw of metaphor.

${ }^{27}$ Conversely, a new metaphor can carry a high level of trust simply because of its novelty - in a situation when other metaphors may seem inaccessible or weak, the creation or introduction of a new metaphor can carry with it not only the excitement of discovery, but also the faith that this new metaphor will eventually be more explanatory than others. 


\section{CHAPTER II}

\section{THE METAPHOR OF PROCESS}

Make the process of writing into atomic fission, setting off a chain reaction, putting things into a pot to percolate, getting words to take on a life of their own.

Peter Elbow, Writing without Teachers

A model is a metaphor for a process: a way to describe something, such as the composing process, which refuses to sit still for a portrait.

Linda Flower and John Hayes, "A Cognitive Process Theory"

If there were to be one prevailing metaphor of composition, representing the act of writing, the teaching of writing, and even the field of Composition itself, it very well might be the metaphor of WRITING-IS-PROCESS. To some, the idea of writing being a process may not seem very metaphoric at all (or even, anymore at least, revolutionary). It stands to reason that writing $i s$ a process. The focus, really, with process-oriented writing, has been in its opposition to the seemingly monolithic perspective of writing as a product, and this has been for many scholars, both past and present, a main drive of process theory and pedagogy. Often situated as part of a long-past movement, ${ }^{1}$ productoriented writing emphasized the final product, the result of writing, as the only real element that could be held as an evaluative measure to assess a writer's ability. Thus, the final product became the metaphoric representation for an entire pedagogical approach, WRITING-IS-ProdUCT. As Richard M. Coe states, such a conceptual approach answered, formally, the question, 'What is good writing?' Because it radically dichotomized form from 'content,' its answer emphasized structure: sentence structure, paragraph structure, essay structure, even the 
proper structures for term papers, business letters, resumes [...]. If the proper forms were defined, they could be described and exemplified for students. After the students wrote, they could be shown where their writing failed to match the ideal forms. (14)

Victor Villanueva comments on this current-traditionalist approach as being "rather like having students watch and discuss a videotape of a prima ballerina and having the students attempt the same dance, with the students then being evaluated based on how well they approximated the ballerina's performance - without knowing how the ballerina came to master those steps" (1). Process-oriented writing redirects the writer to consider what comes before that end product - the way that a writer comes to learn, create, and put together the many pieces that ultimately go into a piece of writing. Thus, much of the scholarship and discussion regarding "process" has focused on ways to understand and conceive of the moments of writing in action. In essence, the journey becomes just as valuable as (if not more than) the destination.

On the surface, neither of these two oft-discussed approaches may seem overly metaphoric. At most, "product" may appear metonymic - representing the whole of the process, activity, and production by a writer in a single, final piece of writing. As for "process," it makes sense that a process logically precedes any such product. Peter Elbow, writing in 1973 at the beginning of the turn towards process pedagogy in composition, suggests an understanding of process that simply begins when "you start writing at the very beginning - before you know your meaning at all - and encourage your words gradually to change" (Writing without 15). Donald Murray, writing a year earlier in his essay "Teach Writing as a Process Not Product," explains the writing process as "divided into three stages: prewriting, writing, and rewriting" (4). In both of these examples, the process being described seems literal enough. Process is then just 
that: a process, with stages that a writer goes through, taking him or her from the very beginning to the very end. A product still exists, but the greater weight is placed on the path by which the writer achieves that product, "for the process can be put to work to produce a product which may be worth your reading" (ibid.).

However, it is important to understand that both process and product have metaphoric qualities that have imbued their meanings extending far beyond their surface literalities. In the case of WRITING-IS-PRODUCT, it could be argued that its overt recognition as a conceptual metaphor has come through the implementation of process pedagogy, as an example of what to resist - it is the arch nemesis, to be avoided and opposed at all cost. The product that is symbolized in this equation is more than the finished product of a single writing act. It represents a gatekeeping move in education, a consumerist agenda, or even for some a misguided attempt to make all writers into literature authors producing finished literary works. Metaphorically, WRITING-ISPRODUCT carries the association of "product" being a fixed item, created for consumption and not for reflection. Conversely, WRITING-IS-PROCESS as a metaphor extends the understanding of writing to a holistic level, encompassing not only various stages of the process (of which product would, by nature, be one part), but also various approaches and processes.

Herein lies the rub, contributing to both the confusion and continued vitality of WRITING-IS-PROCESS as a conceptual metaphor. For, even if we accept at surface level that WRITING-IS-PROCESS is indeed a conceptual metaphor, what is being metaphorized? What process, exactly, is being referred to? While both Elbow and Murray above describe the process of writing in a way that allows us to see writing as a process, the 
process they each refer to is different. Moreover, the process examined by researchers like Linda Flower and John Hayes is altogether a different one. In the discipline of composition, an overwhelming majority of scholarship refers to "process" - "process writing," "the composing process," "process pedagogy," or even as simply that: "process." Oftentimes, it appears even in an off-hand way, an accepted term of the discipline that no longer needs definition or explication. However, as several scholars have noted, what process actually is has regularly and repeatedly been confusingly described, vaguely put, and carried as an assumption rather than a full understanding. This is not to say that scholars and teachers do not still excavate what it means to teach process, of course - discussions of "post-process" theory and pedagogy often spend a sizeable amount of time exploring the process movement, and implicitly the metaphors tied to it. However, the WRITING-IS-PROCESS conceptual metaphor has become such a powerful and dominant metaphor of composition that nearly all discourse within the field of Rhetoric and Composition has been molded by an acknowledgment of it as a shaping concept (even within conversations that resist or reject it).

In the first chapter, I explored the notion of the conceptual metaphor, and how it can shape (or reshape) our conception of reality through metaphoric association. A conceptual metaphor encourages a level of interaction that continues to draw new associations to the metaphor. Ultimately, through these extended associations, the metaphor itself becomes a conceptual framework upon which future discussions are built. In this chapter, I argue that WRITING-IS-PROCESS is such a conceptual metaphor. Not only has the metaphoric connection of writing and "process" been explored by many scholars, the resulting conceptual metaphor has shaped the field of Rhetoric and Composition and 
how we conceive of writing. While the metaphoric qualities of WRITING-Is-PROCESS may seem literalized or "deadened" (for good or ill), I would argue that the metaphor is still not taken as an uncritical assumption. Scholars and teachers have engaged with WRITINGIs-PROCESS in a way that has continually re-energized its conceptual power over the past 40 years, and it continues to play a vital role in the formation of new entrants to the discipline. The interactive ability of WRITING-IS-PROCESS is seen in how it has been appropriated, extended, and resisted as a conceptualization of not only writing, but also the writer and the teacher of composition. This chapter presents some of the interactive moments, snapshots within the larger life of the metaphor, that establish WRITING-IsPROCESS as a viable conceptual metaphor - one that has shaped the history of Rhetoric and Composition as well as continuing to shape new entrants to the field. As a starting point, we can look to some of the "birthing" moments of the conceptual metaphor, to see how early inscriptions of WRITING-IS-PROCESS were intended to act as an intervention in conceptualizations of the act of writing.

\section{The Birth of Process ${ }^{2}$}

Many scholars, teachers, and writers contributed to the shift in composition scholarship to perceive of writing as a process rather than as a product. In fact, in 1964, preceding Donald Murray by four years, D. Gordon Rohman and Albert Wiecke identified the same three stages (prewriting, writing, and rewriting) as the instrumental phases of the writing process. However, the actual birth of the conceptual metaphor WRITING-IS-PROCESS required more than simply discussing the characteristics of writing that qualified it as a process. WRITING-Is-PROCESS, as a metaphor, relies on the use of other metaphors that metaphorize the process itself. As Peter Elbow states in Writing 
without Teachers, there are many learning processes a person may go through in his or her lifetime: "getting up in the morning, playing the piano, learning to play baseball, learning history" (12). As Elbow notes, all of these examples are processes, involving different moments of activity along a certain continuum. Additionally, all of these processes involve an element of learning necessary to fully appropriate that activity. But, in order to refigure writing as a "verb" rather than a (nominalized) product, it was necessary to generate a metaphor that would adequately characterize (and conceptualize) writing - WRITING-IS-PROCESS, while it would become the mantra for many compositionists, is still itself a bit vague. Without metaphoric clarification, it is difficult to say how exactly "process" goes about reconceptualizing writing. "Process" might invoke different sets of commonplaces - ones that structure the concept as an ongoing (developmental) act, or ones that frame it as a discrete tasked geared towards a specific genre-production. Many aspects of the overall term "process" thus remain ambiguous and undeclared. Further metaphoric interaction is needed - the use of secondary metaphors that can characterize the PROCESS side of the metaphor. In Tim Linzey's sample metaphor from the previous chapter, of "psychiatrist as psychic seer," the metaphoric exchange is relatively straightforward. Both "psychiatrist" and "psychic seer" can be seen as two different things, connected through the metaphor by related metaphoric commonplaces that can be explored and expanded upon to create the conceptual metaphor. In the case of WRITING-IS-PROCESS, the differences that necessitate the metaphoric association of commonplaces are not so clear. There may be agreement on the general topic of writing as a process (by nature, it would have to be some sort of process), but what sort of process is it, and what type of process can it be? How does the 
associative connection of the two metaphoric halves, "writing" and "process," strengthen our understanding and allow us to reconceive of the model of writing itself?

The operative way that this reconceptualization has been done is through metaphorically qualifying PROCESS as a concept first. Then the commonplaces that have become metaphorically associated with PROCESS can be transferred to WRITING. This process of metaphorizing writing on the conceptual level, resulting in the conceptual metaphor WRITING-IS-PROCESS, owes its birth to the contributions of a few choice individuals, in their multiple, rich (and sometimes contradictory) metaphoric descriptions of the process at hand and how these descriptions necessitate a reconceptualization of writing, beyond the previous product-oriented model of writing. Specifically, the foundational texts by Peter Elbow and Donald Murray helped to shape and mold the metaphoric interactions that formed WRITING-IS-PROCESS, through explorations and arguments regarding the idea of writing as a process. In addition, the cognitivist movement in composition, represented in this chapter chiefly by the scholarship and research of Linda Flower and John Hayes, acted to continue the shaping and shifting understanding of the conceptual metaphor. In the next few sections, I present the ways that these authors' conversations about writing and process served to create the conceptual metaphor, WRITING-IS-PROCESS, beginning the lifecycle of the metaphor as it has proliferated scholarship and pedagogy on writing.

\section{Peter Elbow, Organic Growth, and the Percolating Pot of Process}

As an example of the formation of the WRITING-IS-PROCESS metaphor, Peter Elbow's 1973 text, Writing without Teachers, is rife with metaphoric and figurative language. In fact, he makes a point of saying, to the writer reading his book, "make as 
many metaphors as you can. And analogies, comparisons, examples. Encourage them. Let them roll off your pencil freely. Too much" (54). After an initial chapter discussing the merits of freewriting, Elbow starts his efforts towards a process-oriented view of writing with a parable, reminiscent of Edwin Abbot's Flatland:

Once there was a land where people felt helpless about trying to touch the floor without bending their knees. Most of them couldn't do it because the accepted doctrine about touching the floor was that you did it by stretching upwards as high as you could. [...] But a few people learned accidentally to touch the floor: if they didn't think too much about it they could do it whenever they wanted. But they couldn't explain it to other people because whatever they said didn't make sense. (13)

The point of this allegory is to prepare the reader/writer for a reconception of writing, which will require an entire reorientation. ${ }^{4}$ While granting that writing is (was) already seen as a process of sorts, Elbow indirectly comments on the product-oriented paradigm and its view that such a method comes naturally to some writers while other writers can only strive to mimic it. Noting that previous notions of a "good writer" and "good writing" have been misguided, he refutes the myth of writing in which writers are expected to "fall back on the oldest and most popular idea: inspiration - some god or muse comes down and breathes into you" (ibid., author's emphasis). The way a written piece comes into being, under this model, is mysterious, inexplicable, and most often seen to be a matter of full, already-acquired mastery. ${ }^{5}$ Writing becomes something only evaluated after the final word is penned to the page, and likewise the teaching of such an approach requires the act of mimicking models until a writer "gets it right."6

After creating the case for a new conception of writing, as a process rather than focusing on the product, Elbow presents for the reader two metaphors, explicitly, for the process of writing: growing and cooking. While he introduces the two metaphors 
together, he explains each one separately, to highlight the specific uses that they have for the writer's conception of the writing process. In order to replicate this, I will examine the two metaphors separately, beginning with the metaphor of "growing." I will have more to say on their presentation in this way afterwards.

When Elbow begins his discussion of "growing," he notes first off that a concept of growing is obviously quite literal when it comes to how real, living organisms develop: "They go through a series of changes and end up more complex and organized than when they started" (22). However, he wants the reader/writer to apply some of these same commonplaces to the process of writing:

The words come together into one pile and interact with each other in that mess; then they come apart into small piles according to some emerging pattern. Then the small piles consolidate and shake down into their own best organization. Then together again into a big pile where everything interacts and bounces off everything else till a different pattern emerges. The big pile breaks up again into different parts according to this new pattern. Then the parts each consolidate themselves again. Then back into the big pile again for more interaction. And so forth and so on [...] till a pattern or configuration is attained that pleases you. (24)

In this model, the development or evolution of "words," or an argument, represents the growth of both the writing as well as the writer him or herself. He notes that the words have not grown, literally. However, the sense of what these words mean, and how they represent the writer's process of sorting through an issue or idea has. Elbow asks that we see in this model the "organic, developmental process in which you start writing at the beginning $[\ldots]$ and encourage your words gradually to change and evolve" (15).

As stated earlier, this is a specific representation of a process, dissimilar to the process of learning to play the piano or baseball, yet envisioned as a process of learning nonetheless. This process, of growing, provides Elbow with the ability to explain and 
suggest how different stages in the process should be understood and approached. Thus, the stages of growth experienced by the seed of a flower or a by the developing animal embryo, become commonplaces that can be metaphorically associated with the stages of growth that Elbow envisions as part of the writing process.

While Elbow does defend this choice of a developmental, growth-stages model by citing similar models created by Freud, Erik Erikson, and Piaget, his choice from a metaphoric perspective has precedent as well. Lester Faigley points out that "Elbow chose the metaphor of organic growth [that is] the same metaphor Edward Young used to describe the vegetable concept of genius in 1759 and Coleridge borrowed from German philosophers to describe the workings of imagination" (530). However, there is one complication, according to even these previous iterations of the metaphor. Faigley notes, "Coleridge $[\ldots]$ realized the plant metaphor implied a kind of organic determinism (Tulip bulbs cannot grow into daffodils.)" (ibid.). Elbow notes this same complication, and signals the need to resist a totalizing embrace the metaphor to the point of literality: "An initial set of words does not, like a young live organism, contain within each cell a plan for the final mature stage and all the intervening stages that must be gone through. Perhaps, therefore, the final higher organization in words should only be called a borrowed reflection of a higher organization that is really in me or my mind" ( 23 , author's emphasis). In this, Elbow not only clearly acknowledges the ways in which certain metaphoric commonplaces do not survive the metaphoric association, but he also blurs the line between the changes that occur to words in writing and the changes that occur within the mind of the writer. 
Elbow's main point for introducing this metaphor is for its value as a heuristic device. In fact, he states that the "growing" metaphor is not set in stone, but instead is to be used as an entry point for understanding one's own relationship to writing: "There is no easy set of rules to follow. [...] And of course I may have some of it wrong here - or my growth cycle may be somewhat different from yours. Thus the main thing you must do if you want to help growing happen in your writing is to try to get a feel for the organic, developmental process" (42-43).

The second metaphor that Elbow introduces to the reader/writer, to describe the writing process as he sees it, is that of "cooking." At the very beginning of his major discussion of cooking as a metaphor for the writing process, Elbow makes the point that this other metaphor is not to be seen as an alternative to the previous metaphor of growing. He states, "growing is the overall larger process, the evolution of whole organisms. Cooking is the smaller process: bubbling, percolating, fermenting, chemical interaction, atomic fission. Cooking drives the engine that makes growing happen" (48). Although these two metaphors represent different processes, Elbow wants us to see them as complementary, contributing to each other to make the whole writing process complete. This also reflects the nature of his philosophy regarding metaphors themselves. Instead of seeing these two metaphors at odds, the disparate metaphoric associations that one might perceive between "growing" and "cooking" are meant to emphasize the fluid, mixed nature of the writing process itself. Thus, in addition to the ways that metaphorized "processes" influence the view of writing, the metaphoric Process itself can be approached and understood for and through its mutability on an individual basis according to a writer's needs and goals. 
With the metaphor of cooking, Elbow is seeking to emphasize the inner workings of the writing process. If "growing" suits to metaphorize the greater process, from the conception of an idea through its development into a fully formed organism (final product), then "cooking" metaphorizes the way that the idea is given flavor and consistency. Elbow shapes his metaphor of cooking as representing "the process of one piece of material (or one process) being transformed by interacting with another: one piece of material being seen through the lens of another, being dragged through the guts of another, being reoriented or reorganized in terms of the other, being mapped onto the other" (49). He speaks of lifting "the editorial lid" (48), taking an idea and "put[ting] it in the freezer" (55), and the notable differences between "internal" and "external" cooking (65-66). All of these metaphoric associations relate back, ultimately, to the process of invention, and its role in the larger writing process. Elbow is addressing the ways in which interaction in necessary between the many disparate bits that go together to make the larger cooking dish, but he also asserts that this interaction goes beyond simply collecting and making a stew or casserole out of multiple ingredients. He spends the bulk of his discussion outlining the many ways that interaction occurs between different types of "ingredients": the interaction between people, ideas, words, even metaphors themselves - with metaphors, he again encourages writers not only to use as many as possible, but to "be as nutty as possible - and explore the metaphors themselves - open them out" $(64){ }^{7}$

The end goal, for Elbow, is to focus on the "cooking" process within invention. For external cooking, the invention process is deliberate, careful, and methodical, a "mixing up [of] dry ingredients in a bowl" (66); for internal cooking, where much of the 
invention process is hidden, almost "magical," like taking the ingredients and "dissolving them in water so they integrate at a molecular level" (ibid.). Just as with "growing" as a metaphor for the overall process, Elbow asserts that the important thing here with "cooking" is not specifically to adhere to a rote recipe method of cooking that fits every piece of writing: "Concentrate on trying to get a feel for cooking - for words and ideas interacting into a higher, more organized state" (67).

As he concludes his discussion of these two metaphors, Elbow again makes the point that the writing process is one in which both metaphors are to be employed: "writing-as-growing-and-cooking" (73). The two metaphors are two parts of the same process - cooking allows materials to interact, mixing, fusing, changing the consistency and flavor of each other, while growing focuses on the stage-oriented nature of his envisioned process. ${ }^{8}$ And, even though he gives examples and suggestions for different stages and exercises that would fit into this process, the more important metaphoric association that Elbow is calling upon is the sense of the dimensions being worked with. Growing means "trying to get a feeling of a shape in the dimension of time, the shape of a set of changes occurring in a structure" (43); cooking emphasizes the nature of invention itself, allowing for transactional exchange between the many levels of interaction at play in the formation of ideas and writing.

A final thing that is important to note about these two metaphors is that they are not metaphors, according to Elbow, for "writing" in and of itself. He states, "they are my model for the writing process" (18, my emphasis). Not only is Elbow's use of the definite article notable (identifying a singular process available for writing), but his assertion that these metaphors are conceptualizations of the process (and not "writing") is important 
because it is one of the key qualities that creates the WRITING-Is-PROCESS conceptual metaphor along with its many associated metaphoric commonplaces. The distinction here firstly separates the process view of writing from product-oriented metaphors for writing. Additionally, by metaphorizing and modeling the process of writing, Elbow allows there to be some interactive room for metaphoric play in how the process is conceived. If writing is directly metaphorized as "growing," then it is not a process - it is growing, a specific type of process. While Elbow, Murray, and others offer different specific metaphors for the processes of writing, the point is often made that these metaphors allow readers and writers to explore the concept of the writing process outside of a black box. Elbow acknowledges this, stating that "models and metaphors make a big difference most of all, those models and metaphors we take for granted" (ibid.). As in Tim Linzey's modeled lifespan of metaphor, Elbow intentionally introduces the metaphors of growing and cooking for their particular heuristic possibility - their potential for allowing writers to discover more about writing, beyond the strictures of a product-oriented process.

In the next section, I present the metaphoric associations offered by Donald Murray to explore and explain his view of the writing process. Through Murray's presentation of PROCESS, we find that the formation of the metaphor, WRITING-ISProcess, does not itself occur in an organic, linear way, with all iterations leading naturally towards the final conceptualization. While he is concerned with some of the same elements of the process that guide Peter Elbow's treatise, it is clear that Murray's approach, and his advice, is directed to form a quite different conceptualization of WRITING-IS-PROCESS. ${ }^{9}$ 


\section{Donald Murray and the Craft of Writing}

In 1968, five years earlier than Elbow's Writing without Teachers, Donald Murray's book, A Writer Teaches Writing, was published. Just as Peter Elbow later does, Murray begins his discussion by dismissing the idea that a product-oriented model for writing is sufficient for anyone teaching, or learning, how to write: "We cannot discover how the writer works merely by studying what he has left on the page" (1). Throughout the book, Murray makes a point of dismissing many myths of writing, and of writers - he states, very similarly to Elbow's assertion early on in Writing without Teachers, that "the writer does not put on a velvet smoking jacket, pick up a quill pen and let God direct his hand across the page. Instead, [...] the writer is engaged in a continual struggle to discover what he has to say and how to say it" (21).

In this section, I will be examining Murray's main metaphors that help shape the conceptual metaphor, WRITING-IS-PROCESS - different metaphors than those Elbow used. However, it is also important to keep in mind how these differing metaphors actually shape two different conceptualizations of WRITING-IS-PROCESS. Thus, while Elbow and Murray are approaching the same task, of redirecting the focus of writing away from PRODUCT and towards PROCESS, the metaphors used to accomplish this task expose a much different prioritization of values within the arena of writing. Murray is interested, as is Elbow, with exposing the writing process, but his (metaphoric) argument diverges from that of Elbow's at a point. While Elbow focuses on creating a "sense" or "feeling for the dimensions" of the writing process, Murray's metaphoric associations often focus more intently on creating the image of the writer within the process. This is not to say, of 
course, that Murray's book is not about the process of writing. For example, he states early on that

the writer understands that writing is a process, not a rigid procedure. He constantly rediscovers his subject. [...] When he creates a design of what he has to say, his outline may show him he needs to expand or limit the subject. He may discover he cannot speak to the people he wanted to speak to, and he must find a new audience. Sometimes he will give up what he has to say and start on a new subject. He must be open to these changes, for writing is a continuing state of discovery. (7)

Quite assuredly, Murray makes a strong argument for a process-oriented model of writing, and his metaphors certainly contribute to the larger act of conceptualizing WRITING-IS-PROCESS. However, not only through his metaphors, but also through the structure of the text itself, we find that Murray strives to create (or perhaps simply correct) an image of how an experienced writer carries him or herself through the writing process. His chapters are set up to highlight the many skills a writer (and writing teacher) goes through, and what actions they complete during the process: according to the table of contents, the writer "discovers a subject," "senses an audience," “creates a design," and "rewrites;" and the writing teacher "listens," "coaches," "is a diagnostician," and "keeps his distance." Murray also, on multiple occasions throughout the book, compares the "amateur writer" with the "professional writer" (or, sometimes, the "good writer").

As is evident even just from the partial listing of chapter/section titles above, Murray, like Elbow, uses many metaphors to describe the writing process, the writer, and even the teaching of writing. For example, he metaphorizes the identity of writing teachers as physicians: "[The teacher] will have many medications and treatments for the same ailment. His job is to diagnose the simple problems of the student and then to be flexible enough so that he can prescribe a treatment which will cure" (21). Writing advice 
becomes a shot of penicillin (20), and editing (which Elbow figures as "mopping up" the kitchen floor after the disorganized mess of "cooking") becomes "surgery" (135). ${ }^{10}$ In other instances, Murray metaphorizes the process of writing in terms of marriage. He suggests, "the difference between an idea and a thought might be described as the difference between a kiss and marriage" (2). He later qualifies the entire prospect of writing through this lens: "The art of writing is no more spontaneous than the art of marriage. There are moments of spontaneity, seconds of inspiration or insight, minutes of delight, but most of the time it is hard work" (6). Later yet, he emphasizes the grappling, or even struggle, that occurs with writing: "As in marriage, there is a constant tension, but it is a productive tension" $(22) .{ }^{11}$

This final example, connecting writing to the tension of marriage, also incorporates another of Murray's metaphors for writing - one that indeed resonates beyond his initial text: the idea of writing as a struggle. As noted earlier, he points out that the student must discover "that the writer is engaged in a continual struggle to discover what he has to say and how to say it" $(21)$. He reaffirms this statement when he argues, "the teacher of writing, teaching individuals, should at one time encourage discipline and at another time encourage creativity, trying to keep the two in a productive conflict. [...] The student must be engaged in this perpetual form of artistic warfare" (23). Murray offers up these examples of the tensions and conflicts potential within the process of writing, signifying the struggle to discover meaning, but I cannot help but feel as if the struggle as Murray frames it contrasts greatly with the type of struggle endorsed by Elbow. The struggle as depicted by Elbow is one of chaos, of disparate elements (such as found in his depiction of the metaphoric "cooking"). However, by taking part in this 
chaos, or struggle, Elbow is not seeking to exert a layer of control. In fact, in his subsequent book, Writing with Power, he reaffirms this embracing of chaos, of struggle: "It is true that I believe most people need to learn to exploit chaos better in their writing: it helps break down preconceptions and old frameworks and permits growth and new ideas. You can use chaos to blast open what you are stuck on" (49). ${ }^{12}$ The "mopping up" that occurs is the aftereffect of the challenge of "surviving" the struggle and chaos. On the other hand, while Murray does not suggest that the struggle of writing should be intentionally avoided, the metaphoric connection between "struggle" and "writing" is one of enforced social order. The surgical precision of editing, and the (heteronormative) acceptance of tension as part of marriage, "in sickness and in health," metaphorically associates the act and process of writing with an internalized image of learning to discipline one's self in spite of struggle or strife, rather than with a genuine desire to initiate growth through struggle, such as Elbow is endorsing.

Most frequently, Murray conceptualizes PROCESS to be part of a craft. This metaphor encompasses many aspects of Murray's discussion of how the writer enables and enacts the writing process. This is a metaphor of building, creation, calculated design, and, most importantly, a stable and solid final product of writing. Murray states that a writer "builds a thought on the page which is so well-constructed that the reader will accept it as his own" (3, my emphasis). The idea of building and construction resonates throughout the text: Murray relates the writer's task to that of a contractor, arguing that

the contractor does not build a house by wandering through a lumberyard picking out lumber, nails, bricks and glass at random. Neither does the writer wander through the area of his subject picking up quotations, 
statistics, statements and facts without reason or purpose. The writer makes a calculated search for his raw materials. (5)

While in this statement Murray relates the research necessary to writing to the nature of collecting the "raw materials" of building, later he associates the same metaphor with the stages of writing that involve shaping an argument:

The good writer is wasteful. He saws and shapes and cuts away, discarding wood ends, shavings, sawdust, bent nails - whatever doesn't fit and doesn't work. The writer cannot build a good, strong, sturdy piece of writing unless he has gathered an abundance of fine raw materials. (6)

This suggestion, of the wasteful nature of a writer, may be contradictory to the earlier quote about the contractor (who, one would think, must account for much of his raw materials if he is as good a businessman as he is a builder of houses). However, the conceptual idea at play remains the same: the writer and the writing process as part of the act of building, of carpentry. In fact, Murray sees this idea as vital for bringing a sense of accomplishment to student writers, saying, "the student lives in a plastic, mass-produced world. The writing course can give him a chance, perhaps his only chance, to be a craftsman" (72).

As stated, Murray's goal with this metaphor is to create an image of the writer, writing. He seeks to provide a way to understand the writing process by connecting it to another act of creation - while Elbow metaphorizes PROCESS as "growing," emphasizing the organic nature of development that can occur in the writing process, Murray metaphorizes PROCESS as a calculated skill wherein the writer has a hand in creating something that was not in existence before. There are similar themes that course through these two metaphors, but at the same time, Murray is seeking to construct a different type of process, based on different qualities. He states, "the writer is a calculator, a schemer, a 
designer; he builds" (51). "Building," as opposed to "growing," emphasizes the skill of the writer in the writing process rather than the "chaotic ordering" of biological evolution or organic growth. Murray makes this point explicit, arguing that "the teacher of writing is a teacher of skill" (20). As in cooking, there are raw materials, but these materials are actively shaped and crafted as opposed to how Elbow presents the of ingredients through internal and external cooking. However, this metaphor does not assume the student writer is starting out tabula rasa, without any capabilities that can be brought to the crafting of writing, as Murray introduces the idea of the "rhetorical toolbox": "The student writer $[\ldots]$ already owns an extensive rhetorical toolbox. $[\ldots][$ S]ome tools are very common the usual hammer or screwdriver - while others are more obscure - a rare chisel, or a special buffer or a shaper" (73). While Elbow's PROCESS is one in which thoughts and words organically pile up or molecularly combine through stages until completion, Murray's PROCESs is one of calculated design, wherein ideas are shaped, crafted, and refined through stages until the final piece of writing is solid and stable. In both metaphors, the process is connected to stages, phases of development. However, the processes being metaphorized are distinctly different in approach and conceptualization. Thus, PROCESS itself can be seen as a metaphor far from stable, which further allowed for its continued interactive capability. In the next section, I present another conceptualization of the metaphor of WRITING-IS-PROCESS, this time from a cognitivist perspective, which expanded the purview of PROCESS through an attempt to redirect the conceptual metaphor's association, beyond the metaphorizations offered by Murray and Elbow. 


\section{Process-ING Writing}

Not long after Elbow and Murray's initial metaphorizations of the writing process, another line of research and scholarship was beginning in composition studies. Starting with the work of researchers like Janet Emig and Sondra Perl, this school of thought emphasized an examination of the thought processes involved in a writer's activity, signaling the "cognitivist turn" in Rhetoric and Composition. While the previous sections of this chapter have shown how PROCESS became initially metaphorized to represent writing, one of the key elements appearing in the metaphoric examples of Elbow and Murray that in turn becomes a node of resistance within cognitivist depictions of the writing process is the implication of linearity. Elbow's idea of "growing-andcooking" suggests a process that moves towards an end goal in a straightforward fashion. Equally, Murray's metaphors of carpentry suggest that the different stages of development, for a piece of writing, steadily progress forward from the "raw materials" to the finished piece.

Indeed, one of the problematic metaphoric associations incorporated into WRITING-IS-PROCESS is the idea that certain clearly defined stages occur at specific points in the writing process. This idea is heavily resisted by many cognitivist researchers. ${ }^{13}$ In Janet Emig's The Composing Processes of Twelfth Graders, published in 1971 and considered to be one of the foundational texts of cognitivist research within Rhetoric and Composition, she argues that writing "does not occur as a left-to-right, solid, uninterrupted activity with an even pace" (84). This sentiment is echoed in Sondra Perl's 1979 article, "The Composing Processes of Unskilled College Writers," as she posits a hypothesis regarding unskilled writers (such as her well-known subject, "Tony"): 
Composing does not occur in a straightforward, linear fashion. The process is one of accumulating discrete bits down on the paper and then working from those bits to reflect upon, structure, and then further develop what one means to say. It can be thought of as a kind of 'retrospective structuring.' (330)

It is the resistance to linearity and acknowledgment of a "retrospective structuring," or recursive nature of the writing process, that draws researchers like Perl, Emig, and others away from some of the metaphors for WRITING-IS-PROCESS established by Elbow and Murray. In addition, the work of these theorists introduced what Ralph Voss calls a "science consciousness" to the research being done within Rhetoric and Composition (279).

The new metaphorization of the writing process came to a head with the scholarship of Linda Flower and John Hayes. In their 1981 essay, "A Cognitive Process Theory of Writing," Flower and Hayes explicitly and implicitly shape a new PROCESS metaphor that diverges from older - and what they see as inaccurate - models such as "growing" or "craftsmanship." First off, they again note the complication with what they call the "stage process model": "This familiar metaphor or model describes the composing process as a linear series of stages, separated in time, and characterized by the gradual development of the written product" $(366-67) .{ }^{14}$ They also argue that a problem with previous metaphors of PROCESS is that "they model the growth of the written product, not the inner process of the person producing it" (367).

After pointing out some of the problems with the "stage process" metaphors that had been offered by previous writers, Flower and Hayes go on to propose a new model (and resulting metaphor) for PROCESS that identifies "the major units of analysis [as] elementary mental processes, such as the process of generating ideas. And these 
processes have a hierarchical structure [...] such that idea generation, for example, is a sub-process of Planning" (ibid., author's emphasis). These are some of the first indications of a marked metaphoric shift in language used to describe PROCESS as put forth by Flower and Hayes. While their cognitivist model maintained an adherence to the metaphor of process, the type of process is markedly different. In contrast to the organic, earthy metaphors of PROCESS proposed by Elbow and Murray, where teachers and students alike were encouraged to metaphorize writing as the growth, cooking, or carpentry, Flower and Hayes' model likened the process to more computeristic metaphors. They depict the writing process as "a dynamic system," which could be studied by identifying "the parts of the system and how they work together" (368). Instead of thinking of PROCESS as a developmental representation of the writing product, Flower and Hayes shifted the focus to PROCESS-ING: the internal thought processes of the writer, writing. Deborah Brandt describes this departure as one that "shifted the basis of explanation. Acknowledging that a text is indeed an evolving product in an act of writing [...], their inquiry went deeper, to seek the constituent processes that underwrite the evolution" (Literacy 36). Through this shift, not only does the PROCESS of writing transform, but the writer is also transformed - as some scholars (both in support and in opposition) interpreted it, the writer becomes likened to a computer system, processing information and translating meaning onto the page.

Flower and Hayes identify multiple processes at play within a writing task, each with sub-processes that can be accessed by the writer when necessary. They suggest that these processes exist within a hierarchical network or system, connected to each other, but at the same time often exist as embedded processes within each other: "A given 
process may be called upon at any time and embedded within another process or even within another instance of itself, in much the same way we embed a subject clause within a larger clause or a picture within a picture" (375). In addition, Flower and Hayes directly equate a writer's memory with computer memory, with short-term memory being "our active processing capacity" (371). They also describe a separate function, a "monitor," identified as a separate entity that "functions as a writing strategist which determines when the writer moves from one process to the next" (374). ${ }^{15}$ Lester Faigley, in his critique of the cognitivist model for PROCESS, notes that in addition to the metaphors of computerization at play within the language Flower and Hayes use, even the tables that they include in their article inject visual metaphors of computer processing: "The box labeled Writing Processes is analogous to the central processing unit of a computer. [...] Diagrams representing the subprocesses of composing (planning, translating, and reviewing) are presented as computer flowcharts" (533-34, author's emphasis). Brandt describes this emergent metaphoric model of PROCESS as "windows into the composing process [that] reveal a kind of multimedia event, a congestion of nonverbal plans, images, loose ends, dead ends, private labels, as well as the public language of the evolving text" (Literacy 36).

There certainly have been critiques of the conceptualizing metaphor of computerization and how it has been used by cognitivist researchers to refigure both the composing process and writer as operating internally, rather than as connected to larger social realities. These critiques represent an important level of metaphoric engagement within the field of Rhetoric and Composition, as I will discuss in the upcoming section. However, within the present discussion, the cognitivist metaphor for the act (and actor) of 
writing also represents a powerful and compelling example of metaphoric interactivity extending beyond the confines of the singular disciplinary discourse of Rhetoric and Composition. Flower and Hayes do explain their metaphoric conceptualization of the composing process, through the descriptive vision of the "design[ed] imaginary, working 'Writer"' (368). They flesh out this vision with all the necessary sub-routines, information retrieval mechanisms, and methods of analysis to make sure the "Writer" functions correctly. In other words, they build a "computeristic" writer from the ground up, and then use that metaphor to explore how writing is processed within the mind of a writer(/'Writer"). Faigley suggests that this prominence of computeristic metaphors in Flower and Hayes' conceptualization of PROCESS is due to parallel models found in other realms of cognitive science, "including artificial intelligence, computational linguistics, and cognitive psychology" (533). Indeed, the parallel seems hardly coincidental, since Evelyn Fox Keller (first introduced in my previous chapter) offers a similar account of metaphoric "trafficking" through disciplinary boundaries that shaped the discourse of biological sciences. Additionally, Keller notes that the early 1980 s represented a powerful moment of "cyberscientific" discursive influence that was apparent in many venues:

"the term cyberspace was coined in 1984 [...]; 1984 was also the year of Danny Hillis's 'Connection Machine' and the launching of a Cambridge, Massachusetts-based coalition of computer scientists and physicists called 'Thinking Machines,' incorporated to build parallel computers. And it was also the year that physicist John Wheeler published his first paper on the universe as a computer. (113)

While the work of Emig, Perl, and Flower and Hayes was initiated in advance of 1984 , Keller's description of the cultural impact of cyberscience, as capable of initiating a paradigmatic shift in conceptualized discourse in multiple disciplines, certainly can be 
seen in the shifted conceptualizations actively engaged through the incorporation of computerized metaphors to conceptualize PROCESS. In the next section, we will also see some possible ways that these metaphoric concepts are engaged with by new generations within Rhetoric and Composition in order to highlight and emphasize the interactive system of writing while also allowing for further metaphoric extension beyond the original iterations offered by Flower and Hayes, as well as other members of the field.

Important to the process of creating the conceptual metaphor, WRITING-ISPROCESS, is first the creation of conceptual metaphoric connections associated to PROCESS. PROCESS must be identified, metaphorized, concretized in some way, and then the metaphoric commonplaces that are being activated can make their way across the divide to WrITING as a concept. Elbow, Murray, and Flower and Hayes all do this in different ways, and the resulting metaphors of WRITING-IS-PROCESS are distinctly directed towards the goals that each of them have in mind as the most important aspect of writing. Faigley, when examining the views of the composing process, implies that the differences indicate contrasting goals for the discipline (528). We see this in Elbow's emphasis on the generative development of "growing-and-cooking," Murray's emphasis on the identity of the "writer, writing" through artisanship and struggle, and Flower and Hayes' emphasis on the (internal) process-ing a writer goes through as part of a computerized system. These metaphorizations represent the fluid and shifting nature of PROCESS itself, allowing scholars and teachers to extend the metaphor to varying aspects of composition. 
However, these are not the only ways that any of these metaphorizations of PROCESS have been developed or shifted. After their initial uses, these metaphors become accessed by other readers, writers, scholars, and teachers, and when this happens, the metaphors begin to show true levels of activity. As Linzey, in the last chapter, notes of the life-span of metaphor, it is after a metaphor's introduction that the discourse community can engage with it, using it to both discover and make meaning. In the cases of these metaphors of PROCESS, there is much metaphoric engagement to be found in the ways that other members of the Rhetoric and Composition community responded to and were stimulated by the "novelty" of the offered metaphoric implications. In addition, however, it is in fact perhaps even more insightful to view the different ways that these metaphors were reacted against. As each individual perceives the proposed metaphors with their own "sets of commonplaces" regarding the metaphoric extensions being suggested, the opportunities for catachrestic dissonance in meaning making becomes more apparent. As efforts to resist the metaphors, or even to further reconceptualize PROCESS in other meaningful ways, become apparent, we can see how PROCESS as an overarching metaphor gather(ed/s) new associations, to be enacted in new sites of composition, in order to "fit into" as well as shape the identities available to members of the Rhetoric and Composition community. In the next section, I offer select examples of metaphoric engagement and interactivity that has influenced both the localized metaphors of PROCESS as well as the overarching conceptual metaphor of WRITING-IS-PROCESS.

\section{Process's Growing Pangs}

One key argument set forth by cognitivist theorists such as Flower and Hayes is that the stage-process model of writing is flawed because it does not allow for recursive 
movement. A writer will not always move straight, in one direction, through any or all proposed stages of writing, without returning to an earlier stage. Rewriting may occur at the same time as writing, and there are certainly points in writing when the whole process needs to be restarted at the beginning. This specific critique, I would suggest, has its parallel in the development of a metaphor. Linzey's model of the lifespan of a metaphor, as discussed in the previous chapter, contains stages of "metaphorization" that are very illuminative to how we understand the influence and impact of a metaphor on a community. However, the "rewriting" or reinscription of metaphoric meaning can be visited many times over, during the process of metaphoric engagement. Thus, a metaphor's lifespan perhaps isn't as neat and tidy as Linzey would have it. In what follows, I explore some of the moments in the life of the WRITING-IS-PROCESS metaphor, but it deserves to be said that this life is not chronologically inclined. As I suggest in the previous chapter, the two qualities that Linzey presents as the bookends to the lifespan of a metaphor (e.g., a metaphor's heuristic and fiduciary potential, respectively) do not always carry forth exactly as Linzey would suggest. There are moments of trust early on for some metaphoric associations, and the discovery potential can be revived with little effort even after a metaphor has become an accepted part of discourse. This is the case, I would argue, with WRITING-Is-PROCESS.

In this section, I present three "moments" in the "life" of WRITING-IS-PROCESS as a conceptual metaphor. However, I actively choose not to do so in the order that Linzey provides for us. WRITING-IS-PROCESS certainly began at a certain point, with the scholarship and teaching of individuals like Elbow, Murray, and Flower and Hayes, but I would argue that there are certain stages after its "beginnings" which continue to be 
revisited. Not only is it unfeasible to chart the entire 40-year-long lifespan of WRITING-

IS-PROCESS in a single chapter, ${ }^{16}$ it is also inaccurate to present WRITING-IS-PROCESS as having a linear lifespan without revisitations, in the form of retrospectives by longstanding members of the composition community and discoveries by each generation of new entrants to the community. Linzey depicts the life stages of a metaphor as progressing from the "gee-whiz" stage to "simile stage," all the while gaining trust within the discursive community while losing novelty. I, however, start with the "interaction" stage of the metaphor (Linzey's "simile stage"), and then turn to those "eureka moments" related to the metaphor (what Linzey identifies as the first, "gee-whiz," stage). Finally, I make an argument for the continued sustainability and vitality of WRITING-IS-PROCESS as a conceptual metaphor for Rhetoric and Composition, beyond what Linzey calls the point of "metaphoric assumption."

\section{The Metaphors of PROCESS Engaged}

As represented in the "simile stage" of Linzey's model, multiple scholarly explorations have interacted of WRITING-IS-PROCESS, to discover how it applies to different areas of Rhetoric and Composition, as a conceptualizing metaphor for writing as well as for the identity of the disciplinary community. This interactive exploration has occurred at two levels, I would argue: first, engaging the metaphorization of PROCESS itself, exploring the merits and the repercussions of conceiving of writing as a process (as opposed to a product, for example), and second, engaging the overall conceptual metaphor of WRITING-IS-PROCESS.

We have already seen one way in which the efforts to metaphorize ProcEss at a conceptual level has been explored and re-envisioned, through cognitivism. Cognitivist 
theories of the writing process not only aided in the formation of the conceptual metaphor, WRITING-IS-PROCESS, but also they represent reactions and interactions with previous metaphorizations, such as those provided by Elbow and Murray. Flower and Hayes, as well as earlier cognitivist researchers, noted the problems with a "stage process model" that implied direct linearity within the writing task, and sought to create a metaphoric perspective that not only allowed for recursivity as a part of writing but also allowed for a better understanding of the internal processing a writer goes through while writing. However, while the cognitivist approach's attempt to redirect the flow of PROCESS-oriented discourse, refiguring it to include recursive, information-based components modeled on metaphoric concepts of information technology ("cyberscience," as Evelyn Fox Keller puts it) offered new conceptual frameworks, it also carried with it "new" metaphoric commonplaces that were seen by critics as conflicting with other goals of the discipline. For example, in 1981 Ann Berthoff qualifies the "computer processing" metaphor as being particularly dangerous, for two reasons:

Metaphors derived from computer technology are extremely hazardous, not only because the difference between brain and mind is obscured by talking about mental operations in terms properly used to describe brain function, but also because certain words have entirely different meanings as terms in information theory than they have in rhetoric. (6)

In this characterization, the first point to observe is the conflation of the "brain" and "mind." Berthoff differentiates between the computer-like functions of a brain and the conscious, sentient formulation of thoughts by the mind. In this, we can see how the commonplaces associated with computer processes, when metaphorically connected to the mental actions of a conscious human being, could be perceived as dangerous: if we view the writing process through the metaphoric lens of computer processing, writers 
(our students) become little more than computers by extension. The actions they take become formulaic, programmed, and lacking in self-controlled will. ${ }^{17}$ Secondly, Berthoff takes up the issue of terminology itself - while the metaphor of computer processing may be intended only to a certain degree, the discursive understanding of certain terms within Rhetoric and Composition at times conflicts with that of information theory. ${ }^{18}$

Berthoff's concerns regarding the use of computer metaphors to conceptualize PROCESS exhibit a vital aspect of interactional metaphor. She takes the metaphor of "computer processing" to its farthest reach, resulting in writers being nothing more than an emotionless computer inputting information and outputting results, an association (or commonplace) that invokes images of mid- $20^{\text {th }}$ century versions of computers, where punched cards were fed into computers to produce a certain output. Berthoff is writing this warning against such a metaphoric extension in 1981, and while much has changed with computers since then, the dangerous vision she has of the computerized PROCESS does not necessarily dissipate with time. As Max Black points out, even inaccurate commonplaces (due to either outdated or deficient knowledge) still become a part of metaphoric extension. The (antiquated) concepts of computerized technology Berthoff is drawing into the metaphor are still accessible as part of a modern, $21^{\text {st }}$ century use of the metaphor, even as nothing more than "metaphoric baggage." Likewise, Patricia Bizzell offers a similar critique, regarding Flower and Hayes' metaphoric use of "monitor," the switch operator between the subprocesses of composing, as an act of "borrowing a term from programming [which] masks the question of why the writer makes certain decisions" (224). As these critiques point out, some resistances to cognitive approaches to PROCESS are explicitly tied to the reactive processing of the theoretical model's 
metaphoric associations. In the cases of both Berthoff and Bizzell, the metaphoric commonplaces that they find highlighted by the figuration of the writer "as a computing system of processes" depicts the writer as a passive element within the process, "going through the motions."

In other cases associated with the cognitivist metaphoric Process, there have been critiques that find issue with its apparent lack of a social element. In the early iterations of the metaphorized approach, Flower and Hayes' model of the writer was of an individual composing as part of an individualized act, separate from contextual and social realities that might be play a role in the construction of the writer as well as the act of writing. As Bizzell argues, "To let the model stand alone as an account of composing is to mask the necessity for the socially situated knowledge without which no writing project gets under way" (231). Similarly, Deborah Brandt (quoted earlier for her descriptive characterization of Flower and Hayes' cognitivist approach) emphasizes the need for a social element to be integrated into any metaphoric notion of the PROCESS of writing (and, more broadly, literacy): "To write down words is to give them over to a public sphere where their meaning or potential meaning is somehow always bigger, and more demanding, than private sense. To write is to deliver words into the domain of the we" (54). For Brandt as well as Bizzell, it is acknowledged that the "how" of PROCESS is valuable for inquiry, but metaphorically speaking that "how" cannot be asked in a vacuum, which they perceive the cognitivist model to represent (metaphorically as well as literally).

This critique of cognitivist theories of PROCESS, that the model of the internal composing process (metaphorized as an interactive system) lacked a social "node," is 
particularly interesting due to the development of both "cyberscience" and studies in cognition. The internet, as well as many other technological networked systems, is capable of adding new, "upgraded" commonplaces to the metaphoric conceptions of information technology within cognitive studies. ${ }^{19}$ In fact, a more current line of cognitive study that has emerged in the past decade is based on notions of distributed cognition, which exemplifies one way in which the social realities and interactional environments that surround individuals are incorporated fully into study. As James Hollan, Edwin Hutchins, and David Kirsh explain in "Distributed Cognition: Toward a New Foundation for Human-Computer Interaction Research," distributed cognition "extends the reach of what is considered cognitive beyond the individual to encompass interactions between people and with resources and materials in the environment" (175, author's emphasis). As this model for study begins to approach Rhetoric and Composition (it has already begun to be an influential force within technical writing and communication arenas), it will be interesting to observe the metaphoric engagement and the implications that it inspires, both from those who would embrace it and those who would resist it. ${ }^{20}$

The cognitivist view of PROCESS, exemplified here by Flower and Hayes' metaphorization, is not the only metaphoric PROCESs that members of Rhetoric and Composition have engaged with, however. One of the key metaphors Elbow provided, to conceptualize the writing process, was that of "growing." Although Elbow suggested this metaphor for its value in conceiving of writing as an organic process, chaotic but ultimately leading towards a complete organism, it too has been extended to other thoughts and conversations within composition, beyond its original metaphoric 
connection. As one key example of this, we can turn to Alan Bleakley's "Writing with Invisible Ink." In his essay, Bleakley points out the darker side to growth, stating that "'growth' and 'development' are framed as idealistic, optimistic terms, forgetting that tumours grow, economies inflate, obesity is growth, and populations grow beyond the capacity of their resources" (13). ${ }^{21}$ While Elbow, of course, is connecting his metaphor of "growing" to the biological development of an organism, and he does warn against extending the metaphor of "growing" too far, Bleakley is not responding as much to the original iteration of the metaphor. What he is highlighting is that Elbow's metaphoric marriage of chaos and order, as seen in his organic model of the writing process, has the potential to carry these other connotations (or commonplaces). Thus, Bleakley is instead responding to the metaphor of WRITING-IS-PROCESS as others have taken up and (as he might suggest) uncritically employed "growth" metaphors as a singularly positive and productive metaphor that stably depicts the PROCESS of writing.

Elizabeth Rankin, in her essay "From Simple to Complex: Ideas of Order in Assignment Sequences," explores a different set of commonplaces associated with "growing." In the same way that Bleakley points out some of the negative types of "growth" potentially exerting influence as part of Elbow's conceptual model, Rankin excavates the metaphoric assumption of evolution (first offered by Elbow) as a developmental metaphor for the writing process. While Rankin does not reference Elbow directly, she examines the use of sequential assignments that start simple and become more complex, a notion of process clearly mirrored in the metaphoric ideal Elbow models in his "growing" metaphor. Rankin describes this evolutionary "ordering" of an assignment sequence: 
Unlike a serial research sequence, in which early assignments are viewed as practice for later ones, this cumulative sequence has a kind of organic structure. In a formalist course, it grows into a traditional research paper; in a developmental sequence, it might produce Macrorie's 'I-Search' report. (130)

As Rankin points out, the emphasis on a metaphor of organic growth or evolution precludes later, more complex writing. However, she is not so much calling for a halt of such metaphoric attachment as she is asking readers to be aware of these dangerous assumptions: "To believe in a 'true' and 'natural' sequence is to contradict the very principles of dialectic and social construction" (133). The notion that intellectual growth follows a linear path, wherein ideas and practices can only be learned in a certain sequential order, contradicts with other ideals and goals of a dialectical pedagogy. I would also point out that another implicit metaphoric complication, although not fully discussed in Rankin's essay, is the mere assumption of a sequence that naturally progresses from "simple" to "complex." If we understand "growing" (either Elbow's original metaphor or Rankin's depicted evolution of the metaphor in other venues) to predicate a development towards a higher order of complexity, then the metaphoric meaning that is carried over includes the assumption that students begin the writing sequence in that writing class, as a sort of tabula rasa: simple, empty of knowledge and skill, to be made more complex themselves. ${ }^{22}$

While these two examples, from Bleakley and Rankin, represent some of the negative metaphoric associations that can be drawn from the metaphor of "growing," this is not to say that the metaphor is altogether seen in a negative light. Barbara Tomlinson, in a study of over 2,000 interviews with professional writers, found that the metaphor of "gardening," connecting to the metaphor of WRITING-IS-GROWING, substantially present 
in how writers described their own writing processes. Not only did authors "seed," "prune," and "compost" their writings (67), but the specific term "grow" was common. While it should not be inferred that this metaphoric use can explicitly and only be connected back to Elbow's 1973 book (as stated earlier, Faigley notes that Elbow is drawing on a tradition of organic metaphors for writing), it is notable that the use of the metaphor is quite similar to Elbow's intended use. As part of the "growing" metaphor, Elbow promotes the freewheeling development of writing as it makes its way towards a final organized form, a view that many professional authors hold as well. Tomlinson states that, of all the writers who used the metaphor of "growing" to describe their writing process, every instance of the metaphor involved a certain life imbued within the writing itself, taking its own course: "Writers do not say, 'I grew the story,' or 'I made the story grow.' The written piece develops somewhat independently, through a natural process of its own" (69, author's emphasis). In these examples, where we see metaphoric uses of "growing" that are not explicitly based on Elbow's 1973 treatise, there are commonplaces of both similarity and dissimilarity that have now become part of the conceptual metaphor. When a teacher aligns him or herself with the metaphoric identity of "teacher as gardener," for example, the conceptual metaphor of "growing" or "gardening" that he or she is calling upon now extends well beyond Elbow's original application. The "growing" metaphor continues to "grow" itself, as it takes on new meanings and associations to answer the call of members of the discourse community.

In addition to presenting "growing" as a congruent metaphor in the eyes of professional writers, Tomlinson also discusses the metaphor of "cooking." Giving examples of the metaphor as evinced in authors' interviews, Tomlinson points out that 
"writers say they had 'ideas in the pot, only partially jelled," their work "may have 'a brewing process," or it "has been 'a long time in the oven"' (61, author's emphasis). In each of these examples, we are again presented with metaphoric associations that cohere with Elbow's presentation of "cooking," as a metaphor for the invention process a writer goes through. Mirroring the way that Elbow creates an argument for "cooking" as invention, Tomlinson observes that "we must actively combine ingredients, do preliminary preparation, or at least put the food in the pot or oven; we often must wait to allow heat and/or time to make the food ready" (ibid.). As with the parallel found between Tomlinson's study and Elbow's metaphor of "growing," here "cooking" becomes reaffirmed as a stable metaphor for the invention process.

However, other perspectives have questions the value of any metaphor for invention. Flower and Hayes, as they go about conceiving their own metaphoric PROCESS, argue against metaphoric applications for invention. In their essay, "The Cognition of Discovery," Flower and Hayes zero in on the metaphoric interaction being emphasized by previous models such as Elbow's metaphor of "cooking." Elbow champions this interaction for its ability to lead to discovery - discovery in the sense of "getting a feel for the process," as well as the discovery involved with invention within the writing process itself. Flower and Hayes point to this discovery as being unduly given merit for its own sake, stating that "it obscures the fact that writers don't find meanings, they make them" (21). While not solely or specifically focusing on the metaphor of "cooking," Flower and Hayes still hone in on what they see as a limitation to such a metaphor, which they argue is found in its elusive nature when trying to pin down the literal elements of the writing and invention. 
When Elbow employs the metaphor of "cooking" for invention, he asks that we see it as a way to enter into an interactive mode of thinking, wherein a writer does make meanings rather than find them. While "cooking" as a metaphor for invention does indicate the need to interact with raw materials in a refining process, Flower and Hayes note that the metaphoric and mythological nature of descriptions of invention and discovery "doesn't warn the writer that he or she must often build or create new concepts out of the raw material of experience; nor does it tell the writer how to do it" (22). In the original form as Elbow presents it, "cooking" is used as an abstract concept, emphasizing the chemical interactions and metaphorically associating them with the interactions between ideas, thoughts, and writers. In such a form, the metaphor indeed does not carry the warnings that Flower and Hayes see necessary to the process of discovery. ${ }^{23}$

If we are to extend a formulation of the "cooking" metaphor that would perhaps "tell the writer how to do it," one metaphoric commonplace of "cooking" that would be instrumental is the application of "recipes." Of course, by incorporating the subsidiary metaphor of "recipe" into the writing process, "cooking" takes on a slightly different form. The process becomes much more linear, and there is quite a bit less variation a writer can have in their stages of process while still arriving at the desired end - now, instead of a conceptually ambiguous "culinary masterpiece" (or fully formed writing/argument), the recipe strictly states "how to make a pineapple upside-down cake."

The extension of Elbow's "cooking" metaphor, to include recipes, or even simply regimented stages of cooking to ensure a final product, has been discussed by many teachers and scholars as well. On one hand, a fear of process-oriented scholars is that 
writing metaphorized with included recipes will lead student writers to focus on the wrong areas of writing. Lad Tobin, in "Bridging Gaps: Analyzing Our Students' Minds for Composing," points out that the "cooking" metaphor, in this form complete with recipe and instructions on how to complete each stage, can be operative for introductory student writers seeking to conceptualize their own writing. However, it is not often the process that they are metaphorizing, but the end product of said process: "writing is a pie rather than baking" (448). Tobin is wary about accepting a metaphoric association that places too much emphasis on the end product, thus sidling too close to WRITING-ISPRODUCT rather than PRocess. Elizabeth Rankin gives us an account of a similar concern, this time from a graduate student teacher, "Peter," who is frustrated with what he sees as "recipe-oriented" writing instruction. Rankin quotes Peter, who describes this model: "The recipe type stuff - two eggs, half cup of milk, that kind of junk, I'm thinking to myself, 'My God,' you know, 'Am I just deluding myself thinking that they're even gonna learn anything from this?" (Seeing 62).

On the other hand, Robert Gorrell reminds us that the end product of writing is indeed an important part of the writing process, as long as it isn't the only part focused on. Referring to Donald Murray's statement, "Process can not be inferred from product any more than a pig can be inferred from a sausage" ("Writing as Process" 3), Gorrell argues that "it is, of course, not easy to infer a pig from a sausage [.... The pig is not the process, although it is essential to the process. The sausage is also relevant to the process. The process is not an image of the product" (274).

These instances represent how teachers and scholars have analyzed and reacted to the metaphoric extensions that exist in the trail of the metaphors suggested by the likes of 
Elbow, Murray, and Flower and Hayes. Linzey describes the simile stage of a metaphor's life as being when individuals explore the metaphor's usefulness beyond its initial introduction. In the case of WRITING-IS-PROCESS, this exploration spans years, and addresses many situations originally unimagined by the first intended use of metaphors like "computer processing," "growing," or "cooking." In addition, the interaction does not simply rely on that first metaphoric invocation. Elbow, for example, did not cite the "ingredients" that would go into "cooking." However, as people appropriate the metaphor, it gains new meanings, and becomes fleshed out in new ways that go far beyond the chemical reactions Elbow was emphasizing in his metaphor.

In addition to the augmentation of metaphor that can develop through the accretion of new metaphoric meaning, associations, and commonplaces, the directions by which the metaphor of PROCESS tracks its evolution can diverge, drawing on even earlier uses of the invoked metaphors. While Elbow intended his model of "cooking" to be taken as a generative metaphor, meant for aiding the writing process, some interpretations have tracked its metaphoric extensions in other directions. Lad Tobin reminds us that Socrates "compared rhetoric to make-up and cooking in the Gorgias" (446), and it should of course be noted (even though Tobin doesn't make this connection explicit) that Socrates' comparison is by no means a positive one. He considers cooking, as well as rhetoric, to be mere flattery, "which appears indeed to be an art but, by my account of it, is not an art but a habitude or knack" (Plato, Gorgias 463B). By extending the metaphoric connections of the cooking metaphor, discussions of writing, rhetoric, and "cooking" begin drawing on commonplaces that go beyond Elbow's original intent, and in this case speak to other conversations, such as the issue of the idea of writing for classroom 
purposes, rather than externalized, "realistic" writing situations. This is what Joseph Petraglia is speaking of, in his essay, "Writing as an Unnatural Act." Petraglia comments on the problematic nature of "insisting that rhetorical skills can be taught as a generative set of axioms or procedures that can be induced within the confines of the writing classroom" (98). When we seek to model the writing process, Petraglia notes, we tend to do it within the strictures of "GWSI" (General Writing Skills Instruction), with an emphasis on the fact that this is for instruction - in classroom settings. He draws on the same material as Tobin does, regarding cooking's relationship to writing, when he states that "if any elements of this argument sound like a reprise of the art/knack debate presented in Plato's Gorgias, that may not be entirely coincidental" ("Bridging" 446). While he does not directly cite Elbow's metaphor for the writing process, we also should not take it as coincidental that his reference to Gorgias and the "art/knack debate" invokes one of the foundational metaphoric models for the writing process, "cooking."

As a final example of how the specific metaphors for PROCESS have been explored, reacted to, and interacted with, we can look at a metaphor that has some shared qualities between the versions provided by Elbow and Murray. Both writers touch on the metaphor of "struggle" when describing their proposed processes for writing, while emphasizing different elements and values associated with the metaphor. Beyond observing this in their initial texts, however, we see how the metaphoric dissimilarity can actually come to a head when teachers and writers are confronted with the metaphoric notion of "struggle" in writing the writing process. Margaret Mansfield, for example, discusses how she introduces professional writing assignments into traditional composition courses (rather than business or technical writing classes) to encourage her 
students to "grapple with notions of audience, authority, and 'real' (i.e., serious) writing; to reflect upon their roles as writers; and to discover much about themselves, their topics, and the writing process" (70). This pedagogical move is much in line with Process as championed by Murray - centering on discovery, and the struggle, in attaining an identity as a writer. On the other hand, Peter Elbow himself relates a story in his 1991 piece, "Reflections on Academic Discourse," in which a particular student's essay, when read by a group of teachers in a teaching workshop, caused a certain level of outrage amongst the readers after the student claimed the piece was easy and fun to write, requiring little revision. Elbow states, "I sensed resentment against the most basic impulses that are involved in being a writer: to have fun telling a story and to give pleasure to others" (136). Indeed, if we consider WRITING-IS-PROCESS to be a metaphoric process of struggle, of carefully and laboriously honing a skill, according to Murray's construction, the idea of pleasure and "fun" can easily be edged out.

Unlike Murray, Elbow encourages writers not to dwell on the struggle of the writing process. Of course, he does acknowledge that there are times when the process can become arduous, chaotic, challenging and more. However, his main assertion is that such a process, as an open-ended step of development towards a writer's end goal, allows for the organic, natural ordering of thoughts and words in the end: "You might well try to write [a paper] four times, not once, and try to help the piece evolve through these four versions. This sounds crazy and impossible because the writing process is usually so slow and tortured, but it needn't be" (Writing without 19). Instead of focusing on the metaphoric struggle of writing, Elbow redirects our attention to the evolution and growth of a piece through multiple versions of writing. This model of writing "preaches, in a 
sense, lack of control: don't worry about knowing what you mean or what you intend ahead of time; you don't need a plan or an outline, let things get out of hand, let things wander and digress" (Writing without 32-33). Rather than a struggle, the chaotic process of letting things wander out of control is part of Elbow's metaphoric ideal of growing, wherein the writer can "let go" and thereby let the writing take its own shape. As stated in the previous section, this is in stark contrast to Murray's figuration of struggle: a controlled, clinical treatment of "messy business" (such as surgical work or war) that seeks to exert a force of order onto the struggle. This idea of forcing struggle to "work for the writer" creates, then, a parallel trajectory for the metaphoric notion of "writing as a struggle" - one that only shares a minimum of commonplaces with Elbow's metaphoric vision. However, as these two different metaphorizations of struggle coexist, one might wonder how they begin to influence each other, as well as those individuals who believe they are choosing to adhere to a singular conceptual metaphor highlighting the struggle of writing and making meaning.

A third way, however, that offers a way to refigure struggle as neither controlling chaos or allowing anarchy is suggested in Min-Zhan Lu's essay, "From Silence to Words: Writing as Struggle." While for both Elbow and Murray the metaphoric struggle is still a secondary concern, Lu offers a refigured metaphoric writing process altogether: WRITING-As-NEGOTIATION. The struggle that Lu focuses on that of conflicting voices an interaction that extends the writer into conflict as characterized by social and discourse realities. She states, in imagined response to naysayers, “'Don't teach [students] to 'survive' the whirlpool of crosscurrents by avoiding it. Use the classroom to moderate the currents. Moderate the currents, but teach them from the beginning to struggle"" $(447)$. In 
this figuration, the struggle that Lu emphasizes hearkens to commonplaces of both Elbow and Murray. Like Murray, Lu authorizes an effort to exert a controlling hand over struggle and chaos, to "moderate the currents," while avoiding the disconcerting violence and viscera that dominates aspects of Murray's metaphoric struggle ("surgery," "warfare"). Like Elbow, Lu suggests an embracing of struggle and of chaos, but not as a point of pleasure - instead it is a matter of social interaction, a necessity to be heard as part of the Burkean CONVERSATION. A final aspect of how struggle as a metaphoric concept of (social) process, in Lu's shaping and redirection of it, is found through the discovery of that very social nature of struggle. Elbow's metaphoric struggles are mainly internal grapplings with one's self, and while Murray figures struggle as something to engage students in, to create "productive conflict," several of the times that he invokes the metaphoric struggle, that struggle is set on a private stage (marriage/relationships) or in sanctioned-off arenas (operating rooms). Alternatively, Lu metaphorizes social interaction writ large as struggle, conflict, and negotiation - done through the interconnected nature of linguistic and ideological interaction.

$* * *$

Up to this point, I have shown ways that the individual, specific metaphors for the conceptualization of PROCESS have been examined, interacted with, and extended to other conversations within Rhetoric and Composition. However, this only represents one avenue of metaphoric interaction. ProcESS-IS-GrowING (-AND-COOKING), or PROCESSIS-BUILDING (or CRAFTSMANSHIP) are necessary steps to creating a conceptual awareness of PROCESS that in turn can be applied metaphorically to WRITING-IS-PROCESS. In the previous examples, the specific types of PROCESS themselves have been explored by 
writers and teachers; in the following examples, we find how the PROCESs has informed the conceptualization of writing itself, and how varying scholars have responded to WRITING-IS-PROCESS as the overarching conceptual metaphor.

The idea that the conceptual metaphor WRITING-IS-PROCESS encompasses multiple, varied and divergent notions of writing causes concern for some people. Lisa Ede suggests that while the metaphor of PROCESS is applied to many scholars' work within Rhetoric and Composition, the variance between the applications of WRITING-ISPROCESS becomes baffling:

Janet Emig's, Donald Graves', Peter Elbow's, and Linda Flower's research projects differ in as many ways as they are similar, for instance, yet all have been cited as examples of process research. [...] A class structured around freewriting and personal narration differs substantially from one that emphasizes structured heuristics and academic writing, yet both approaches have been cited as examples of 'process' teaching. (36)

As seen in the previous section, the PROCESS as metaphorized by Elbow, Murray, and Flower and Hayes differs, to be sure. And, just as Ede points out, the conceptualization of WRITING-IS-PROCESS that evolves out of each metaphorization has different foci, emphasizing different processes and encouraging the development of different attributes within the individual writer. However, they are often all enveloped into the same umbrella concept of "process theory," following the increasingly amorphous and ambiguous metaphor of WRITING-IS-PROCESS.

Gary Olson comments on this same issue, from a different perspective. While Ede focuses on the problematic way that the multiple perspectives on WRITING-IS-PROCESS are subsumed despite their dissimilarities, Olson examines the end result. The problem, for Olson, 
is not so much that scholars are attempting to theorize various aspects of composing as it is that they are endeavoring (consciously or not) to construct a model of the composing process, thereby constructing a Theory of Writing, a series of generalizations about writing that supposedly hold true all or most of the time. (8)

If we replace Olson's use of the term "theory" with "metaphor," we see that his concern lies within the overall construction of a conceptual metaphor that encompasses WRITING at its metaphoric foundation. WRITING-IS-PROCESS subsumes all types of writing, on the conceptual level, and disallows, or at least discourages, metaphorization (or theorization) that takes writing down different paths.

This is not to say that WRITING-IS-PROCESS is the only metaphor that conceptualizes writing for the sake of instruction, elucidation, or practice. Keep in mind its "predecessor": WRITING-IS-PRODUCT. While writers like Robert Gorrell, as mentioned earlier, call for us to remember that product is still a vital part of the writing process, the prominence of the process-oriented metaphors for writing have often overshadowed product's place within the writing process. This is, in fact, the problem that James Kinneavy has with the many iterations of WRITING-IS-PROCESS. He argues, "Process so enthroned and separated from any relation to product can be as meaningless as grammar or vocabulary taught in isolation from the actual act of writing" (8). With the emphasis being placed so highly on the metaphorization of the process of writing (not to mention the demonized metaphorization of "product" as a negative and unproductive method of writing), Kinneavy's concern is that it can be easy to wholly embrace the metaphor of PROCESS as representing the entirety of writing instruction, disregarding any product. On the other hand, Erika Lindemann notes that the elements of PROCESS that still tempt 
teachers to focus on a product of writing and instruction undermine the overall goals of the conceptual metaphor WRITING-IS-PROCESS. She states,

We turn process-centered courses into what-centered courses every time we're tempted to interrupt students engaged in writing with an explanation of some subject matter. Or, if we 'explain' prewriting strategies during the first few weeks and never refer to them again, we've made prewriting a subject matter, a body of information to learn about rather than an activity to practice. (252)

This warning about "what-centered" versus "process-centered" writing instruction hearkens back to the concerns with specific metaphors for PROCESS. If the emphasis for instruction is on teaching prewriting as a subject matter, or as a stage in the recipecooking process, the focus is no longer on the activity of discovery, of "getting a sense for" the process of creation. ${ }^{24}$ Instead, it is now about a preset notion of the writing process: a black-boxed metaphor that presumably can be codified (and commodified) as a "stable" meaning for the concept of WRITING.

PROCESS become enthroned as the operative concept of writing, in a way that leads some to feel a sense of "controlling ambiguity" as to what writing is, and what it can do. Richard Coe, in "An Apology for Form," points out that "it has become commonplace to juxtapose process writing with a so-called 'product approach.' Rather than defining what the traditional approach is, this inadequate and derogatory title shifts our attention to what it is not (i.e., not process)" (14). Granted, Coe is constructing in this piece a defense for the teaching of form in a non-current-traditionalist pedagogy, and so seems particularly bitter about how the previous administration (i.e., "product approach") is being demonized, in his eyes, by proponents of WRITING-IS-PROCESS. However, his point is still relevant. Much of how the process movement depicted the state of composition relied on terminology and metaphoric association. While the WRITING-IS- 
PRODUCT concept stands perhaps more strongly as a metonymic relationship between the final piece of writing and all that went into it, the creation of a "negative metaphor," in which PROCESS could be shaped and understood through contrast and resistance, depicted PRODUCT as a greater beast than the many pedagogues and scholars who had been practicing product-oriented pedagogies thought. At the same time, as Coe points out, by relying on the metaphoric commonplaces that would be associated with "product approach," the association is built that defined both PRODUCT and PROCESS as "not each other," rather than emphasizing exactly what each one $i$.

Another issue that shows the interactivity of WRITING-Is-PROCESS comes to surface in the idea of a process's implied linearity. Although cognitive theory incorporated aspects of recursivity into the model of PROCESS, there has clearly been a continuation of process-oriented metaphors such as "cooking" and "growing." As I have previously pointed out, as a metaphor such as "cooking" gets metaphorically extended beyond its original context, commonplaces not originally associated with it come into play, such as the linearity necessary to a cooking recipe. Thus, as PROCESs becomes metaphorized as a linear stage-process, the larger conceptual metaphor WRITING-ISPROCESS becomes perceived as equally linear. In 1981, around the same time that cognitivist theories began to help shape WRITING-IS-PROCESS, Anne Berthoff confronted the problematic perception of linearity: "Composing is not a process like playing a game of tennis or cooking a meal; there are no hard and fast rules, and it does not proceed in one direction - in a straightforward manner. Composing is not a linear process, though what it creates has linear form" (20). Not only did Berthoff note the problems of metaphorically associating writing with other processes that imply linear progression, but 
she also noted one of the reasons that a linear model is tempting: a writing piece often has a "linear form." 25

The issue of linearity continued well beyond early interactions of the WRITING-IsPROCESS metaphor, to the point that many conceptions of WRITING-IS-PROCESS become directly associated, for good or ill, with a linear approach to writing. Thomas Kent, writing in 1994, echoes Berthoff's comments:

No process or system can explain, in any precise way, how we shift ground appropriately when we employ our vocabularies. Therefore, if we want to encourage students to think about writing as communicative interaction and not a skill (like riding a bike) that can be mastered and internalized, I believe that we should become strong externalists and stop talking about writing in transcendental and internalist terms. (307-8)

As Berthoff argued 13 years earlier, Kent makes an argument that resists the imposition of a process that emphasizes not only linear patterns like riding a bike, cooking a meal, or playing a game of tennis, but also relies on metaphorically ambiguous ways of accomplishing the act of writing. In contrast, George Pullman writes in 1999 that "the product of writing (a text) is an unstable entity, the diaphanous effect of multiple interpretative efforts by people who may or may not share contexts or interpretative practices, $[\ldots]$ who may in fact have the text in common only as a site of combat" (27). While Kent and Pullman differ in their depictions of writing (Kent resists "transcendental" terms while Pullman describes writing as working towards an unstable, "diaphanous" entity), their goals are similar: to reject conceptualizations of writing as a stable, linear process.

Lisa Ede states that the pedagogy embodied by WRITING-IS-PROCESS was "coopted and commodified," but not by those teachers and writers who espoused the conceptual metaphor in its pure sense. Instead, she argues that the misinterpretations of 
the metaphor was caused "by textbooks that oversimplified and rigidified a complex phenomenon, by overzealous language arts co-ordinators and writing program administrators who assumed that the process approach to teaching could be 'taught' in one or two in-service sessions" (35-36). In this figuration, the blame lies with third parties, outside of the community, who wish to appropriate useful methods in order to create a marketable commodity, in this case writing.

Lad Tobin offers another perspective on how WRITING-IS-PROCESS became associated with problematic linear, stage-centered processes that limit and restrict a writer. He narrates a brief story from his memory, of "Evelyn," a fellow writing teacher:

I still remember the day in the mid-1980s when my office mate, a very traditional teacher who had always required each student to go through a series of prescribed steps that she would check off before moving to the next $[\ldots]$, came back from summer break to announce that she had finally been won over. I remember being surprised and pleased that Evelyn had come over to the process side of the force, but not so surprised or pleased when the next week, from the other side of the partition, I heard her explaining her version of the method to one of her students: 'You have not done any freewriting here. You can't just jump from brainstorming straight to composing. You can't skip steps.' ("Process" 11)

In this case, I might suggest that Evelyn is seen here as acting under the assumption that the metaphoric concept of WRITING-IS-PROCESS represented a black box that was prepackaged for use. However, when she is faced with an aspect of PROCESS obscured by the black box (a student's participation in different prewriting activities), the "associated set of commonplaces" that she does have available to her are those that informed her "previous" metaphoric understanding of WRITING. In this case, it might seem that the commonplaces are indeed not common enough to allow an interactive meaning-making moment between Evelyn and PROCESS. However, it could be argued even that Evelyn's explanation, that "you can't skip steps," carries interactive weight within development of 
the conceptual metaphor. As other examples show, it is not entirely shocking that a metaphorization of PROCESS - be it cooking, growing, or building - would lead to a belief that WRITING-IS-PROCESS placed a high emphasis on the strict progression of stages. In fact, Tobin acknowledges that WRITING-IS-PROCESS has indeed become a "regimented product" in some cases, but he also argues that "this regimentation has more to do with the quirks of some individual teachers and the nature of the textbook business than with some inherent flaw in the process approach" ("Process" 11).

I would argue that the aspects of WRITING-IS-PROCESS that have been "regimented" or "commodified" over the 40 years since its early moments are not the sole fault of individual teachers, or textbook companies. This is not to say that textbooks don't regiment the writing process, of course. Case in point, the fourth edition of Purpose and Process (a reader for writing courses published in 2001) calls for students to read a sample student essay, given in the order of a clustering exercise, draft, and then final version. The textbook states, "notice how [the student] discovers her idea in a journal entry and then uses her clustering exercise to collect ideas and focus her subject.

Compare her first draft to the final draft to see how she shaped and revised her essay. Finally, read her Postscript to her final essay" (Reid 78). ${ }^{26}$ However, while textbooks and readers do indeed play a role in the propagation of certain forms of WRITING-IS-PROCESS, the metaphoric interactions as evidenced in this section show that this has by no means been a passively received phenomenon within the discourse surrounding the Rhetoric and Composition community. Instead, we find that multiple individuals have contributed to a steady interpretation of the conceptual metaphor WRITING-IS-PROCESS, finding where the 
metaphor holds strong, where it slips, and how other commonplaces and metaphoric attributes act to continue its conceptualization.

\section{The Eureka Moments}

When people are first exposed to a metaphor, and are able to see the preliminary metaphorical connections it offers to their way of thinking, we find what Tim Linzey calls in his model of the lifespan of a metaphor the "gee-whiz stage." This is the moment when, according to Linzey, the heuristic potential for that metaphor is at its highest individuals are struck by its novelty, and while they may not yet trust it entirely for all of their conceptual needs, they begin to explore its power for what it has to offer.

In the case of the conceptual metaphor WRITING-IS-PROCESS, as well as with the connected and subsidiary metaphorizations of the concept of PROCESS, the "gee-whiz stage" is not limited to one moment in time. In 1982, Maxine Hairston wrote of what she saw as the "winds of change" within the teaching of writing. She proclaimed, "the move to a process-centered theory of teaching writing $[\ldots]$ indicates that our profession is probably in the first stages of a paradigm shift" (77). This paradigm shift, as she put it, was the culmination of the various constructed elements of WRITING-IS-PROCESS. The moments of change, from previous orders of writing that emphasized product over process, has been discussed in this chapter already, but what is important in Hairston's statement is the "eureka moment" that she observed as occurring within the whole of the field of composition. In fact, we find that such moments have resonated throughout the metaphor's 40-year lifespan. In this section, I explore some of the "eureka moments" of WRITING-IS-PROCESS found throughout its duration within Rhetoric and Composition, as evidenced in the scholarship of the field. I also point to examples that show both the 
moments of excitement associated with the experience of discovery that comes with initial exposure to the metaphor, and the moments of consternation (or even fear). Observing these instances does more than represent a key characteristic or stage within the model offered by Linzey for the lifespan of a metaphor. These moments of discovery, retrospective, and rediscovery show how the metaphor WRITING-IS-PROCESS continues to shape the field of Rhetoric and Composition, as well as showing how the conceptual metaphor itself continues to be rediscovered and reshaped as new entrants to the conversation become exposed to it. Thus, these "eureka moments" do not necessarily only herald the beginning of the metaphor, but also its continued vitality and discovery within conversations of WRITING-IS-PROCESS.

The "eureka moments" of WRITING-IS-PROCESS are evident in more than the discipline-wide moments, such as those alluded to in Hairston's declaration. Individual accounts trace back to the early moments of the metaphor. In her essay, "Road RhetoricRecollecting, Recomposing, Remaneuvering," Theresa Enos recounts her own levels of enthusiasm for the WRITING-IS-PROCESS metaphors that she discovered in Elbow's Writing without Teachers:

When I read [Writing without Teachers], I shouted, 'Yes! Yes!' I felt I had discovered the world, not just the Pacific Ocean. I had never heard of such a concept, but I knew it was the way I wanted to teach. So I had my students free write, every class period. Of course, I really didn't know yet why I was having them free write - I hadn't yet connected with the rich theory behind Elbow's method - but I was a firm believer in the 'cooking' metaphor for invention. $(81-82)$

Similarly, Lisa Ede remembers her own experiences with discovering the WRITING-ISPROCESS metaphor, stating that "many of the early studies of the writing process evoked in me that 'eureka' or 'aha' response that hits when we suddenly see that which our 
common sense understanding - of writing, of our students, of our roles as teachers - has kept hidden from us" (33).

In both of these descriptions, from Enos and Ede, the identification of the "eureka" response signifies more than a new configuration for writing, one that had been at that point unheard of; rather, it was an image of writing that had already existed, hidden by "our common sense understanding," in Ede's words. Both Enos and Ede describe the moments of discovering the metaphor of WRITING-IS-PROCESS as one in which their personal paradigms shifted, to borrow Hairston's terminology. However, WRITING-IS-PROCESS becomes more than simply a new way to look at things - for Ede it supplants previous notions of common sense, becoming inherent to the basic comprehension of writing itself. For Enos, her reaction is one of intuition: she "knows," at a nearly instinctual level, that the metaphor of "cooking" draws on a deeper theoretical value, and thus she is compelled to engage in it even before she connects to the "rich theory" behind the metaphor. However, in the case of Ede's account, the "eureka moment" she describes also allows her to segue into a complication of the WRITING-ISPROCESS metaphor. Observing that iterations of the WRITING-IS-PROCESS metaphor as offered by cognitivist theorists metaphorize the process in "mechanistic" terms, Ede critiques the "eureka' or 'aha' response" that she and others experienced, suggesting that the excitement of such reactions leads to a situation in which "the concept of 'process' governing its own theory and practice was seldom scrutinized" (35).

In the last chapter, I argued that Linzey's model for the lifespan of metaphor unduly weights the beginning of a metaphor's life with a high heuristic potential but a very low fiduciary, or trust, potential. Ede's point, regarding the rareness of scrutiny 
placed on the WRITING-IS-PROCESS metaphor at the moment of "eureka," supports my argument in this regard. According to her account, there was perhaps too much trust placed in WRITING-IS-PROCESS at the outset, without enough exploration of the potential repercussions of such a metaphor. There have been many moments of metaphorically engaged interaction within the duration of WRITING-IS-PROCESS as a conceptual metaphor, as discussed in the previous sections of this chapter. However, it is worth noting that these early moments also carried for some scholars and teachers of writing such a powerful force of trustworthiness that retrospective accounts such as Ede's force a reconsideration of the metaphor.

Ede is not the only one who retrospectively reevaluates the early stages of excitement and "eureka" related to the WRITING-IS-PROCESS metaphor. Nearly two decades after Hairston's declaration, of the shifting paradigm within teaching writing towards the WRITING-Is-PROCESS metaphor, George Pullman refers back to Hairston's article, declaring that the change never really came. He states that "the paradigm is really a metaphor for a rhetorical situation, and both current-traditional rhetoric and the process theory of writing have an identical rhetorical situation: the classroom" (27). By incorporating Hairston's comments, Pullman does more than attempt to refute the "eureka moment" that Hairston identifies as occurring on a community-wide level within the field. He is calling into question the metaphoric assumptions that have carried forth over the years, critiquing what he sees as the problematic associations between currenttraditional pedagogy, embodied in the conception of WRITING-IS-PrODUCT, and pedagogies that engage the WRITING-IS-PROCESS metaphor. In both conceptualizations of writing, the rhetorical exigency remains the same: a focus on the classroom, and on how 
to teach writing itself. Pullman is arguing for a reconception of writing, one in which "writing, whether the acts or the products of the acts, cannot be usefully theorized" (ibid.). We could easily replace his use, as in other situations, of "theory" with "metaphor," thus showing that not only does his argument stand for the inability to create a theory of writing, but also his resistance to the metaphors associated with writing. In addition to the initial moments of discovery, found in scholarship from the early moments of WRITING-IS-PROCESS as with Hairston as well as in retrospective accounts provided by the likes of Enos, Ede, and Pullman, the "eureka moments" of the conceptual metaphor continue to surface as new members enter the field of Rhetoric and Composition. However, the process of discovery now takes on a new characteristic, one of "history." When graduate students, for example, read Elbow, Murray, or other scholars instrumental to the creation of the WRITING-IS-PROCESS metaphor, the readings occur outside of the initial context - now showing "where we've come from," rather than "where we're going." The readings are collected into anthologies like Cross-Talk, and it could be argued that this decontextualized nature, while presenting a historical account of the theoretical (/metaphorical) progression of the field, removes the exigency and discovery potential of metaphors like WRITING-IS-PROCESS. It may be easy, then, to see the metaphor of PROCESS as already solidified or "deadened" to the point of metaphoric assumption. However, while graduate students and other "initiate" members of the Rhetoric and Composition community may not be party to the memory of past interactive moments and previous iterations of the WRITING-IS-PROCESS metaphor, they are able to incorporate the characteristic of "history" into their metaphoric discovery process. As initiates make their entry into the community, their absorption of the historicized and 
metaphorized narrative of disciplinary and teacherly identity (as I will discuss in Chapter III) works in tandem with Linzey's life-span model of metaphor to stimulate discovery through the exposure to previously unknown metaphors,. In these moments, the "lifespan" of varying PROCESs metaphors restart, with renewed opportunities for discovery and new "eureka moments." Each new generation of initiates that explores the theories and metaphors of WRITING potentially move those metaphors even further forward, reinventing WRITING-IS-PROCESS into their own pedagogical, scholarly, and disciplinary identities.

In this chapter, I have discussed the prevalence of the WRITING-IS-PROCESS conceptual metaphor. In addition to examining a few of the initiating instances of PROCESS, metaphorized for writing, I argued that the interactive quality of WRITING-ISPROCESS can be seen in both the appropriations and resistances to the metaphoric associations it offered for a conceptualization of writing, of the writer, and of the teaching of writing. Equally, we find that the "eureka moments" within the life of WRITING-ISPROCESS represent its vitality at different moments in time, and the usefulness of such moments of discovery for retrospectives on the course of the metaphor as well as resuscitations of the conceptual metaphor that keep it from becoming entirely "deadened." In the next chapter, I present a distinctive genre of writing, the teacher narrative, to explore how teacherly and disciplinary identity is metaphorically figured according to concepts that, rather than guiding our scholarly considerations of writing, become shaping forces in how we "story" our experiences and identities as part of metaconversation predicated on a shared community of teachership. 


\section{Notes}

' Since, of course, we all know that current-traditionalist pedagogy isn't still used anymore, anywhere.

${ }^{2}$ The concept of "process" as a mode of writing, as well as a way to describe writing in more general and ambiguous terms, is quite pervasive. While the overall metaphor that I am examining in this chapter is WRITING-IS-PROCESS, it is quite possible to understand the "PROCESS" part of that conceptual metaphor as encapsulating the entire metaphor. Thus, there are times when, in reference to the conceptualization of "process," it seems apt to refer to it simply as such: Process. This maintains the association with its conceptual, metaphoric origins, while focus strictly on the way that "process" itself becomes metaphorized.

${ }^{3}$ Suggesting an affinity with interactional theories of metaphor itself, Elbow points to the value in creating connections between disparate things, especially encouraging mixed metaphors, stating that "connections are loosened so that something may develop or grow in whatever its potential directions are" (55).

${ }^{4}$ Elbow here (and elsewhere) uses allegorical and metaphoric use of spatial dimension to describe and conceive of writing - later he refers to aspects of the writing process as "surveying the terrain" (21), "emerging center of gravity" (25), and "keep[ing] out of any swamps" (32). These metaphors, while notable for their metaphorization of writing as a spatial activity, appear to be secondary to his overarching metaphoric models for the writing process.

${ }^{5}$ Of course, Elbow's own endorsement of a process-oriented writing style has also been critiqued as one that emphasizes the "mystery" of writing.

${ }^{6}$ This view of writing is similar to the Aristotelian model of metaphor itself, in which only masters and "geniuses" could fully control the power of metaphor - it was not something that could be taught.

${ }^{7}$ While a comment like "be as nutty as possible" certainly fits Elbow's idea of creatively mixing metaphors, one shouldn't ignore the more subtle metaphoric food association of "nuts," especially considering the end of that sentence, where he encourages the reader/writer to "open" the metaphors up exposing their meat.

${ }^{8}$ We could take this a step further, to envision Elbow's metaphorization as WRITING-IS-BIOCHEMISTRY not only emphasizing the chemical reactions, but also the potential combustion as fuel for writing ("cooking drives the engine that makes growing happen" [48]).

${ }^{9}$ It should be noted that I do not comment on perhaps one of Elbow's other famous personal metaphors, that of the "believing game." While this metaphor has certainly blossomed into conceptual status within the field of rhetoric and composition, I would argue that it is a conceptual metaphor that characterizes the "intellectual enterprise": ARGUMENT-IS-THE-BELIEVING-GAME, rather than WRITING-IS-PROCESS. If it were to be examined, it truly does deserve undivided attention, which is not possible in this specific project.

${ }^{10}$ In fact, while Elbow seems to revel in the messiness of the writing process, when Murray refers to the correcting and editing of a student's paper he states that it must be done in order "to show the student that he cannot get away with sloppiness" (135).

"I must resist the urge to "biographize" Murray's statements when it comes to writing's metaphoric connection to marriage and relationships - I find that the majority of his comments in this vein present marriage with at least a slight connotation of negativity, or cynical acceptance. He states that "the most elemental reason that writers do not write, that scholars perish rather than publish, is the fact that writing is a commitment" (8), which associates closely to his other comments regarding relationships. I am left wondering how much of the nature of these comments is based on the cultural perspective of marriage in the 1960s. Certainly other comments he makes reflect the cultural sentiments of the time, such as when he states that "a writer is sensitive, but not in a dainty, limp-wristed sort of way" (2). 
${ }^{12}$ It should be noted, though, that he does follow this statement by saying that his aware that sometimes too much chaos might become a problem, as it (potentially) "increases anxiety and may make the job take longer" (49).

${ }^{13}$ Equally, critiques of Process have addressed the focus on a single author/single text approach often associated with traditional process pedagogies; however, this has been equally critiqued of early cognitivist models of the PROCESS (Bizzell; Brandt, Literacy)

${ }^{14}$ Interestingly, after this point, Flower and Hayes drop the "process" from their identification of this model, simply calling it the "stage models of writing" while immediately afterwards identifying their proposed model as "a cognitive process model" (367, my emphasis). I would suggest that part of the reason for this comes from the implied assertion they are making that such a model for writing creates a "wrong" or inaccurate association to "process," and therefore should not be identified as such.

${ }^{15}$ In 1989, Flower takes the metaphoric associations of "networking" established in this piece further. She suggests that not only can a writer's process of writing be represented by the computeristic metaphor of networking, but also the generation of personal knowledge and meaning through writing, to "see how writing adds new nodes and new connections in the writer's representation of the meaning on this unique structure" ("Taking Thought" 201).

${ }^{16}$ The metaphorical journey that WRITING-IS-PROCESS has taken is one of many paths, with divergent directions and a lot of pit stops. As Richard Fulkerson points out, the previous metaphoric/theoretical perspective WRITING-IS-PRODUCT is much easier to label through its oversimplification of the writing process encapsulated in the final product. However, WRITING-IS-PROCESS, and its metaphoric applications, has "diverged into cognitive-process views, linear-stage views, expressive views, social views, etc." (418). Thus, while there may be much more to say about the lifespan of WRITING-IS-PROCESS, such an expansive project is outside of the scope of this chapter.

${ }^{17}$ Of course, this also allows for a transition into discussions regarding the nature of social construction and the possible ways in which a human mind may already be programmed to respond to situations.

${ }^{18}$ Keller points out a parallel incident in her accounting of discourse metaphors: Francis Crick's formulation of the "Central Dogma" of molecular biology "appropriated the cybernetic term information, but used it in its colloquial rather than in its technical sense" (93, author's emphasis). As I discuss in Chapter I, metaphor is not easily controlled, and metaphors are not always chosen for their "correctness" or harmony with previous forms of meaning and knowledge.

${ }^{19}$ An example that initially appears outside of discussions of writing but still has the ability to inspire the integration of new commonplaces into the metaphoric models of cognitive PROCESS-ING is that of the postmodern metaphor of the "cyborg." First popularized by Donna Haraway's "Cyborg Manifesto" and followed by such works as Michelle Ballif's "Writing the Third-Sophistic Cyborg," this metaphoric identity merges the discourses of cybernetics, feminism, and rhetoric to create an embodiment of rhetorical, networked, and socially engaged posthumanism that capitalizes on the progressive nature of technology and postmodernity.

${ }^{20}$ Notably, one current criticism of "DCog" is its use of a common language register for all elements in a "socio-technical system," regardless of whether these elements are human, animal, or inert objects: "This common language has led others to critique the theory for assuming people are equated with artifacts in some way that denies their humanity" (Halverson 247).

${ }^{21}$ For another example of growth being a bad thing, see also The Blob (1958) and (1988).

${ }^{22}$ Not only does this pose a problematizing of Elbow's "growing" metaphor, but it also suggests a dangerous connection to the "banking metaphor." 
${ }^{2.3}$ At this point, it is worth noting the separation of "growing" and "cooking" in these metaphoric interactions. Elbow originally offered the two metaphors together: "growing-and-cooking." These metaphors were not intended to be interchangeable, as he pointed out that they represent different orders within the writing process - "growing" for the larger developmental process of writing, and "cooking" for the inner, bubbling chaos of invention. Even though these two were originally intended to co-exist, they have developed, at points, independently of each other, giving way to conversations and interactions that take their metaphoric meanings in multiple, sometimes contradictory, directions.

24 The idea of "creation" also evokes certain metaphoric connections beyond the original metaphors" intents. Phillip Arrington notes that "on a grander scale, the composing act repeats, in small, the larger act of God's own creative process or, if not God's, nature's. Both depend on the ability to make, to give form, and the unfolding of that form in time and space" (332).

${ }^{25}$ On the other hand, in a defense of stage-process models such as Jean Piaget's (cited by Elbow in his metaphorizations of PROCESS), Janice Hays writes in 1987 that "a spiral would be a more accurate geometric representation of concepts of adult development" (13).

${ }^{26}$ While these lines might seem repetitive of Tobin's "Evelyn," I would note that this is not a "quirked" teacher, but it is a textbook that explicitly purports to black-box the PROCESS of WRITING for easy transmission. 


\section{CHAPTER III}

\section{SHAPING OUR STORIES AS THEY SHAPE US: METAPHOR AND THE TEACHER NARRATIVE}

If that storyline takes on a dramatic shape, a beginning with complications (Chapters 2-4) that grow into major crises (Chapters 5-7) that resolve themselves into a professional life (Chapters 8-10), it only writes large the narrative shape of many a tale.

Richard Haswell, Comp Tales

The metaphor of WRITING-IS-PROCESS represents much of the interactive efforts within the field of Rhetoric and Composition to conceptualize the act of writing itself. While the discipline is strongly centered on how to conceive of the act of writing, one of the other chief tenets of Rhetoric and Composition is, of course, the teaching of writing. Perhaps it should come as no surprise, then, that alongside the more theoretical and academic conversations about writing, in which metaphors of writing abound, there are as many (if not more) written reflections from teachers, narrating the actual experience of teaching. These teacher narratives represent a bit of a niche market for publishing within the discipline, and they garner much interest and aid in the continuing conversations of our field. Many scholars, in fact, have made the case that the stories teachers tell should be included and acknowledged alongside traditional scholarship, that these stories extend our knowledge beyond theoretical and analytical pursuits and into the actual lives of teachers as they negotiate their own roles in the classroom (Stock; Elbaz-Luwisch; Jalongo \& Isenberg; Ritchie \& Wilson). 
Within the field of Rhetoric and Composition, teacher narratives appear in anecdotal form to illustrate a point, or as a framework for an entire essay. Multiple collections strictly of teacher narratives have been published, exploring many of the situations and sites of teacherly experience. These collections, such as Richard Haswell and Min-Zhan Lu's Comp Tales, Tina Lavonne Good and Leanne Warshauer's In Our Own Voice, and Joseph Trimmer's Narration as Knowledge hold to a commonly-held belief, summed up by Trimmer in his introduction: "To narrate is to know. We need to tell our teaching stories if we are to understand our teaching lives" (xv). These narratives are a rich breeding ground for metaphors, as they proliferate in the dialogue of teachers' stories, buttressed by their appearances within other published forms of discourse within the field. As these metaphors perpetuate, the larger, conceptual metaphors that fuel them come into focus and give us a better picture of the discipline as a whole - not only a discipline that studies writing, but a discipline that is intent on the reflexive refinement of the shared experiences of teaching writing.

While Chapter Two examined the origins and perpetual development of some of the metaphors associated to writing itself, in this chapter I intend to discuss the metaphors specific to the narrated teacherly experience as exhibited in teacher narratives. There are, to be sure, overlaps between the two foci. The teacherly experience, however, has been a topic as integral to Rhetoric and Composition as the act of writing. The primary metaphors of teacher narratives, such as CONVERSATION, COMMUNITY, or the metaphor of STORY itself, make clear the power of metaphors in the telling of teaching stories, to characterize the act of teaching. In addition, however, to the benefit an individual might receive through telling (or receiving) a teaching story, there is also a clear metaphoric 
definition of the teacherly experience that extends beyond the individual to shape the grander meta-narrative of teaching itself. There are complications with this use of metaphor in teacher narratives - while the individual teacher's development and reflection is often made chief amongst the goals of the teacher narrative, this metanarrative of teaching often becomes the greater force. The story becomes more than that of a single teaching body in the classroom, shaping a mythos of teaching definitive of the entire field. While this has certain benefits, there are also drawbacks, or limitations, to what the individual teacher, narrator, or even the reader can ultimately do with the resulting narrative.

The uniquely narrativistic metaphors of teaching stories inform us of the shaping of our discipline as a lore-driven, almost mythological community. ${ }^{1}$ The prevalence of certain key metaphors creates a narrativistic system that most productively combines multiple conceptual frameworks: the teacherly experience becomes a story, but one that contributes to a communal conversation that ideally spans generations of teachers and scholars within the field. These conceptual metaphors do reflect and reproduce the core ideas and values of Rhetoric and Composition, but it is important to also note how they represent a potentially problematic re-inscription of the teacherly experience. The individual teacher, reading narratives in journals and published collections, is exposed to a specific type of story: the "Story of Teaching." This singular story can preempt the individual teacherly experience in favor of specific, pre-formed narrative meaning, and can leave dangerously little room for an interactive development of the metaphoric commonplaces available to the narrator and reader. In this chapter, I will explore the metaphors of TEACHING-IS-STORY, TEACHING-IS-COMMUNITY, and TEACHING-IS- 
CONVERSATION, as they appear within the teacher narrative as a genre (and subject of scholarship). Ultimately, I argue that the most productive understanding of the metaphors of the teacher narrative genre comes through an amalgamation of all three metaphors. To ignore any of the engaged metaphoric elements represented by STORY, COMMUNITY, and CONVERSATION puts the individual teacher at a disadvantage as he or she attempts to position his or her teacherly experience and ideals amongst those of the field in general.

\section{Metaphorizing the Shared Narrative}

The teacher narrative represents the individual teacherly experience, connected to the ideas and notions of the greater discourse within Rhetoric and Composition as a field. One of the most powerful drives within the teacher narrative, as a genre, is to contribute to the larger narrative - the shared experiential narrative that all teachers can access. Patricia Stock, in championing the anecdotal telling of teacherly experience, argues that teachers "recognize elements of the [shared] anecdote as similar to ones they have experienced; because in the particularities they recognize the details of their own teaching circumstances" ("Function" 186). The "particularities" that Stock mentions may imply that the specific, different details of each teacher's experience play a strong role in the reception of anecdotal (or, as I would extend it, narrativistic) material, but the key point that Stock is emphasizing is that teachers reading or hearing other teachers' anecdotes, stories, and reflections will be able to see "the details of their own teaching circumstances." The teacher narrative, as a genre highlighting the ideals suggested in Stock's definition of the anecdote, contributively creates a story that can be shared amongst all teachers - each submission of individual teacher narratives becomes part of 
the larger teacher narrative that encompasses all teachers within Rhetoric and Composition.

Out of these statements, and the teacher narratives they draw upon, we can make associations to three connected conceptual metaphors, which are all integral to the valuing of the teacher narrative as a part of Rhetoric and Composition: TEACHING-ISStory, Teaching-Is-Community, and TEACHInG-Is-Conversation. As Stock indicates, the narrative as read by teachers becomes significant when they see the story as one they themselves have had their own role in - the story becomes a universal constant. But there's more: through this universal constant of STORY, a shared community is created - the stories become a gateway into a fellowship of teachers, a membership that comes from the recognition of one's self with the STORY, as the STORIED experience is shared laterally. In Comp Tales, Min-Zhan Lu concludes the collection of stories within the book with a further encouraging call for telling the stories of teaching in as many contexts as possible:

Sharing stories with trusted colleagues through regular mail and email or working face to face with a small community of teachers in graduate seminars, in faculty workshops, self-initiated writing or reading groups, co-teaching and mentoring arrangements, varied professional development activities, task forces and in-house journals are also good ways of exploring storytelling. (226)

Not only is there value in storytelling, Lu asserts, but the potential sites of storytelling proliferate the many venues of teacherly community, and the act of sharing these stories ultimately anticipates and even invites response from other teachers, as they read and hear the narratives of the teaching community.

As mentioned earlier, there are countless examples of teacher narratives woven into the disciplinary conversations of Rhetoric and Composition, as individual anecdotal 
accounts, as frameworks for essays, and as part of book collections such as Comp Tales and Narration as Knowledge. For this chapter, I offer examples of these teacher narratives, and the related scholarship and reviews that speak directly to the nature of the teacher narrative, to examine the metaphoric trends within the narration of teacherly experience. In the following sections, I explore the specific metaphors of STORY, COMMUNITY, and CONVERSATION - separately but still as they converge with each other. Their presence in teacher narratives, and in the scholarship promoting such narratives, solidifies the conceptual framing of the teaching experience according to the commonplaces brought to the table by each metaphor (and through the combination of them all). I begin, in the next section, with the overarching conceptual metaphor of TEACHING-IS-STORY. There is a strong emphasis on this specific metaphor (in my examination as well as in the published discourse on teacher narratives) - it represents in many ways the nexus point for the ideals and goals of the teacher narrative as a genre. To put it metaphorically, the metaphors of COMMUNITY and CONVERSATION become grafted to the base trunk of TEACHING-IS-STORY to create an organic whole, while each of the three conceptual metaphors retain many of their individual metaphoric characteristics. Storying the Teacherly Experience

It may seem perfectly natural that writers within the teacher narrative genre would acknowledge their roles as storytellers - they are, of course, doing more than simply listing chronological or sequential moments without any thematic or "plot-driven" elements. It is a story that the teacher/narrator is telling - what Stock defines as "figured shapes of human activity" ("Function" 186). Freema Elbaz-Luwisch, in fact, firmly argues that "story is the very stuff of teaching," and that "teachers' knowledge in its own 
terms is ordered by story and can be best understood that way" ("Research" 3). As a genre as well as in individual instances, the teacher narrative places a high value on STORY as a conceptual, metaphoric framework by which the teacherly experience is both structured and interpreted. Equally, there is much value placed on the very act of telling the story. Lu, as previously quoted, indicates the importance of sharing stories in a myriad of settings - something that is echoed by many other writers and teachers promoting the value of the teacher narrative. When telling these stories, though, the elements that make them stories often become central to the conversation. Metaphoric associations within teacher narratives combine to form a scaffolding that emphasizes STORIED qualities that are recognizable beyond the individual narrative, towards the goal of creating that grander, master narrative to which teachers can relate their experience both as narrators and as readers. This structure becomes metaphorized within the actual stories being told, as many teachers define their teacherly experiences, as well as their own attempts to narrate these experiences, in a STORIED way. In "The Story of the Story Is the Story," for example, Douglas Reichert Powell begins to tell his own story of teaching by equating the teacher narrative to the genre of the fairy tale: "the 'Once upon a time' for this story goes, 'Well, in my classroom...." (11, author's emphasis). The standard fairy tale beginning becomes the standard teacher tale introduction, and Powell uses this metaphoric association to process his own classroom experience reflectively by way of the pre-established storyline. He later identifies the turning point in his narrative by returning to the template offered by the STORY metaphor: "Narrative logic, plain-old 'good storytelling,' demands that this be the big scene. This is act three, scene four or so - where it all comes down" (16). Powell may be shifting the genre, from fairy tale to 
play, but the metaphoric framework that he has engaged remains the same. The conceptual metaphor of TEACHING-IS-STORY is intact - a generic form of the fictionalized (or, perhaps more apt, novelized) story. ${ }^{2}$

The interactive metaphoric engagement at play in the genre of teacher narrative, in regards to TEACHING-IS-STORY, goes beyond simply acknowledging that the teacher/narrator is "telling a story." As discussed in Chapter 1, the metaphoric commonplaces that are associated with a metaphor are carried over into the new conceptual framework, regardless of the intent of those who initially employ the metaphor. It's one thing if the extent of metaphoric engagement went only as far as comparing certain points in a narrated experience to classic storytelling structures like the fairy tale or play (Powell's "plain-old good storytelling"). It's quite another situation when the conceptual metaphor of STORY shows itself to be a guiding influence within teacher narratives, actually becoming a prime element by which the teacher/narrator constructs his or her narration. The metaphoric commonplaces of STORY then begin to shape the actual narratives themselves, steering the narration in certain specific directions. Deborah Klein, for example, invites her readers to listen to her teaching story, from her experience of being a missionary teacher in Africa with a student being emotionally abused and intellectually oppressed by an authority within the school system. While she is narrating a particular moment in her own experience as a teacher, Klein points out that her account is not unique - as she puts it, what she is about to tell the reader is a "twice-told tale," with "new names, different settings, but the same characters and episodes" (169). The specifics of her story may seem remote and unique to her readers, but Klein assures us that the tale she tells is not uncommon. She even invokes a 
literary continuum with the title of her essay: "Iago Lives in the Panopticon." Drawing on the canonical power of both Shakespeare and Foucault in equal measure, Klein consciously frames her story from the very beginning as one that is part of this larger series of likeminded tales - different names and settings, as she says, but "the same characters and episodes."

Klein's acknowledgment of the canonical is not only in regards to a literary or theoretical canon, however. She is also drawing on the canonical story of teaching - the Story that is Teaching. In Actual Minds, Possible Worlds, Jerome Bruner refers to such narrative examples as those "stories [that] define the range of canonical characters, the settings in which they operate, the actions that are permissible, and comprehensible" (66). Klein, somewhat despairingly, is describing her "twice-told tale" as one that is common, not unique - she is not the first to witness or experience these events, and she won't be the last. For her, the metaphoric placement of TEACHING-IS-STORY becomes the guiding principle of not only the narrative she is writing, but also the actual, initial teaching moment as it occurred. It speaks to the tragedy of the event she narrates - her student is only one in a long line of students placed in unfortunate circumstances, and she as the teacher is one of many who can only helplessly observe. Klein both sees and presents her experience itself as being canonical in its own right - the narrative only reflects the canonicity that has already taken hold of the situation surrounding her and her student. The STORY, it seems, becomes inescapable - as is the experience that she witnessed as a teacher and is now narrating to the reader.

Klein's narrative centers on the metaphoric adherence of her teacherly experience to the canonical storyline, the plot of TEACHING-IS-STORY. Other narratives show the 
additional elements of narration and reflection a teacher can provide that make his or her teacherly experience become inherently STORIED, shaping to fit the traditional elements of the larger metaphoric concept of STORY. In "Reading Student Silences," Eileen Schell tells of her experience coming up against student resistance to feminist pedagogy that was exhibited through resentful silence. As she reflects on the experience, Schell directs our attention to the powerful metaphoric pull of STORY - she declares that she wishes to resist [...] classifying this essay as a pedagogic 'success' narrative wherein I serve as a sort of heroine who enlightens my students. Nor do I want readers to see this as a pedagogic 'failure' or 'recovery' narrative wherein my students and I find redemption in a failed or botched project. (103)

In addition to opposing (while invoking) a stereotypical tale of "redemption" (giving the reader a fleeting religious image), Schell's attempt to avoid becoming "a sort of heroine" exposes the tempting draw of the conceptual metaphor TEACHING-IS-STORY, even in her resistance to it. She acknowledges that the easiest way for both her and her readers to interpret her experience would be to invoke STORIED metaphors that place herself (the main character) as the "heroine" of the story. Schell attempts to reject that approach and interpretation, but even the apparent need she feels to voice this metaphoric opposition speaks volumes - the metaphoric inherency of TEACHING-IS-STORY must be addressed. Additionally, it could be argued that even though she declares resistance to the STORY conceptual metaphor, the mere metaphoric invocation of the "hero/ine" that might appear in such narratives is enough to case her own narrative in a STORIED light.

While Schell tries to pull away from the STORY of teaching, other teacher/narrators have engaged with the metaphor for their own reflective and narrative purposes. The (resistive) engagement Schell exhibits to the metaphorizing, STORYING, of 
the teacher as "hero/ine" is reflected at the other extreme by the many ways the antagonist, the "bad guy" of the teaching story becomes metaphorically figured. In some cases, the foil to the teacherly hero is represented by a specific student, tactfully villainized by the teacher/narrator to exemplify classroom resistance, like Robert Connors's legendary, silent, male student from "Teaching and Learning as a Man": "He was one of the guys. Burly, thick-necked, [...] watching me through lowered eyelids" (137). Of course, this metaphorization of the student-as-villain poses a particular problem: the suggestion then is that the (heroic) teacher and the (villainized) student are at odds - enemies against one another. As this tends to go against many teachers' goals of creating a conducive, constructive pedagogical experience, it is in fact more common to see the antagonist of the STORIED narrative as an abstract concept. This is what we find in Schell's classroom, where the silence itself becomes the antagonist; Richard Haswell, when describing the stories found in Comp Tales, abstracts such villainy further to include administrative restrictions that inhibit productive teaching: "rules-and-regulations itself, a multi-cloaked villain [...] who outmaneuvers the innocence of the learner and the experience of the teacher" (39-40). In any case, the villain must be overcome by the hero of the teacher narrative, just as in a traditional story. And, along the way, both the narrator and the reader will learn a "lesson," what Katy Gottschalk identifies in her teaching story within Comp Tales as "the morals to be drawn from this episode" (40). The STORY of teaching often leads to such a lesson, "the moral of the story": alongside other story genres like fairy tale and play, the teacher narrative can perform the generic role of bildungsroman, in which the teacher/hero gains pedagogical maturity after experiencing (and reflecting upon) the trials of teacherly experience. ${ }^{3}$ 
In addition to these more generic, archetypical figures of STORIED experience, many teacher/narrators metaphorically extend the teacherly experience into specific literary or cultural examples, of pre-existing stories and plotlines - concrete reference points by which the narrated experience can be both metaphorized and understood. We have already seen one example of this, in Deborah Klein's narrative, wherein she refigures one of her colleagues as not only the main "villain" of the story, but specifically Iago from Othello. The association between Klein's "Iago" and Shakespeare's villain in fact becomes more than a convenient metaphoric allusion: the Shakespearean Iago's covert and manipulative villainy is reflected in equal measure by Klein's "Iago," the unsettlingly aloof and lurking administrator who is distantly unaffected by the painful events that unfold within the narrative. At the end of the tale, Klein gives one last glimpse of the unresolved plot, summed up in the final sentence: "Invisible on his screened-in verandah, Iago sits still" (189).

In "The Teacher as a Dostoevskian Novelist," Timothy Lensmire follows this same vein of literary appropriation as he re-conceives his own teacherly identity "as a novelist who creates a classroom-novel and takes up relations with student-characters. A Dostoevskian novelist" (368, author's emphasis). Bill Wandless creates similar metaphoric literary allusions in his teacher narrative (indicated even in its title, "The Scarlett Letters: Toward a More Reflective Method of Grading Process Writing") when he voices his discomfort with having to give grades, "emblazon[ing] our students with Scarlet Letters" (275). And, as seen previously, Eileen Schell extends the STORIED commonplaces even further by delving into traditional religious/literary readings as she denies that her narrative is a story of "redemption." In due time, however, her narrative 
leads to a greater insight: "no longer could I present myself as [a] seamless, rational, fully constituted pedagogic self $[\ldots]$ instead, I exposed myself as a partial, contradictory emotionally invested self' (116). In this insight, as well as the (resistant) invocation of redemption, Schell brings to attention a traditional form of the teacher narrative, identified by Andy Convery as the "transformative epiphany": an acknowledgement by the teacher/narrator of a past failure or transgression that results in future redemption or conversion (134). ${ }^{4}$

In each of these narratives, the metaphor of TEACHING-IS-STORY becomes an integral part of the narration as well as part of the original experience itself. The metaphoricity is laced with an interactive engagement of the metaphor of STORY that goes beyond a simple acknowledgement that the teacher/narrator is "telling a story." TEACHING-IS-STORY becomes a foundation for how teacher/narrators not only narrate their experiences, but also how they reflectively give those experiences meaning. The genre of teacher narrative is hardly lacking in such examples. Teacher narratives exhibit an actual reliance on the framework provided by TEACHING-IS-STORY - both in embracement and resistance to its power to shape the narrative that a teacher/narrator chooses to tell. As the teacherly experience continues to be STORIED, the canonicity (or universality) of the stories being told reaffirm the power of TEACHING-IS-STORY as a way to make sense of the teacherly experience and then share it with others. ${ }^{5}$

As many scholars argue, the world is a story, for that is the only way by which we can connect to, relate, and make sense of our surroundings (Bruner; Funk; Coles). We, as human beings, extract meaning from the human experience by understanding it in terms of the story we see it to be. The question is, what kind of story do we see the teacherly 
experience being? As the teacherly experience becomes narrated and metaphorized through the conceptual framework of TEACHING-IS-STORY, the teacher/narrator's narrated teacherly experience can potentially become too reflective of the metaphoric archetype of STORY, a generic storytype that loses its impact. In his 1980 essay, "The Value of Narrativity in the Representation of Reality," Hayden White distinguishes between a narrative of historical accounts and "narrativized" accounts (accounts that have become STORIED), to address modern historiographers' resistance to narrating historical events:

Their example permits us to distinguish between a historical discourse that narrates, on the one side, and a discourse that narrativizes, on the other; between a discourse that openly adopts a perspective that looks out on the world and reports it and a discourse that feigns to make the world speak itself and speak itself as a story. (6-7, author's emphasis)

For White, the "narrativized" discourse is dangerous because it creates a forced perspective, generating a view of the world that is already a STORY - a specific form of story, with metaphorized protagonists and antagonists, climactic moments and plot twists. Recognizing this potential danger is vital when considering the metaphorized teacher narrative, where the STORY metaphor is invoked to describe (thereby shaping) the narrated teacherly experience. The teacher narrative runs the risk of becoming more than a reflective self-examination and sharing of experience, if the metaphor "takes control."

Of course, if we make meaning of the world through stories, we are ultimately unable escape the story - as Robert Funk states, "human beings cannot get outside of story $[\ldots]$ we can get outside of particular stories, or particular forms of stories, but not outside of story as such" (ix). This would apply as equally to the meaning we make of our experiences as teachers - they will always be related as some sort of "story." Instead, the 
real motivation is to make sure we are in agreement with the "particular form of story" as constructed through TEACHING-IS-STORY. When the narrated teacherly experience becomes "narrativized" (or STORIED, as I have described it) within the larger conceptual metaphor of TEACHING-IS-STORY, it represents that teacherly experience itself as a singularizing type of story, an artificially-constructed discourse with specific roles for its participants and predefined paths for its plotline. The teacher and student have already been given their roles in which to act, along an already-established plot trajectory, and the STORY becomes hard to resist, much less break free from, as both Klein and Schell show us.

Lynn Bloom, in "Subverting the Academic Master Plot," echoes this concern, as she points out that "teachers' tales out of school, the stories we love to hear, seem to have two basic master plots, both with happy endings" (116). What she notes is that the "dismal story," the "utter failure" narrative, "seldom attains the public status of lore or legend - and when they do, they happen to someone else" (117). Bloom is identifying a byproduct of the TEACHING-IS-STORY metaphor, by noting the lack (or at least scarcity) of "dismal" teaching tales. ${ }^{6}$ Elbaz-Luwisch comments on the same issue, as she relates her experience running writing workshops for teachers. When there was a "dismal" tale, or teaching experience that was overly negative, "the stories held to a single basic plot, which in its unity brought about a resolution of the conflict" ("Writing as Inquiry" 421). As the teacherly experience becomes inherently STORIED, the types of stories a teacher/narrator can actually tell diminish, and the potential endings for any teaching tale narrow down to a single possibility: the happy ending. 
While Elbaz-Luwisch notes the tendency of stories to narrow in on a single plotline, she argues that the teaching narrative ideally "constitutes a powerful tool in the fostering of teachers' professional growth" ("Writing as Inquiry" 405). The value, for Elbaz-Luwisch, is in the potential of what "storying the teaching self" (echoed in her title) offers the teacher/narrator, as a retrospective into his or her teacherly experience. She cites Bakhtin to draw out the teacher narrative's power as an "internally persuasive discourse": "discourse is that used by individuals and small groups to speak about their own lives and experience" ("Writing as Inquiry" 406). This is in contrast to "authoritative discourse," which Bakhtin describes in The Dialogic Imagination as "demand[ing] that we acknowledge it [...] it binds us, quite independent of any power it might have to persuade us internally [....] Its authority was already acknowledged in the past" (342). This authoritative discourse, monologic in nature, assumes a level of "already established truth" that ends up dictating how the recipient of such discourse may use it. While ElbazLuwisch sees the teacher narrative as internally persuasive, allowing the teacher/narrator to generate meaning of his or her teacherly experience, I would suggest that when it becomes a strictly STORIED account, the teacher narrative actually takes on the characteristics of authoritative discourse more readily. Through the generic configuration of STORY, such a narrative assumes already-established forms and elements to communicate its message - a message that in turn becomes monologic. The message is not intended to be manipulated, re-interpreted, or refigured for any purpose other than originally outlined. The STORIED teacher narrative has a preset structure that guides both the teacher/narrator and the reader to the end, to the "moral of the story" or the "happy ending" that comes from the lesson learned. For the reader of the narrative, as a second- 
generation witness to the experience, the unified structure of the narrative is provided without his or her participation, disallowing "any power it might have to persuade us internally."

The examples offered by Klein and Schell aid in this distinction: in both cases, the teacher/narrator makes explicit metaphoric connections that pre-construct the meaning available to the reader, potentially precluding any co-construction of (alternative) meaning by the reader. Klein begins her narrative by expressly metaphorizing her experience as a "twice-told tale," and as the STORY metaphorizations take hold, with dark figurations of literary characters, it becomes a detached experience even to Klein, the teacher/narrator. ${ }^{7}$ Schell invokes the STORY metaphor through her attempt to dictate how the reader will metaphorically read both her identity and her narrative ("to resist [...] a pedagogic 'success' narrative wherein I serve as a sort of heroine"), therein making an effort to ensure a specific reading that will lead to her desired conclusion (which includes a "happy ending" through a lesson learnt). In both cases, the reader is not expected, or invited, to metaphorically engage with the reading of the narrated experience, and is in fact given a monologic metaphoric directive by which he or she should process the experience. Any ability to make the narrative internally persuasive has been quelled by an imposed, "pre-engaged" metaphorization. As previously noted in Schell's case, even by declaring her resistance to the metaphoric STORY, she has acknowledged its authority and unwittingly handed over the control of her narrative to its shaping influence.

When exerting its influence, TEACHING-IS-STORY figures (or refigures) the main character(/teacher) according to a heroic archetype, leading to an equally archetypical "happy ending" that is reified into the grander narrative of teaching. However, the ideal 
configuration/conceptualization of TEACHING, merging with the metaphoric commonplaces brought to the fore by STORY, has the potential of going beyond just engaging the TEACHING-IS-STORY metaphor. As I will argue in the next section, the metaphoric teacherly experience of TEACHING-IS-STORY is envisioned by its proponents as providing an entry point for other teachers, as readers, to see themselves as more than just witnesses to the events unfolding within the STORIED teaching tale - they are sharing in the experience of the story, as part of an interactive audience. This is not done through the use of STORY alone, but also through the introduction of another conceptual metaphor that engages both the narrator and the reader: TEACHING-IS-COMMUNITY. While we have already seen some of the ways that the STORIED teacherly experience becomes an effort to create a community, there are many examples that call upon the metaphor of COMMUNITY directly. This metaphoric community-building occurs through the universality of TEACHING-IS-STORY, while incorporating the commonplaces of COMMUNITY to mitigate the potentially problematic, monologic aspects of the STORY metaphor that appear when it is engaged on its own. The reader and the narrator, both recognizing their connection through STORIED universality, are metaphorically positioned as members of the same community, defined in part by that shared master narrative.

\section{A Commune of Teachers}

In the previous section I excavated the metaphoric implications of STORY in its own right, as a shaping force that can ultimately dictate the creation and direction of the individual teacher's experience. To add to this conversation, it is necessary to also see how TEACHING-IS-STORY converges with the metaphoric depiction of the teacherly experience as a communal exercise - a shared body of experiences that are accessible by 
all members of the disciplinary community within Rhetoric and Composition, in order to strengthen everyone in that community. This ideal for the teacher narrative genre is embodied by the conceptual metaphor, TEACHING-IS-COMMUNITY. However, it is not enough to simply identify a distinctly separate conceptual metaphor, because many of the ways that this new conceptual metaphor makes itself known is still by way of TEACHINGIs-STORY. The two concepts are interconnected. In this section, I will show how the metaphor of TEACHING-IS-STORY becomes combined with TEACHING-IS-COMMUNITY, not only through the actual teacher narratives, but also through the reception and promotion of the genre itself.

As previously mentioned, the stories of teaching must be told if they are to be of any value. In many ways, the teacher narrative is seen functioning as a "support system" for the Rhetoric and Composition community - letting other teachers know that they're not alone in their experiences, or celebrating successful teaching moments. Robert Connors, in 1996, worriedly commented on what he then saw as the diminishing communal space available to share such moments. Envisioning the future of Rhetoric and Composition (as he put it, Composition Studies), Connors argued that the community was beginning to forget its raison d'etre: the classroom, and the experiences that come from there. One of the symptoms that he cites, as evidence of this move away from a pedagogical enterprise and towards a more theoretical, ivory-towered discipline, was "the eclipse of the "Staffroom Interchange' section of $C C C$ " ("Composition" 13). The "Staffroom Interchange," which ran in College Composition and Communication from 1962 to 1992, emphasized the sharing of short writings on various ideas, exercises, experiments, and stories directly from the classroom. In Fan Shen's Staffroom 
Interchange essay "The Classroom and the Wider Culture," a piece appearing in 1989 (two years before the dissolution of the Staffroom Interchange section of $C C C$ ), the Interchange came with the following description: "Two kinds of articles make up 'Staffroom Interchange': compact descriptions of specific instructional or administrative practices and fuller essays of application, speculation, and introspection" (459). While these essays obviously took a number of different generic approaches, what Connors was lamenting the loss of was specifically the communal sharing of information and experiences. The specific accounts of teaching practices and the sharing of individual stories from the classroom represented the opportunity to "congregate" in this shared space, in the "Staffroom." The genre of the teacher narrative represents for many this same opportunity, to come together as part of a teaching community through the metaphoric sharing of the STORIED teaching experience.

While the teacher/narrator relating his or her experience through the lens provided by TEACHING-IS-STORY has a fundamental role in how the teacher narrative becomes STORIED, the reader's response is equally a participatory force in the expectation and reception of the conceptual metaphors of the teacher narrative as a genre. This is one of the ways by which the teacherly experience, as represented in teacher narratives, exhibits a necessary cross-metaphorization on a conceptual level. For many proponents of the genre, the value of teacher narratives resides in more than just the idea that a story is being told: the teacherly experience is a story that contributes to the greater store of similar stories, told by many teachers, so that the greater community benefits from the mutual, experiential narrative. As a champion of the anecdote and "teacher talk" (and, by my extension, the genre of teacher narrative), Patricia Stock argues for the merits of 
teachers' stories by virtue of their "very occasionality, in their very particularity" ("Function" 186). This "occasionality" or "particularity" is what those reading or hearing the stories of teacherly experiences will be able to recognize as being connected to their own experiences as teachers. In Wendy Bishop's words, "I strive to make meaning through storytelling; analogy building; choice of metaphors; descriptions of thoughts, practices, and insights that will resonate from my experience to your experience" ("Rhetoric" 217). More than seeing a likeness in another teacher, it is the individual teacher's recognition and engagement of the "occasionality," or "resonance," within the STORIED teacherly experience that acts to build a community connecting teachers in their related experiences.

The recognition of a larger communal pool of narrated teacherly experience, reflecting the universality of the STORY of teaching, factors heavily into the figuration of TEACHING-IS-COMMUNITY. In this recognition, there becomes a self-identification from the reader who experiences the narrated teacherly experience by proxy - the reader recognizes the universality, and becomes both a vicarious participant in the teaching story and a fellow member of the community of teaching defined by the narrated (STORIED) experience. In "How to Tell a True Teaching Story," Kate Ronald reviews three collections of teacher narratives, stating that "I've spent the last two months reading the seventy-four teaching stories in these books, and all the elements of good narrative appear in their pages: heroes, villains, colorful characters, tragedy, comic relief, suspense, happy endings, and instructional morals" (256). This is not an uncommon reflection for readers of teacher narratives - not only are they able to identify the STORY metaphorizations within these narratives, but they also contribute to the further 
metaphorization of TEACHING-IS-STORY. Nancy Welch, in another review of teacher narrative collections, returns several times to STORY - not the stories being told, but the metaphoric STORY framework that is being transposed upon the narratives. She refers to "the moving-toward-a-brighter-tomorrow storyline" and "the construction of the compositionists as fantastically heroic" (941). In both of these cases, it is not just the teacher/narrators of these narratives who are applying these metaphoric associations: both Ronald and Welch are actively participating in the effort, identifying (and self-identifying with) STORIED elements within. When Avis Winifred Rupert, reviewing Comp Tales, asks the rhetorical question "Who should read Comp Tales," she answers,

The audience for this book includes not only those communities represented by the contributors, [...] but also anyone who has an interest in what the writing teacher encounters on a daily basis. As I wrote this review I both laughed and wanted to cry at the same time. It was amazing to see myself in this book, both the pains and the joys of what I do. (142)

Part of the universality inherent to TEACHING-IS-STORY comes from this ability to see one's self in the stories being told by other teachers. Rupert, Welch, and Ronald have become part of the effort towards framing the narratives, as participatory readers, and as they do, they enter the shared COMMUNAL space structured by the STORIED narratives.

These responses, from reviewers of teacher narratives, may just seem to again emphasize the fact that the genre has a way of being metaphorized through TEACHING-IsSTORY. While the conceptual framework of STORY is certainly being reaffirmed through these accounts, I would argue that these reviews also confirm the ideals as put forth by many of the editors of those same teacher narrative collections to which the reviewers are responding. Joy Ritchie and David Wilson refer to this sentiment, as they argue that the stories teachers tell 'create a sense of belonging; teachers' stories represent insider 
knowledge and insider membership" (67). This "sense of belonging" to an "insider membership" is as important as the story that is being told.

The adherence that Ronald, Welch, and Rupert exhibit in their readings of teacher narratives through the conceptual metaphor of STORY, which leads to their feeling of a shared COMMUNITY, is not limited to book reviews. Scholars who have endeavored to place a higher value on teacher research or teacher knowledge have emphasized the community-building potential of the teacher narrative as a genre. In "Writing as Inquiry," Freema Elbaz-Luwisch relates her experience conducting writing workshops for teachers, in which the participants wrote teacher narratives. Reflecting on this experience, she notes that "in reading between the lines [of the teacher narratives] one could detect a familiar plot: the super-heroine career woman; the always-caring ideal teacher; the teacher as frustrated, unappreciated civil servant" $(420) .{ }^{9}$ While Elbaz-Luwisch suggests a singular "familiar plot" to the narratives, I would want to point to her examples, which are not necessarily all the same character/teacher, nor will they always inhabit the same STORIED teaching "plot." The teacher narrative as metaphorized through these STORY elements creates a plurality of possible characters, of potential community members, to which reader/teacher can relate. Stock, in "Toward a Theory of Genre in Teacher Research," also observes the sharing of STORIED teacherly experiences within the workshop setting, noting that the workshop is "the favored and logical forum for the publication of teacher research, [and] also the venue in which that research reveals its inter-textuality, undergoes broad peer review and becomes widely available for community use" (106). ${ }^{10}$ In this context, we might even see the metaphoric extension of the shared teaching story and connected community on the physical plane, as the engaged 
workshop participants are actively sharing and building upon the stories and anecdotes of teaching.

The meta-narrative of teacherly experience (or, in Bruner's terms, the "canonical story" of teaching), in its universality, thus contributes to the potential creation and affirmation of a COMMUNAL experience that is shared amongst teachers, beyond their individual experiences. For the reviewers and workshop participants reading or hearing numerous teacher narratives, from book collections or teacher workshops, the common threads of storylines, characters, and lessons start to connect the individual narratives: it becomes that master narrative which defines the COMMUNITY as a whole.

This assertion may seem contradictory to my argument from the previous section, wherein I addressed the danger of TEACHING-IS-STORY taking over the individual teacher narrative, forcing the narrative trajectory and inhibiting any variation or resistance. This is the point, however, where the importance of considering the two conceptual metaphors working in congress is vital. What the above examples, and many others like them, highlight is the necessary participatory action of the reader in interpretation and comprehension of the teacher narrative. As the teacher narratives accumulate, they contribute to that overarching story of teaching, constructing the tale of the teacher "everyman/woman" to which all teachers can presumably relate. The reader, when invited into this framework, is given the opportunity to inhabit the role of teacher/narrator - to share the victories and to feel the pain of failure (although the latter happens much less often). This is the difference between observing the "twice-told tale" with selfacknowledged STORYING elements within which the reader has no participatory action, as it has already been created as a canonical structure that invites no additional engagement, 
and recognizing the common metaphoric STORY being exhibited through the universality of the narrated teacherly experience. " Just as with the metaphor of TEACHING-Is-STORY, however, there are dangers to be aware of. The metaphoric COMMUNITY that readers may recognize and self-identify with may carry certain commonplaces that instead of being positive or empowering could be silencing or restrictive. One hypothetical example of this, which calls on previously mentioned metaphorizations of the teacher narrative through a religiously-oriented STORYING such as I suggested with Schell's voiced resistance (but, still, invocation) of the "redemption" story, would be if the reader recognizes a narrativization of the teacherly experience that calls up metaphoric images of the teaching community as a religious order. There is already a vein of religious metaphoricity in many aspects of Rhetoric and Composition, describing various parts of the act of writing (Bloom, "Hearing"; Price; Hashimoto), the roles and act of teaching (Tobin; Deletiner; Wandless; Mayes), and the very nature of our discipline (North; D'Angelo; Hesse). In the genre of teacher narrative, when a teacher's negative experience in the classroom cannot be rectified by the act of "redemption," through the "happy ending", the next best thing is martyrdom, wherein the teacher sacrifices his or her own self in pursuit of "the true way." The recognition of such a STORIED narrative, while engaging the reader, may only affirm an acknowledgement of shared suffering that is necessary if one is "called" to the service of the classroom. Being cast in this COMMUNAL role of a religious martyr removes the individual teacher's ability to enact any agency over their own situations, to interpret their own teacherly experience in a transformational way that goes beyond martyrdom. The teacher instead becomes silenced, righteously suffering for the cause - his or her lack of agency permissible within the metaphoric 
COMMUNITY they perceive because of the higher, more "noble" purpose that "all teachers" are called to.

Most important in this convergence of conceptual metaphors is the metaphoric engagement being displayed by both narrator and reader. While the narrator may be consciously employing the metaphor TEACHING-IS-STORY, the reader is consciously recognizing his or her placement within that STORY, becoming part of the STORY rather than simply being a passive recipient of a "master plot" that gives them the "happy ending" through a pre-packaged lesson to be learned and applied in future situations. As the reader engages and interacts with the STORY of teaching, the experience that connects the reader and narrator becomes something more than just a story: it becomes both SHARED and STORIED. This new metaphorization incorporates commonplaces that extend the metaphorization of the teacherly experience beyond TEACHING-IS-STORY. It isn't simply enough to think of the teacher narrative as calling upon common tropes of storytelling; it now accesses a communal narrative tradition that includes a membership that can identify with, and react to, the way individual teacher narratives figure into the larger master narrative that defines both the teacherly experience as well as the teacher/members. At this stage, TEACHING-Is-STORY combines with these new metaphoric engagements to become a shared, communal story. This is the ideal that Stock, Lu, and others call upon when encouraging the proliferation of anecdotes, teaching stories, and teacher narratives. Not only is the teacherly experience part of a master narrative, it is also integral to teachers' self-identification with an "insider membership." The reader/teacher sees not only him or herself in others' teacherly experience, but also 
the combined populations of teachers and scholars that construct the community of Rhetoric and Composition.

In the teacher narrative, the operative element that structures the metaphoric framework of the teacherly experience as more than simply just part of the conceptualization of STORY is the inclusion of the reader's response or reaction to the "narrativized" or STORIED commonplaces. This takes more than calling the teacherly experience a COMMUNAL exercise - by recognizing and engaging with the metaphorized STORY of the teacher narrative, the reader takes on the role of framing the narrative alongside the teacher/narrator, and forges the metaphoric connection to the COMMUNAL qualities of teacherly experience. This metaphoric engagement not only invokes the elements of TEACHING-IS-COMMUNITY, it also acts to mitigate the monologic nature of TEACHING-IS-STORY by allowing the reader to consider the narrated experience as internally persuasive. The participation of the reader, as an equal voice within the metaphorization of the teacherly experience through the narrative, sets a precedent for the final conceptual metaphor within this triadic configuration. In the next section, I present this final metaphor, TEACHING-IS-CONVERSATION, as an expansion of the COMMUNAL space available for other voices to join in the act of shaping the narrated experience as an internally persuasive moment that is openly accessible.

\section{The Dialogic Metaphorization}

The teacher narrative, as envisioned at its most productive, creates not only a shared master narrative of teaching but also a COMMUNITY defined by each teacher's recognition of (and self-identification with) the STORIED elements of that master narrative within their own teaching lives. We have seen how the metaphor of TEACHING-IS-STORY 
is a foundational conceptual framework for the teacher narrative as a genre, both as a constructive (internally persuasive) and potentially dangerous (monologic) force. When the teacher/narrator does not consider his or her fellow readers, as members of the same COMMUNITY, and their response to the narration of the teacherly experience, the STORIED elements of the experience become the main (or only) driving force of the narrative. By the incorporation of the reader's response into the equation, the STORY of teaching transforms into a more mediated and productive model - one that takes into account the metaphoric COMMUNITY of teaching as well as the CONVERSATION that centers around the teacherly experience.

The sharing of teaching stories that Lu, Stock, Bishop, and others refer to as a key element of the teacher narrative functions on both of these two levels: as a recognition of universal stories experienced by both the reader and teacher/narrator that forges the metaphoric bond of TEACHING-IS-COMMUNITY, and as the actual telling of stories that places both parties in a dialogic exchange to make meaning of the narrated experiences, resulting in the metaphoric configuration of TEACHING-IS-CONVERSATION. As Rupert puts it, "we intentionally or unintentionally join the conversation as we see our lives as professionals and that of neighboring colleagues jump off the page" (142). Haswell, in framing the teacher stories of Comp Tales, states that "the best way to read a comp tale is to tell one of your own" (192). The reader is encouraged to join the community by becoming part of the conversation, to share their own experiences as responses to the narrated experiences of others. This is, in fact, what Douglas Reichert Powell is himself doing when he re-inscribes the teacher narrative through the tropes associated with fairy tales: "the 'Once upon a time' for this story goes, 'Well, in my classroom..." (11). Not 
polyphony of voices, multiple readers and multiple narrators, all simultaneously in response and in anticipation of the next inclusion, taking place "not in the past, but right now, that is, in the real present of the creative process" (ibid.).

In addition to Bakhtin's configuration of the dialogic, Kenneth Burke's metaphorization of the "parlor conversation" provides much of the inspiration behind the shaping of the teacher narrative as a conceptual element of TEACHING-IS-CONVERSATION. In The Philosophy of Literary Form, Burke metaphorically places us as part of the "unending conversation" of human interaction (110). Burke echoes Bakhtin's notion of answerability, as no sooner do we join the conversation then "someone answers; you answer him; another comes to your defense; another aligns himself against you" (ibid.). This metaphoric, continuing (and continuous) conversation, the Burkean Parlor, has become a powerful conceptual metaphor engaging multiple perspectives within the field of Rhetoric and Composition - it has become a fundamental and integrated part of how we conceive of ourselves and what we do. It has been metaphorically applied to the classroom as a way for students to understand the research writing process (Davidson \& Crateau; McMillen \& Hill), to the writing center as a way to conceive of the tutoring environment (Lunsford; Neaderhiser \& Wolfe), and, of course, to the reflective practice of interpreting and sharing the teacherly experience (Ballif, Davis, \& Mountford).

In addition to echoing Bakhtin's dialogic ideal, Burke's particular metaphorization of CONVERSATION provides a location from which that conversation occurs: the Parlor. Those who would participate in the CONVERSATION can envision themselves residing in a place, regardless of distance or accessibility, surrounded by other conversationalists who have already participated, are currently engaged, or will be 
potential respondents. This metaphoric Parlor, in turn, can then be transposed upon other sites and locations of potential CONVERSATION - in the case of Rhetoric and Composition, places like the writing center, the classroom, the (real or further metaphorized) staffroom, or even the sections of a journal (such as the now-defunct "Staffroom Interchange" from $C C C$, or the still-running section of Rhetoric Review that bears the name given to the CONVERSATION by Burke). These sites provide not only a venue for the CONVERSATION to continue, but also the identification of participation within the COMMUNITY of teaching conversations.

As so many teacher narratives do appear in publication - as part of essays, journal articles, and books, the metaphoric positionality of the teacherly experience as part of a larger communal CONVERSATION continues to be evident. Not only do readers offer reviews of books within the pages of journals, but also, when the teacher narrative appears in scholarly journals, responses from other readers become part of the CONVERSATION that defines the teacherly experience being narrated. Robert Connors's 1996 essay "Teaching and Learning as a Man," for example, presented a retrospective reflection on his experience of teaching that elicited a strong reaction from many teacher/scholars within the field. Published in College English, Connors' narrative uses a classroom experience with one of his male students (the "villainous" character of this tale) as a lens to clarify his own understanding of gendered discourse and student-teacher relations within Rhetoric and Composition. In "Two Comments on "Teaching and Learning as a Man"' (printed later the same year, also in College English), Patrick McGann and Gesa Kirsch offer their responses - strongly. McGann, for example, voices his struggle with creating a non-confrontational response that opposes Connors's 
interpretation while "step[ping] away from that internalized agonistic response" identified by Connors (964). In addition to voicing his reaction to Connors, though, McGann also inserts his own interpretative reflections into Connors's story and subsequent argument: "Would Connors, for instance, assume that the student who wrote 'Horsing Around' might benefit from feminism? [...] How does this student construct his worth as a man? How might he construct it differently?" (966).

Kirsch, in her response, takes a much more confrontational approach that questions Connors's interpretative argument, which she qualifies as a "nostalgia for days gone by when boys had rites of initiation" that were used to promote and perpetuate "systems of oppression, including homophobia and misogyny [as well as] the domination of many men who participate in such rituals and the ostracism of men who do not" (967). She also questions Connors's use of scholarly support in light of a tradition of feminist scholarship she finds lacking in his essay. Connors, in turn, responds to both McGann and Kirsch, elaborating further on the conversation, but he must consider so much more than what either he or they originally said. The story Connors told has become a conversation with new characters written into it, beyond the ones he initially considered no longer is it only his own reflection on the relationship between himself and the surly male student; new voices and perspectives have become part of the conversation: McGann, Kirsch, the organization NOMAS (the National Organization for Men Against Sexism, first brought up by Connors but emphasized by McGann), the many voices of feminist scholarship that Kirsch calls upon, and even College English, since Kirsch indicts the journal as a whole for publishing "such a partial, poorly documented account of an important educational trend" (968). After Kirsch and McGann's responses, Connors 
is able to reply back, and with his reply, his position as member of the extended conversation has shifted: he reasserts certain claims, but he also has to adjust his argument to account for the specific answerability that Kirsch and McGann represent. New topics have entered the conversation, including the differences in McGann and Connors' perspectives as males, as well as the differences in the tone and style in which the two respondents have written. The story has become fully dialogic, and although it could be that Connors didn't "change his mind" or recant after responding to Kirsch and McGann, the threaded nature of the conversation evolving from the narrative retroactively influences that original STORIED account of Connors's personal teacherly experience, beyond a definitive (monologic) interpretation authored by Connors. In the final words of his response, Connors (a bit challengingly) invites the story to continue even further, if Kirsch would be willing to write a piece that meets his expectations of unbiased perspective on the topic of disadvantaged masculinity, ending the dialogic tale with the parting (perhaps a bit taunting) words, "I would eagerly await such a piece" ("Robert" 974).

As the teacher narrative is often seen as a reflective genre that allows an interpretation of a past teacherly experience, the words of both Burke and Bakhtin are particularly salient: the past experience isn't the only thing being highlighted within the dialogic, conversational form of the teacher narrative. Equal to (if not greater than) the past experience being narrated, the interpretative present "of the creative process" of STORYING the teacherly experience involves newly anticipated and answerable voices that exist within and as part of the CONVERSATION along with the teacher/narrator. As so often is the case, some of the best examples of metaphoric engagement with TEACHING- 
IS-CONVERSATION come from instances where the metaphor hasn't been properly “attended to.” Robert Yagelski's essay, "The Ambivalence of Reflection," provides a clear example of what might happen when the narrative becomes actively resistant to the ideal of TEACHING-IS-CONVERSATION. Yagelski attempts to narrativize, to STORY, his account of a negative past teaching moment in which, after transitioning to a new university where he was now working with graduate students rather than undergraduates, he taught a graduate-level course that "became a sometimes tense forum on issues of gender and authority in the classroom and, I felt, on my teaching" (36). Yagelski narrates his experience of teaching in what he diplomatically considers a hostile classroom environment that split between those students who supported his teaching approach (whom he identifies as mainly part-time graduate students and those taking the class for teacher certification) and those who critiqued/criticized the class's approach (mainly fulltime PhD students). Employing Freirian pedagogical theory, as well as Zen Buddhist notions of generosity, Yagelski concludes his interpretation of the personal teacherly experience as one with a "happy ending" of ambivalence, of accepting a certain degree of humility. As often is the case with teacher narratives that relate accounts of "failure" (or at least "not-success"), he treats the experience as a "learning moment" on the nature of teacherly identity.

If we only consider the teacher narrative to be representative only of TEACHINGIs-STORY, this would be where the moment would end - with Yagelski having successfully STORIED his experience, giving it meaning. However, two of his graduate students from that class, Chris Gallagher and Peter Gray, enter into the narrative by way of their own essay, published in response to Yagelski's. In "Ambivalent Reflections: On 
Telling 'True' Stories of the Classroom," Gallagher and Gray challenge Yagelski's conclusions, as well as the STORIED nature of his narrative itself. They ask, "Is this story 'true'? Is Yagelski a reliable narrator of his own experiences?" (653). As respondents as well as (unnamed) "characters" of the original narrative, Gallagher and Gray directly acknowledge the metaphoric CONVERSATION, stating that Yagelski's account is a useful contribution to our field's conversation about 'how to tell true teaching stories.' We view it as an extension of the reflexive, narrativebased knowledge-making project commented on by Ronald, and engaged by writers such as Wendy Bishop, Peter Elbow, Nancy Welch, and Joseph Trimmer. On the other hand, as former students in the Composition Theory course Yagelski describes in the essay, we read it with much...well, ambivalence. (652)

Their ambivalence comes from the way they see Yagelski's interpretation of the "truth" to be drawn from the experience being intertwined with, and undermined by, the narrative's STORIED elements. The "lesson" that Yagelski concludes with only relates to him specifically, as the teacher/narrator( $/$ "hero"). In the process, this self-depiction obscured, or even erased, any results or lessons that Gallagher and Gray, as other "characters" of the STORY, might find relevant to themselves or to other teachers. Yagelski's STORIED narrative has become, even unintentionally, part of a larger CONVERSATION on the narrated teacherly experience.

Gallagher and Gray point out in their response that their intent is not to "engage[e] Yagelski in a representational war, a heroic battle for The Truth" (654). Instead, their intent is to point out the necessity of acknowledging and allowing accessibility for other readings within a text. By pointing out Yagelski's emphasis on his own process as "hero" in the story without attending to the potential of other readings or other voices, Gallagher and Gray show the "finalized" nature of Yagelski's narrative and 
resulting "lesson." When a narrative becomes STORIED, a finalized and monologic utterance, the teacherly experience is "black boxed" in the past, inaccessible for further interpretation. In Bakhtin's words, the monologically STORIED version of the experience, as the only thing left to access, is "an objectivized and finalized image of a dialogue, of the sort usual for every monologic novel" (Problems 63, author's emphasis). The narrated teacherly experience actually rejects any interpretation that resists the original "lesson," thus becoming a pale reflection of the full potential offered by TEACHING-ISCONVERSATION. Gallagher and Gray, reflecting on the original experience that Yagelski refers to as well as the narrated experience he provides, ask, "So where does this leave us? What if we 'have' alternative stories to tell, different 'seemingness"? [...] What would we do with such stories?" (653). Without the awareness, and anticipation, of the potential answerability inherent to the narrated teacherly experience, the remaining STORIED narrative becomes incapable of truly contributing to the larger CONVERSATION of teaching.

After Gallagher and Gray's response, Yagelski offered his response to both their words as well as the original narrative. However, I will not provide any false anticipation that this narrative finally blossomed into a full CONVERSATION despite its rocky beginnings. While Yagelski gracefully accepts Gallagher and Gray's criticism of his STORIED account, his final conclusion is that the full experience stands as a reminder of "the need to be cautious of narrative in general," and that ultimately, neither their [Gallagher and Gray's] story nor mine is anything but a construction of the experience that inevitably misrepresents it. And to include more or different voices would only change that misrepresentation rather than make it 'more true.' ("It's My Story" 657) 
I would argue that Yagelski gets the wrong point, according to his assertions here. As I have argued in this chapter, the combination of the conceptual metaphors TEACHING-ISSTORY, TEACHING-IS-COMMUNITY, and TEACHING-IS-CONVERSATION create a shared and relatable teacherly experience that both reflects and shapes the teaching community of Rhetoric and Composition. Instead of creating that multiply metaphorized narrative of teacherly experience, Yagelski only focuses on the STORY itself. Not only does his narrative contain STORIED elements that ultimately guide the final interpretation of the experience, but also, through his defense of that narrative, as well as in Gallagher and Gray's response to it, the only value he appears to see in the publicly disseminated (published, as his essay was) teacher narrative is to show that he indeed does reflect on his own teaching. Before it seems I am being too critical of Yagelski, I would point out that this is his own expressed opinion, as the final words of his response reflect:

The challenge, as I see it, isn't just to make our representations of those experiences 'richer, more complicated - and, yes, more ambivalent,' as Chris and Pete put it - an effort that can easily be self-serving if we're not careful; the challenge is also to tell stories that enable us to confront the difficulties of engaging in this imperfect and decidedly human endeavor of teaching. That's why I wrote my version of the story of that Composition Theory course - a story still being written. ("It's My Story" 657)

In his estimation, even though he states that the story is "still being written," the CONVERSATION of this teacherly experience is over.

While this is only one account, extended through three published moments, this example of a teacher narrative stands in stark contrast to the nature of Connors's exchange with his own respondents. In both cases, the responses attempt to complicate the original narrative, offering interpretations that differ from the narrator/teacher's. However, in Connors's case, the conversation extends to include those voices. This does 
not mean that Connors must necessarily agree with the interpretations provided by McGann and Kirsch, but their responses become alternate readings that flesh out the original narrative. On the other hand, the nature of the teacher narrative as provided by Yagelski is controlled, through the attempt to inhibit the meaning available to readers. Additionally, Yagelski calls into question the value of allowing the narrative to interact with CONVERSATION as a conceptual structure for the teacherly experience he has related. Not every narrative receives this much treatment (as not all teacher narratives are published with responses and reactions from other readers), but the underlying assumptions that Yagelski has for the value of the teacher narrative expose the dangers inherent to anyone treating the narrative as only appealing to the metaphor of TEACHINGIS-STORY. If we are to truly embrace the calls from Lu, Stock, Elbaz-Luwisch and others to share our stories, to find the particularities that make those stories relevant to our own experience, and to help shape the greater framework of teacherly experience, the disparity between these two examples, from Connors and Yagelski, help us to see what happens when those stories are only told, rather than shared as "open-source" narratives wherein the readers can find their own meaning through a CONVERSATIONAL insertion of their own voices.

Again, just as with the instances of metaphoric interactivity that engage TeACHING-Is-COMmUniTy, the metaphoric STORY of the teacherly experience has the potential to be shaped by readers' active engagement of TEACHING-IS-CONVERSATION. In the past examples of teacher narratives in which the metaphor of TEACHING-IS-STORY has become the greatest influence, no longer simply ordering the narrated teacherly experience but instead forced a specific telling of the tale, the narrative becomes a "black 
box" - a sealed unit that can allow no more development. This ending of any interactive elements within the teacher narrative affects the reader and teacher/narrator alike, as they are neither capable of engaging the subsequent metaphors of COMMUNITY or CONVERSATION to continue and enhance the shaping of the narrative as the interpreted teacherly experience. For both Burke and Bakhtin, it is necessary to be continually aware of the perpetual answerability and interaction that fundamentally fosters internally persuasive knowledge to develop from the narrative.

When metaphorized as CONVERSATION, the narrated teaching experience becomes the language of communication that not only allows for a mutual understanding of the conditions of teaching, but also fosters the construction of new knowledge. This is the ideal that Gallagher and Gray, working with Shari Stenberg in the essay "Teacher Narratives as Interruptive," focus on when they present their three separate teacher stories in dialogue, with the interest of goal of seeing "how the connections and tensions between narratives open new possibilities for revising our own pedagogical frameworks" (33). ${ }^{12}$ While TEACHING-Is-CONVERSATION often works in tandem with TEACHING-IsCOMMUNITY, Gallagher et al. provide an example of how the metaphor of CONVERSATION is capable of going beyond the recognition of COMMUNAL affinity by the reader. In this model, the metaphoric CONVERSATION provides a productive sense of difference, of tension, in the interpretations of a singular teacherly experience by the reader and teacher/narrator. ${ }^{13}$ This emphasis on the disjunctures in the CONVERSATION of narrated teacherly experiences is echoed by others as well, with different terms leading to the same ideal. Mimi Orner, Janet Miller, and Elizabeth Ellsworth see it as an effort of juxtaposition, wherein teacher narratives are not only placed alongside each other, but 
embedded within each other, in order to highlight "associations never intended or sanctioned by the interests that construct and require such boundaries" (73), and Michelle Ballif, D. Diane Davis, and Roxanne Mountford employ Lyotard's concept of the differend to interrogate the ways it "affirms the perpetual withdrawal of understanding" (589). In these examples, we can see how the metaphor of CONVERSATION is engaged and developed as a way to construct new understandings of the teacherly experience through complex, multi-voiced readings and interpretations that resist singular readings and univocality - monologic STORYING - without eradicating the presence of the STORY that is still integral to teacher narrative as a genre.

As discussed in the previous section, it is often when the reader/teacher is able to see themselves in the individual teacher narrative, to recognize how the narrated teacherly experience mirrors their own personal experiences as teachers, that their own self-identification with the larger COMMUNITY of teaching is established. However, if the reader is unable to access that narrative further, to voice how they might interpret that shared experience differently (or even how they have had a different outcome to a similar experience), the CONVERSATION of the shared teacherly experience can't go any further. Burke's metaphoric Parlor, as an iteration of the CONVERSATION, gives us the ability to locate a shared space for the COMMUNITY of teaching, exhibited in the pages of disciplinary journals and published monographs as well as in the one-on-one interaction of workshops and personal conversations. It isn't enough though to simply state that the CONVERSATION parallels a COMMUNITY. To create Burke's "unending conversation," or Bakhtin's "unfinalizable dialogism," there must be an exchange between the members of the COMMUNITY past, present, and the anticipated future - the invitation of the 
multiplicity of voices allow for the continuing interpretation and further development of the teacherly experience. The STORY may activate the recognition of similarity (or difference), expanding the (still important) grand narrative of teaching, but to forget or dismiss how the teacher narrative both reflects and contributes to the conceptual metaphors TEACHING-IS-COMMUNITY or TEACHING-IS-CONVERSATION cuts short the full potential reflective capabilities of the genre of teacher narrative that its many champions emphasize.

\section{Conclusion}

As previously stated, the teacher narrative in many ways represents a potential black box to the teacher/narrator. Its function appears to be quite straightforward: it allows the teacher to reflectively account for a teaching experience. The teacher/narrator excavates a "self-teaching moment" by which he or she can better understand his or her pedagogical practice, goals, and ideals. By sharing the narrative, telling the story, the teacher/narrator can offer what he or she has learned to others who might also benefit from the original reflection. In turn, these readers enhance the consideration of the narrated teacherly experience even further as they reflect on how it compares with their own personal experience. This may be what teacher narratives (ideally) do, but when we break open that black box to explore how the narrative becomes metaphorized, the inner workings at play are actually more complex. We see that the varying levels of metaphoric engagement in action within the construction and reception of teacher narratives can lead to very different results.

"When we tell stories about our teaching, we add to the larger conversations of the field." This statement, echoed by so many teachers and scholars about the value of the 
teacher narrative, is packed with metaphoric meaning. While we might consider all human experience to be framed and shaped as stories, part of what Burke calls the "social drama," the telling of teacher narratives is a STORIED event, wherein there are familiar, relatable tropes that conceive of the specific teaching experience. The teacher, as "hero" of many teaching tales, follows certain plotlines and trajectories that are recognizable to other teachers, as they access stores of knowledge both from the field as well as from their own personal experience. As we tell these stories, they also create a larger story, the story of TEACHING itself, which might have multiple plots, characters, and motivations, but still figures in as the grand, master narrative of teaching. This master narrative exists to connect the many teachers of the field together, not just through a similar story, but as part of a metaphoric COMMUNITY that gives a sense of meaning to their actions as part of a shared effort. When teachers read or hear the STORIED teacherly experience from someone else, they are able to access both the greater narrative of teacherly experience as well as the individually specific meaning of that one specific teacher narrative. Equally, this COMMUNITY that is formed by the shared teacherly experience is one in which its many members can speak back to the narrated experience, a CONVERSATION that goes beyond the immediate interaction between the reader/teacher and the specific teacher/narrator. It is also a CONVERSATION with the characters within the story, and one based on past CONVERSATIONAL moments and anticipating how future other members of the COMMUNITY will respond to the things being said at this moment.

In that simple statement above, then, there exist conceptual metaphors that shape and frame what will be told and to whom, how it will be told and why. These three main metaphors, TEACHING-IS-STORY, TEACHING-IS-COMMUNITY, and TEACHING-IS- 
CONVERSATION, all directly influence how the teacherly experience itself is understood. At the very heart of it, of course, is the reflection on our experiences as teachers. But with the teacher narrative, it isn't just that by writing or speaking about those experiences that reflection occurs. Metaphorically, the genre of the teacher narrative is constructed to receive, process, and disseminate those experiences so that they don't stay just within our own heads. Especially with the published teacher narrative, but also in workshops, at conferences, or even in faculty staffrooms and each others' offices, teacher narratives are meant to be shared - to make sense of the teacherly experience not only so it benefits whoever experienced it, but also so it can give meaning to others as a way to approach or understand similar situations, or as a way to frame a larger issue of pedagogy and scholarship.

These metaphors are interlocked and interwoven with each other. However, the value of CONVERSATION or COMMUNITY does often get missed, as teacher/narrators only attend to the needs of the STORY of their teacherly experience. While the metaphor of TEACHING-IS-STORY carries much of the prominence within teacher narratives (again, as human experience is ordered and understood through story), the STORIED teacherly experience (without mitigation through an awareness of TEACHING's metaphoric nature as both a CONVERSATION and a COMMUNITY) can only, at most, be interpreted or made meaningful to the teacher/narrator him or herself, inaccessible and unanswerable by a reader. In still other cases, however, even the teacher/narrator loses meaningful connection to the narrated experience as the STORY takes over control of the reflection, dictating how the narrative will play out. Ultimately, one of the values of the genre of teacher narrative is posited by many to be its ability to be shared. The solely STORIED 
teacherly experience becomes monologic, lacking any internally persuasive discourse. It becomes nothing more than a single voice speaking in a vacuum.

The teacher narrative that becomes a self-packaged, singularizing story may still act as a reflection for the teacher/narrator, but the resistance to responses and interpretations that "read against" the teacher/narrator's intention is still surprising, considering the overall goal voiced by many teachers and scholars to contribute to that larger metaphoric conversation of teacherly experience. ${ }^{14}$ Just as Burke proposes the metaphoric, spatial "place" of the Parlor as where CONVERSATION happens, I might propose the spatial metaphor of FORUM to conceptualize of the combined commonplaces of TEACHING-IS-STORY, TEACHING-IS-COMMUNITY, and TEACHING-IS-CONVERSATION. This metaphoric FORUM of TEACHING draws on modern notions of the online forum, with threaded conversations and community-based sharing of stories and ideas, as well as historicized ideas of the forum, from the town hall meeting dating all the way back to the ancient Greek agora, which represented a shared communal space not only for commerce, but also for legislative decision-making, congregation for worship, and "soap-box" lecturing. ${ }^{15}$ While I think that some teacher/narrators conceive of the accumulation of teachers' stories, into the larger conversation and narrative of teaching, as a metaphoric storehouse with the individual reflective narratives (only accessible to the teacher/narrator) stacked up to show the "wealth" of the discipline, the notion of TEACHING-IS-FORUM refigures the narrated teacherly experience as one sharing space with other experiences, with other members of the COMMUNITY, in a public place where the voices call out responses to multiple individual conversations, blending together into a polyphony of voices reflecting agreement, questioning, tensions and similarity. ${ }^{16}$ And, 
just as the Burkean Parlor is a specific iteration of the conceptual metaphor of CONVERSATION, the specific tripartite nature of STORY, COMMUNITY, and CONVERSATION factor individually into the FoRUM as it stands on the foundations of all three while still ensuring that none of the three metaphors are ignored or overlooked.

Overlooking or dismissing any of these three basic conceptual metaphors when considering the genre of teacher narratives is done at the detriment not only to the individual teacher but also the larger community, conversation, and narrative of TEACHING. Jerome Bruner, channeling the spirit of Victor Turner, points out how individuals associate their own experiences with the "dramas," or narratives, already present around them. He points out that "in time the young entrant into the culture comes to define his own intentions and even his own history in terms of the characteristic cultural dramas in which he plays a part" (67). It is not hard to envision the "young entrant" within the discipline of composition - graduate students and teachers new to the field, attempting to understand their own roles as teachers. When these conceptual metaphors, as powerful shaping forces within the teacher narratives available to the initiate (or even the experienced teacher), are disregarded or left unattended, the teacherly experience is shaped as a monologizing and particularly singular thing, unable of being fully shared or accessed as part of the meaning making process. When the voices and visions of shared teacherly experience are "black boxed," the ability for new teachers to make meaning of their own teacherly experience in relation to teacher narratives is diminished - the envisioned ideals that teacher/scholars carry for the genre of the teacher narrative are stripped away. 
In this chapter, I have excavated the prevalent metaphors at play within the genre of the teacher narrative, as it sets about the task of constructing a conceptualization of teacherly experience as part of a larger notion of TEACHING itself. The three metaphors, of TEACHING-IS-STORY, TEACHING-IS-COMMUnity, and TEACHING-IS-CONVERSATION, come together to create a conception of how the experiential knowledge of individual teachers is utilized to make meaning not only within their own personal pedagogical experience but also as part of the larger community of Rhetoric and Composition. While this focus illuminates many of the aspects of the teacherly, disciplinary identity, one element of the teacherly experience is mainly unexamined - that of the student in relation to that teacherly experience and identity. The absence of such an important element of the classroom dynamic and teacherly consideration is not to be seen as a valuating judgment of the student's role within the consideration of the teacherly experience; instead, this chapter should be read mainly as a foray into how the major metaphors of teacher narratives construct the many ways that teachers are ultimately able to make meaning of their own placement within the classroom, thus enabling them to consider the multiple roles they play in relation to their students, as well as the roles their students play. The more specific metaphoric concepts that guide and inform the teacherly identity as an intimately connected part of the student-teacher relationship, within the classroom, is considered at a higher degree in the next, final chapter.

In the next chapter, I will examine the metaphors teachers use to describe their teaching, their students, and the act of writing as they conceive of it, on a most localized level: through the teaching statements teachers produce as a primary and fundamental representation of their philosophical and conceptual identities. Of chief interest will be an 
exploration of the ways entrants to the discipline attempt to employ many of the metaphors they have come into contact with, through the scholarship and narratives of the discipline, in comparison with the metaphoric identities performed by their more experienced counterparts, such as professors within the field. 


\section{Notes}

'In fact, the notion of "lore" shared amongst teachers precedes much of the written/published teacher narratives and sets different ideals or precedents for how teacher narratives are written. Robert Cummings identifies oral teacher narratives themselves as part of "the departmental lore and myth that seemed to guide graduate instructors' conferencing methods" (214). Even Stephen North's discussion of "practitioner lore" hearkens back to a storytelling practice, before the creation of institutions like NCTE, which recalls a type of epic oral tradition of sharing the teacherly experience within the community of compositionists.

${ }^{2}$ The inclination or temptation to apply STORY elements to narrative is not restricted to teacher narratives. Lee Ann Carroll cites "Following a Script" as one of the standard formats for the student papers she gets in her first-year composition course (918), and Bronwyn Williams notes that the student literacy narrative often follows themes representing the student/narrator in the role of "hero" (343).

${ }^{3}$ Cynthia Lewiecki-Wilson, reviewing several collections of personal teacher narratives, notes that in fact the autobiographical move in such narratives "is deeply complicit in [...] creating a unified and transcendent (male) self as 'hero' of its story" (105). Not only does she focus on the creation of "hero," but she makes the interesting point of the "masculinizing" of such a move.

${ }^{4}$ Convery dates this narrativistic move back to an Augustinian influence. He also makes a strong argument for how this plot element (as I would call it) is a calculated move by teacher/narrators to present a performative, falsely-sincere persona in which the teacher as "main character" is seen as humble, vulnerable, and approachable.

${ }^{5}$ It is quite interesting to observe the many teacher narratives and connected articles whose titles directly address the telling of a true or "real" story (Belzer; Gallagher \& Gray; Ronald; Rupert; Tobin; Yagelski, "It's My Story"). Equally, other titles invoke incredibly specific types of fictional tales: "Life-Saving Stories," "Pomo Blues," "A Personal Odyssey," "The Scarlet Letters," and (my personal favorite, just for its dramatic flair) "Tales of Neglect and Sadism" (Bloom, "Subverting"; Carroll; D'Angelo; Wandless; Taylor \& Holberg).

${ }^{6}$ There have been some "unhappy endings," although not many. In recent years, however, there has been a stronger push to value the "failure" or "blunder" narratives for the value they bring in not matching the expectations of STORIED teaching moments (Tassoni \& Thelin; Belzer).

${ }^{7}$ Not only does Klein invoke the villainous Iago and the Foucauldian panopticon, she also comments on how her retrospective is tinged by a blurred boundary she begins to see between her African students' lives and postcolonial visions of literature. The experience becomes almost dream-like, inaccessible, in its overwhelmingly STORIED nature. Her narrative becomes filled with unanswered questions, with the final question plaintively asking, "What does my teaching do?" (188)

${ }^{8}$ The "Staffroom Interchange" had a metaphoric positioning that seemed to parallel Rhetoric Review's "Burkean Parlor" as a space for conversations about articles and professional concerns, with the additional inclusion of shared stories. Interestingly, Richard Gebhardt notes, in his editorial accompanying the final issue of CCC to include a Staffroom Interchange, that there were those who "grumbled" about the title. It implied, for them, "brief notes tacked on the coffee room bulletin board" (9) - the name was used, according to Gebhardt, by some promotion and tenure committees to "devalue good writing" (10).

${ }^{9}$ Elbaz-Luwisch's article indicates its intimacy with the conceptual metaphor TEACHING-IS-STORY through its full title: "Writing as Inquiry: Storying the Teaching Self in Writing Workshops." Her "verbed" use of "story" inspired my own understanding of the STORIED teacher narrative.

${ }^{10}$ In her essay, Stock is making a move to frame "teacher research" specifically as the ways by which "teachers share and swap anecdotes" ("Toward" 106), which I would consider to be part of the larger genre of teacher narrative. 
${ }^{11}$ This is based on the same distinction that Bakhtin makes between monologic and dialogic discourse within literature. While Bakhtin's iteration of dialogic discourse focuses on the novel, he is not making stating that the novel is always dialogic (or, rather, that every novel is dialogic). He emphasizes the potential of dialogism in any genre - it just so happens that he traces the origin of such discourse, and the most prolific and resonant examples, to the novel. I would make the same assertion regarding the genre of teacher narrative - it has a powerful potential of being "novelized," inviting the voices of others (reader/teachers), but when the metaphor of STORY controls the narrative and the possible interpretations available to the reader (and narrator), the possibility of responsive readings is reduced to one - a monologic transmission.

${ }^{12}$ This ideal, of not only connections but also the tensions evident in teacher narrative, is also noted in Gallagher and Gray's response to Yagelski's narrative, which Yagelski responds to with resistance.

${ }^{13}$ Kenneth Bruffee, John Trimbur, and others have debated the value of tension or "difference" in a related discussion on classroom collaborative learning and the nature of consensus. While Bruffee asserts that "abnormal" discourse of difference necessarily exists outside of normal discourse, where it "sniffs out stale, unproductive knowledge and challenges [...] the authority of the community" (648), Trimbur argues that difference and affinity (dissensus and consensus) work complimentarily, with dissensus representing "the resistance and contestation both within and outside the conversation" (608).

${ }^{14}$ As seen in Schell's firm assertion that her narrative should not be read in certain ways, or Yagelski's suspicion of the inclusion of multiple voices to unearth tensions within teachers' narratives.

${ }^{15}$ The ancient Greek verb agoraomai quite literally means "to agorize" - to speak in the agora, to voice one's mind in the assembly or simply in the public setting.

${ }^{16}$ While the Burkean Parlor is conducive to understanding CONVERSATION, the image of the parlor invokes in my mind a more private arena, with a rather linear conversation occurring. With the FORUM, I envision a more "public," open and overlapping nature of the conversations and membership. 


\section{CHAPTER IV}

\section{INVENTING A TEACHERLY IDENTITY: TEACHING STATEMENTS AND METAPHORIC IDENTITY}

One of the hallmarks of a philosophy of teaching statement is its individuality. However, some general format guidelines can be suggested.

Nancy V.N. Chism, "Developing a Philosophy of Teaching Statement"

A teaching philosophy statement provides the stability and direction during the storms of ambiguity most teachers face in their teaching careers.

Dieter J. Schönwetter et al., "Teaching Philosophies Reconsidered"

The statement of teaching philosophy represents a genre of writing that uniquely examines the singular teaching experience. Whereas the teacher narrative, as discussed in the previous chapter, often emphasizes the metaphorized communal sharing of experiences and identities amongst multiple practitioners within the field, the teaching statement focuses on a teacher's individuality, their ability to recognize their own unique and particular teaching style and philosophies as they stand apart from others, while at the same time fitting into the larger conceptual frameworks of the discipline. This simple statement can be one of the hardest documents a teacher ever has to prepare, and it is typically associated with high-stakes situations such as job applications or tenure files. And yet, despite the teaching statement's ubiquity as a vital aspect of composition teachers' professional development, there has been very little attention paid to it in scholarship. There are, of course, multiple texts (in print as well as via online resources) that give advice on how to structure a teaching statement, but perhaps due to its very 
individualized and personal nature, teachers must, time and time again, "recreate" the genre for themselves as they write their own statements.

Despite the relative paucity of scholarship interrogating the genre, the teaching statement exists as a critical textual moment in which teachers are expected to represent their most central identities as teachers. In the case of Rhetoric and Composition, perhaps more than many other disciplines, this genre represents a nexus point that intimately places the individual teacher alongside the scholarship and identity of the discipline. At this nexus point, we can see some of the most localized and personalized examples of disciplinary metaphors and their effects on individual members of the discursive community. While the introduction of a metaphor is popularly recommended by "advice texts" as a way to "organize one's thoughts" when writing a teaching statement, the way that metaphors get used in these statements often goes beyond mere organization. This is the opportunity for both entrants to the discipline and more experienced teachers to invoke the conceptual metaphors of the field, to show how their philosophies of teaching are "endorsed" by the various metaphors they have been privy to through the conversations and scholarship of the field. Not only are the acts of teaching and learning metaphorized within teaching statements, but so is the very identity of the teacher writing the statement. When teachers invoke metaphors related to the discipline of Rhetoric and Composition, we are able to see how individuals absorb and process these metaphors, interacting with them on a personal level.

In this chapter, I explore these issues by examining statements of teaching philosophy collected from graduate students and professors of Rhetoric and Composition. This study serves a dual purpose. Firstly, it can be seen as providing a vehicle for 
observing the metaphors of the field in action on that localized level. Secondly, by examining the teaching statements of graduate students and professors within the field, we can see how different teachers employ the same metaphors in their statements of teaching philosophy. How do teachers actively employ these metaphors to most effectively convey that identity? And, are there identifiable ways that disciplinary members invoke these metaphors differently, in response to their level of "establishment" within the field?

\section{Review of Literature}

In one way, it seems a natural progression to move from the teacher narrative, as discussed in Chapter 3, to the teaching statement. Certain similarities exist in what the two documents offer. First and foremost, both the teacher narrative and the teaching statement represent a perspective of the teacher, for the sake of reflection on both a personal level and as part of the larger community. Gail Goodyear and Douglas Allchin note that a teaching statement "can serve as an occasion for professional dialogue, growth, and development" (3). Equally, Patricia Stock notes that one of the values of the teacher narrative is in fostering a sort of shared conversation, invoking the notion of dialogue that allows a solitary teacher to connect the narratives to his or her individual experiences, "because in the particularities [of the narrative] they recognize the details of their own teaching circumstances" ("Function" 186). At the same time, while the teaching statement allows for a more localized representation of the teacherly experience, which can ideally be contributive to the metaphoric disciplinary conversation along with teacher narratives, the teaching statement's main objective is to allow the individual teacher to reflexively construct his or her teacherly identity. ${ }^{\prime}$ 
There is little scholarship that explores the teaching statement and its rhetorical placement within pedagogical development and representation. The teaching statement's very individualized nature makes it a quite personal document, painting it as a more private genre of writing: many teachers may have to write a teaching statement, but that statement may not be publicly distributed (unless the teacher explicitly chooses to do so). On the other hand, the teaching statement is not only used for personal, reflective purposes: one of the primary reasons that teachers have for creating a teaching statement is to include it as part of their teacher portfolio, for job applications, tenure, or promotion. Baron Perlman, John Marxen, Susan McFadden, and Lee McCann report that in their study of 156 application files for an assistant professorship position in cognitive psychology, only 35 applicants included a statement of teaching philosophy. Perlman et al. report these findings with a certain level of shock and concern for the valuing of teaching within the field of psychology. They argue that more schools should require a submitted teaching statement for such applications, stating that it "would force applicants to consider pedagogy and provide recruitment committees with valuable information" (104). On the other hand, in the field of Rhetoric and Composition, individuals applying for positions or preparing their files for promotion and tenure are much more likely to expect the teaching statement as a necessary and required element of their file. Thus, the value our discipline places on reflective pedagogy may in fact make a study of the teaching statement even more vital. ${ }^{2}$

Even though the discipline of Rhetoric and Composition may place a higher value on the teaching statement than, say, the field of psychology, the scholarship on statements of teaching philosophy tends to focus on instructional advice to create structured, 
"template-style" statements (Goodyear \& Allchin; Schönwetter et al.). What I find in the scholarship that address teaching statements, then, is a relative lack of examination pertaining to the rhetorical moves that go beyond this structural advice. One cause of this lack is due to the "gray area" in which teaching statements reside - these documents aren't particularly part of a teacher's public professional development (they aren't going to appear on their curriculum vitae, for example). But at the same time, the statement of teaching philosophy plays a vital role in an individual teacher's pedagogical development, both in terms of their own personal reflexivity as a teacher and in regards to their public "success" at representing a teacherly identity in the statement when it is included as part of a teaching portfolio for job acquisition and advancement. In the following sections, I offer a way to look at the teaching statement that addresses both sides of this "gray area," to make a case for the importance of analyzing the statement of teaching philosophy as a representative genre that necessitates certain rhetorical moves. These rhetorical moves are inherently tied to the metaphoric associations teachers make when they describe their teacherly identity, and the ways that this identity connects to both the localized teaching experience as well as the larger conceptual notions of the discipline.

\section{The Occluded Genre}

While the emphasis on pedagogy within Rhetoric and Composition may be more widely recognized than in other fields, the teaching statement still exists as what John Swales calls an "occluded genre" of the professional development of a teacher. In his essay, "Occluded Genres in the Academy," Swales offers a partial list of genres that "assist" the process of professional development, including submission letters (sent with 
articles submitted for publication), application and recommendation letters for job searches, and evaluation letters for tenure or promotion (47). Swales suggests that these genres (and others beyond his partial list) function in an occluded state, working "behindthe-scenes," with one foot in both public and private arenas. These occluded genres play a vital role in the development of a professional academic, slipping in and out of public view at varying levels, presenting an author's scholarly work as well as an overall scholarly identity. While these genres tend to have a formalized structural body, Swales notes that the rhetorical moves that take place within occluded genres often get overlooked because of their position within that gray area between public and private audiences.

Swales's discussion mainly focuses on genres that assist in the development of the research/scholarly identity, but its attention is valuable in application to the teaching statement as well. Just as there are occluded texts and materials that function as part of the research process, residing in a realm that is both public and private, there are certain genres of writing that support the pedagogical imperative in overlapping public and private spheres. In this overlap, we find both the documents of the classroom, such as the syllabus, and the documents of teaching development and assessment, such as the statement of teaching philosophy. ${ }^{3}$ Whether they be research or pedagogical in nature, the importance and relevance of occluded genres to the professional development of scholars and teachers is often minimized, if not overlooked altogether. Swales seeks to compensate for this by presenting his own exploration into the occluded genre of the submission letter. Others have followed in this trend, exploring such genres as dissertation acknowledgments or graduate application materials (Hyland; Samraj \& 
Monk; Shaw \& Okamura). ${ }^{4}$ As I would argue that the statement of teaching philosophy is indeed situated as an occluded pedagogical genre, a similar discussion must occur, one that goes beyond the (at best vague) structural advice or templates often found in the scholarship on teaching statements. Particularly in the case of Rhetoric and Composition, where writing and the teaching of writing is put at the forefront of the discipline, the way this genre is enacted as a representation of the writer's identity becomes increasingly relevant. Additionally, in regards to my own project, the use of metaphor plays an important role in that generic representation of the teacher. In this chapter, and with this study, I endeavor to flesh out the teaching statement, especially when it comes to the metaphors that are endorsed and invoked in this occluded genre.

\section{Enter the Metaphor}

One of the main ways that the teaching statement presents the image of teacherly identity is through the invocation of key conceptual metaphors that display the teacher's pedagogical and theoretical influences, connecting the individual teacher to larger disciplinary conversations. The structural advice on statements of teaching philosophy does often suggest the use of metaphors, although not for their ability to indicate influences, or a connection to larger disciplinary conceptual metaphors. Nancy Van Note Chism argues that writers of teaching statements can benefit from using metaphors for the purpose of framing their discussions in an organized, thematic way: "Drawing comparisons with known entities can stimulate thinking, whether or not the metaphor is actually used in the statement" (2). However, when it comes to teachers actually being pressed to describe how learning occurs, and how a teacher's role fits into the process of learning, Chism suggests that many college teachers "draw a blank." She posits that "this 
is likely due to the fact that their ideas about this are intuitive and based on experiential learning, rather than on a consciously articulated theory. Most have not studied the literature on college student learning and development nor learned a vocabulary to describe their thinking" (ibid.). While it may be true that teachers in many disciplines draw their conceptions of teaching and learning more from experiential evidence rather than from the scholarship of their fields, the examination and discussion of the writing process, as a specific learning process, is a key conversation in Rhetoric and Composition, and has been since the beginning of the discipline. Additionally, there are multiple prevailing metaphors that already frame the discipline, as discussed in previous chapters. By studying teaching statements from within Rhetoric and Composition, then, we should be able to see what metaphors maintain their prevalence in the self-reflective and self-representative writings of individual members of the composition community. In addition to excavating the prevalence of disciplinary metaphors within teaching statements, another pertinent issue involves the degree of interaction and engagement performed by the teacher/writer of such statements. Chism, in the same section as pointed to earlier, encourages writers to consider how metaphors can be extended to cover multiple aspects of teaching. She states, "for example, if student learning has been described as the information processing done by a computer, is the teacher the computer technician, the software, the database?" (2). In this example, Chism advises the writer to use a conceptual metaphor as an entire framework, extending it to more than a single part of the teaching statement - if using LEARNING-IS-INFORMATIONPROCESSING, then the writer should engage this metaphor to describe not only the student, but also the teacher, and even the classroom or course material. 
For my project, preliminary conversations and research led me to believe that the level of metaphoric engagement would differ based on the amount of "experience" the writer/teacher would have. My hypothesis was that "younger" members of the discipline (more accurately defined as "initiates") would be more inclined to attempt to use a single metaphor, such as Chism suggests, in an attempt to present a confident, unified teacherly identity. This is the sort of notion exemplified in Kristine Johnson's essay, "The Millennial Teacher: Metaphors for a New Generation." Johnson relates her own panicked attempt to conceive of her own metaphoric identity as a graduate student preparing to teach for the first time. She states that "once a good operative metaphor is found, it seems to bring everything into focus, just as the gardening metaphor I received has implications for every part of teaching" (11). Several texts seem to mirror this notion, that there is value for the beginning teacher to embody a singular metaphoric identity - Carolyn Hill comments on her own realization that, when she supervised new teachers, she had tried to “initiate [new teaching assistants] all into the nourishing mother role, warm and softedged" (52). On the other hand, then, I expected more experienced members of the field to be more likely to "mix" their metaphors, being more comfortable with multiple teacherly identities specific to different teaching moments and goals. In the following sections, I present a study of a body of teaching statements, to explore the metaphoric interactions that members of the Rhetoric and Composition community make in order to rhetorically construct their identities as teachers and practitioners of composition Methodology

The amount of empirical research done on teaching statements has been limited. Equally, studies of actual teaching statements often have limited their data to singular 
sources or pools, such as applications for a single professorship position or from workshops conducted by the researchers at their home institutions (Perlman et al.; Goodyear \& Allchin; Schönwetter et al.). ${ }^{5}$ While this allows the data collection to remain feasible for the researcher, it also limits the variation one might conceivably find within teaching statements. Teaching statements are used for multiple purposes, including job applications, tenure or promotion files, or even strictly for a level of transparency offered to a teacher's students by the teacher posting a copy of their philosophy of teaching online. The varying motivations that fuel the creation and display of a teaching statement in these different situations betray the notion that an easy fix is possible for the advising of statement creation. However, it is this variation that can be of value for a study such as mine, which hopes to see how the metaphors specific to the field of Rhetoric and Composition find their way into the many different situational moments occupied by teachers in which they must offer a self-reflective representation of their teacherly identity.

In order to examine a broad range of statements of teaching philosophy, this study gathered statements from multiple sources. I requested teaching statements from three professional listservs: WPA-L, ATTW-L, and WCenter. These listservs represent multiple foci and specializations within the composition community (including writing program administration, technical writing, and writing centers), and are populated by graduate students, tenure-track professors, and non-tenured faculty across the country. Through these listservs, I received a total of 33 statements of teaching philosophy, from 31 unique participants. In addition to requests made on the listservs, I requested statements from graduate students at twelve different universities that had strong $\mathrm{PhD}$ 
programs in Rhetoric and Composition. My requests were answered by respondents at four of the twelve schools, for a total of 24 statements received from 20 unique participants. Several individuals sent two statements: I chose to include only the most recent statement unless the two statements represented distinctly different points in the participant's career. ${ }^{6}$ In addition, two statements were deemed invalid: one was submitted as an internet link that was no longer functional, and one was a created as a video teaching statement. ${ }^{7}$ Ultimately, I was able to conduct the study with a total of 50 teaching statements from 49 unique participants.

Instead of separating the statements according to the distinction of "graduate student" or "professor," I chose to use two different group categories: "initiate" and "fluent." For this study, I felt that these terms qualified the two groups more accurately than "age," "status," or "level of education." They do more to indicate the "establishment" of a member within the discipline - at an early stage, still going through phases of becoming "initiated in," or at a stage in which they have spent many years “doing" Rhetoric and Composition. Instead of (inaccurately) relying on a distinction, then, that places graduate students against professors (as well as dismissing any adjunct faculty), I preferred to emphasize this status of "initiate" versus "fluent." Using this distinction between initiate and fluent status, I separated the 50 statements into two groups, based on each participant's amount of time in the field as noted in their answers to brief identifying questions I included in my original request or through follow-up questions after I received their statements. ${ }^{8}$ The ratio of initiate and fluent teaching statements was even, with 25 initiate statements and 25 fluent statements being examined, from a total of 28 different schools. 
To code the body of data, an initial pass was conducted that examined the statements for certain prominent and prevalent conceptual metaphors within the field of Rhetoric and Composition. These metaphors, as noted in previous chapters, included Writing-IS-PROCESS, WrITING-IS-CrAFT, TEACHING-IS-COMMUNITY, and WRITING-ISCONVERSATION. During this pass, the data was also coded for any explicit uses of other metaphors, when the writer acknowledged that they were applying a metaphor to their description (e.g. "sometimes I take on the role of "devil's advocate"). After this initial analysis, the data was further coded through multiple recursive passes for more deeply embedded metaphors. The coding thus accounted for language that invoked disciplinary metaphors (e.g. "students' essays need to contain certain moves to be part of a conversation") as well as conceptual metaphors being used without being explicitly addressed as metaphors (e.g. "this helps students to visualize their audience"). The analysis was also progressively refined to identify both the invocation of a "prepackaged" metaphor, as seen when a writer might simply refer to "the writing process" without further development, as well as the use of metaphors to modify a concept, such as "[writing is] an on-going learning process [students] will be experiencing as long as they live" (thus further modifying WRITING-IS-PROCESS as part of a lifelong journey). To ensure reliability, a sample of 20 statements was coded independently by a second rater, with a $94 \%$ agreement rate.

Through this recursive coding process, patterns such as seen in the above example, metaphorizing PROCESS as a journey, emerged to indicate even other conceptual metaphors being used to frame teachers' philosophies and identities. Accordingly, through the multiple passes, additional metaphoric classes were created to categorize the 
data. The number of teaching statements invoking the categorical conceptual metaphors was recorded, as well as each individual instance of metaphoric interaction as it appeared within the teaching statements. In the collected data, a unique instance was counted each time a conceptual metaphor was invoked, whether directly calling upon the main conceptual element ("their ability to grow as writers") or indirectly indicating an inferred metaphoric extension ("these approaches continue to be fruitful pedagogical applications").

Also in regards to the categorization of unique metaphoric instances, any cases of interwoven metaphoric language creating a type of "mixed metaphor" of more than one conceptual metaphor were coded multiply, in order to quantify each metaphoric concept at play. As an example, in the statement "opportunities for students to [...] 'try on' different writing voices," the metaphoric expression "“try on' different writing voices" was coded as two unique instances - once as the conceptual metaphor VOICE-IS-AGENCY and once as an iteration of WRITING-IS-EXPERIMENTATION. In cases where the two instances could later be resolved into one (such as when one conceptual metaphor is determined to be an extended modification of a second conceptual metaphor, therefore existing in a "nested" relationship), efforts were made to do so."

After being identified and coded, the metaphors were grouped according to how they were integrated into different parts of the teacherly identity and philosophy. Five components were identified as being most commonly included and addressed in the teaching statements: discussions of students, the teacher, the act and method of teaching, the class(/room), and, of course, writing itself. These components were made into separate categories, which were then used to characterize the specific intended 
application of the metaphoric instances coded and recorded. Metaphoric descriptions that encapsulated more than one component (e.g. student and classroom) were counted as multiple, separate instances. The final listed category, of writing, also included metaphors used to provide a conceptual frame for the act and/or process of learning in general, since in many statements the depictions of learning and writing were intimately connected.

\section{Results}

A beginning noteworthy observation regarding the coded data pertains to the sheer volume of metaphors exhibited in the teaching statements, as unique instances of metaphoric interaction. A total of 1,269 individual uses of metaphoric language were identified in the 50 teaching statements, and the original set of conceptual metaphors grew from four categories ("PROCESS," "CRAFT," COMMUNITY," and “CONVERSATION”), to a total of fifteen. Another category was created to act as a "catchall" of sorts, for metaphoric expressions that only appeared a handful of times or less, thus not meriting separate categorical distinction. Collectively, the fifteen categorical metaphors made 319 appearances overlapping the 50 teaching statements (the overlap possible since the categories of metaphors were recorded distinctly for each of the aforementioned five common components). These conceptual metaphors were supported by 934 unique instances of metaphoric language. ${ }^{10}$ Table 1 lists the six categories of conceptual metaphors with the highest occurrences within the teaching statements, by the total count of unique instances as well as by the number of teaching statements within which these individual instances appeared.

A final general note applies to the five different areas framed by these metaphoric instances. As stated, these common components were students, writing (practices, acts, 
etc.), teaching (methods, goals), teachers (roles, identities), and the classroom

(environment, dynamics, etc.). Out of the five components, the one metaphorized the least was the teacher, at 147 unique instances as opposed to nearly double that for students (279), a surprising revelation considering the overall purpose of the teaching statement being the depiction of the teacherly identity. Of course, the other components often indirectly depicted different aspects of a teacher's identity through his or her pedagogical philosophy, but it was striking how infrequently teachers would metaphorize themselves directly. One observation relating to this is that there were occasional direct comments made by teachers stating an apparent resistance to self-metaphorizing, which I will address later. In addition to metaphoric depictions of the teacherly identity (direct or indirect), the act of writing was metaphorized through 293 unique instances - more than any other component.

Table 1: Most frequently used metaphors

\begin{tabular}{|c|c|c|c|c|c|c|}
\hline \multirow[t]{2}{*}{$\begin{array}{l}\text { METAPHOR } \\
\text { CLASS }\end{array}$} & \multicolumn{2}{|c|}{$\begin{array}{l}\text { OVERALL } \\
\text { APPEARANCES OF } \\
\text { THIS METAPHOR } \\
(N=50)\end{array}$} & \multicolumn{2}{|c|}{$\begin{array}{l}\text { INITIATE } \\
\text { TEACHING } \\
\text { STATEMENTS } \\
\text { USING THIS } \\
\text { METAPHOR }(N=25)\end{array}$} & \multicolumn{2}{|c|}{$\begin{array}{l}\text { FLUENT TEACHING } \\
\text { STATEMENTS } \\
\text { USING THIS } \\
\text { METAPHOR }(N=25)\end{array}$} \\
\hline & $\begin{array}{l}\text { Number of } \\
\text { teaching } \\
\text { statements } \\
\end{array}$ & $\begin{array}{l}\text { Count of } \\
\text { unique } \\
\text { instances } \\
\end{array}$ & $\begin{array}{l}\text { Percentage } \\
\text { of teaching } \\
\text { statements }\end{array}$ & $\begin{array}{l}\text { Count of } \\
\text { unique } \\
\text { instances }\end{array}$ & $\begin{array}{l}\text { Percentage } \\
\text { of teaching } \\
\text { statements } \\
\end{array}$ & $\begin{array}{l}\text { Count of } \\
\text { unique } \\
\text { instances } \\
\end{array}$ \\
\hline Visualization & 50 & 271 & $100 \%$ & 152 & $100 \%$ & 119 \\
\hline Craft & 45 & 171 & $96 \%$ & 108 & $84 \%$ & 63 \\
\hline Process & 31 & 97 & $64 \%$ & 53 & $60 \%$ & 44 \\
\hline Journey & 36 & 88 & $72 \%$ & 45 & $72 \%$ & 43 \\
\hline Growth & 24 & 44 & $68 \%$ & 34 & $28 \%$ & 10 \\
\hline Community & 21 & 59 & $52 \%$ & 38 & $32 \%$ & 21 \\
\hline
\end{tabular}

\section{Metaphoric Prevalence, Prominence, and Interactivity}

As seen in Table 1, most of the highest rated metaphors found in the teaching statements are quite recognizable to a member of the Rhetoric and Composition field.

Both the number of teaching statements as well as the counts of unique instances, I would 
argue, is distinctly and separately significant. A conceptual metaphor's overall prevalence and influence within the conversations about the teaching and learning of writing, for example, is well indicated by the number of statements in which it was invoked.

Separately, the count of unique instances was an effective representation of how each metaphor was being developed within the different teacher's discussions. In some cases, the high level of unique instances was a strong reflection of the many ways that teachers were interacting with the metaphor, considering its implications, and creating new metaphoric extensions. In other cases, the high number of metaphoric instances was more indicative of how the corresponding conceptual metaphor had become embedded into the discourse at a level of what Tim Linzey calls "metaphoric assumption," as discussed in Chapter 1. This was most evident in the case of PROCESS.

\section{The Family of Process}

Metaphoric references to WRITING-IS-PROCESS were common and recognizable. However, there were notable differences in how some of the metaphors were incorporated into the teaching statements that went beyond the use of direct or embedded metaphors that indicated the level of interactivity being engaged by the writer. While there were instances in which writers invoked the conceptual metaphor WRITING-ISPROCESS to elucidate detailed understandings of writing and the roles of teachers and students, an overwhelming majority of references to PROCESS were just that: references, without further discussion beyond invoking the commonly understood metaphor of the field. Many statements referred to students having "a reflexive awareness of that process," or needing to "take full advantage of the writing process." At least 50 of the 97 instances of PROCESS were no more than a passing reference to "the writing process" (or 
similar phrasing). However, while references to "the writing process," "processes of learning," and "thinking processes" were often used with little or no further extrapolation, other metaphors that predicate on WRITING-IS-PROCESS were still highly active, as seen in WRITING-IS-JOURNEY, as well as WRITING-IS-GROWTH.

The metaphor of GROWTH can most definitely be seen as a nested example of WRITING-IS-PROCESS, while being separate in the fact that it did not directly call on "processes" to define "growth." All of the 24 unique instances of metaphoric application centered in one way or another around metaphoric commonplaces that recalled Peter Elbow's original metaphor from 40 years ago, WRITING-Is-GROWING. As discussed in Chapter 2, the metaphors of growth, as initiated by Elbow and then expanded by others, often apply to both writer and writing, and this was very much seen in the teaching statements. WRITING-IS-GROWING appeared via direct references, such as in the statement "texts [are] vehicles for growth," as well as in more indirect, embedded metaphors to describe the process of writing or the environment needed encourage growth: "the evolution of an idea from its chaotic beginnings," or "my goal is to create a rich linguistic and rhetorical environment [where] students can flourish." While these statements, set side-by-side, refer to different commonplaces of growth (internal development, organic evolution, cultivation of fertile grounds), they each connect into the network of embedded metaphors that conceptualize WriTiNG-Is-Growing. ${ }^{11}$ This suggests that Elbow's original iteration of WRITING-IS-GROWING is still pertinent and relevant to teachers and writers in the discipline. However, one notable observation about this conceptual metaphor's appearance is that it was overwhelmingly exhibited in the statements of initiates, with only a very small number of appearances within the statements of fluents. 
In contrast, the metaphor of JOURNEY was used by both initiates and fluents nearly equally, showing up in the same number of teaching statements. Like the metaphor of GROWTH, the metaphoric journeys being described were often connected to WRITINGIS-PROCESS, but it was hardly an exclusive relationship between the two concepts. Nearly $30 \%$ of the instances of JOURNEY metaphorized learning itself as a journey, a journey that continues throughout life. There were many ways that this was described by teachers in their statements. Some of the comments focused on the temporal aspect, looking forward to the future in regards to what students would learn in the writing class as well as after the class ended: "long after leaving my classroom," "learning challenges they will encounter throughout their lives," "wherever their education takes them." Metaphoric comments like "assignments outlive the semester time period" and "[students transferring] practices to some as-yet unrealized future work" indicate the ways teachers envision the future benefits of their teaching or the practices learned in class, as being necessary travel items for the students' future journeys. Other comments focused on the spatial aspects of JOURNEY, metaphorically depicting the classroom as a waypoint along the students' (and teacher's) travels, a stopping point wherein "students enter my classroom" with certain expectations and later "leave my class" to continue their journey. Another common metaphoric use of JOURNEY comes in the form of TEACHER-ISGUIDE. This was one of the most common direct metaphoric identities assumed by teachers in their statements, as they envisioned themselves guiding students through the intricacies of learning and writing. Teachers would state that their job was to "guide my students," "provide them guidance," "point them to resources," or have "commitment to see the journey through." However, the journeying and guiding metaphors extended to 
other commonplaces as well, to include how writing was "a map of one's thoughts," or how different strategies represented "multiple pathways" or "routes" towards a writer's goals. One observation regarding the journeying metaphors, however, is that they had a very low rate of occurrence in regards to the student personally (as opposed to how the student's journey would be influenced by what the teacher had to offer). Only $10 \%$ of all metaphoric instances invoking WRITING/LEARNING-IS-JOURNEY depicted the students as active elements within the metaphor, something that suggests certain implications about the level of student agency at play in teachers' use of JoURNEY. Some of these instances included the efforts by students to actively "navigate uncertainty," their involvement in the journeyed "search" or "pursuit" for knowledge and truth, or even the choices they make as to which "skills," "knowledge," or "experiences" they "bring with them" as part of the journey (in other words, their awareness of necessary travel supplies). The majority of other student-oriented metaphorizations of JOURNEY depicted their role in a way that suggests a perceived passivity, wherein the students are clearly being guided (or even steered) with an expectation that their own involvement in the journey is only contingent on which direction they are pointed in and told to go by the teacher.

\section{Constructing the Class and Student}

In addition to metaphors that hearken back to Elbow's metaphoric depictions of WRITING-IS-PROCESS, another familiar metaphor that made a strong appearance in teaching statements was that of CRAFT. Reminiscent of Donald Murray's early metaphorizations of writing through metaphors of carpentry and craftsmanship, the statements often referred to the different components in terms of building, construct, and manipulating raw materials to create a refined product. This conceptual metaphor was 
most often invoked through the use of metaphors about "skills" and "tools": students are (or should be) "equipped" with "the tools to be successful writers," assignments "offer students the tools and awareness," and teachers help students to "build a toolkit of writing skills." Of course, many activities in general necessitate certain skills, but in the teaching statements, such phrases and terms were intimately connected to the notion of construction or creation. Teachers used this metaphor to describe how students "shape their [writing] project and craft a document," "build effective writing practices," and "construct arguments." The strong metaphoric sense of carpentry suggests the emphasis on the practical nature of writing, but also the nature of writing being approachable and learnable - in one case, the teacher stated quite clearly:

I view writing as more than an artistic form in which some people are gifted and others are not. Rather, I understand that writing is a craft, and that great writers are made, not born.

While most teachers of writing wouldn't disagree with this statement, it more exemplifies the efforts that many of the statements exhibited to distance the practice of composition from artistic notions of inspiration and pure talent: writing is a practiced, teachable act in which multiple resources are drawn upon to create something that is a clear reflection of the creator.

The CRAFT metaphor also becomes a strong element in the specific teacherly identity, beyond simply metaphorizing the activities and goals of composition. The teacher often becomes associated with certain roles of artisanship: the carpenter and the architect. Many teachers called upon the metaphor of "scaffolding" to describe their creation of assignments, syllabi, and courses. Additionally, teachers described how they "structure" assignments and pedagogies to provide "framework" that would "build 
around the writing process," as well as their desire to "reinforce and build fundamental skills" in their students. One teacher, describing how she worked not only with composition students but also with graduate student teachers (who would be considered initiates, by the terms of my study) learning to teach for the first time, stated the intended goal of offering "nuts-and-bolts strategies for teaching.,"12

Unlike the more PROCESS-oriented metaphors found in the statements, the CRAFT metaphors also extended frequently into discussions of teaching rhetorical awareness as well. While there were strong uses of the metaphor that centered completely on the actual practice of writing, with $64 \%$ of metaphoric instances directly addressing writing, many teachers also applied it to a lesser degree to the more theoretical considerations of audience, discourse analysis, and knowledge itself. In this way, the CRAFT metaphor indicates something seen in a few of the other conceptual metaphor categories as well, which is the extension of the metaphors into the other desired outcomes in the classroom beyond simply writing abilities. Metaphoric instances of rhetoric were indeed perhaps most frequent within CRAFT, and tended to fall into two categories: metaphors depicting rhetoric as an object of use, and metaphors depicting activities that are made possible by rhetorical awareness. ${ }^{13}$ Much in the way that writing was metaphorized at times as an object of implementation, teachers asserted that "rhetoric $[\ldots]$ is a tool," and that students must "adopt the rhetorical tools and critical skills" necessary for communication in the classroom as well as in the other communities they may be a part of. "Rhetorical forms" were metaphorically to be "implemented" as part of this larger design of interaction, in writing as a classroom practice and as part of an integrated social/cultural discourse, and the different aspects of rhetoric (such as the "rhetorical triangle" of speaker, audience, 
and purpose) are figured both as tools for the design of discourse and as the design, or "framework," itself. Alongside the tool- or implementation-based metaphorization of rhetoric as part of CRAFT, teachers also declared the importance of activity-based rhetorical work through metaphoric CRAFT-work. This was most apparent through the metaphorization of rhetorical knowledge as enabling active construction (and deconstruction): the "construction of audience," the "construction of an ethos," and the figuring of "[rhetorical] modes as building blocks" were common within this specific metaphorization. Additionally, though, the awareness of rhetoric was seen as allowing the active "deconstruct [ing] of rhetoric" (my emphasis). Also, alongside rhetorical concerns, this category offered the ability to employ the metaphoric reference of "social construction": the knowledge emphasized to students would expose "education as a social engineering tool," allowing them to see how "writing shap[es] the world" or allows for "the construction of knowledge." Rhetorical skills, as well as social awareness, become an equally important goal of the teacher through this metaphoric construction.

A final observation regarding the CRAFT metaphor identifies what I would consider an interesting dichotomy, wherein on one hand we have the conceptual metaphor WRITING-IS-CRAFT, while on the other hand we are to see TEACHER-ISARCHITECT - implicitly, builder of students into "sound structures." Several metaphoric instances explicitly noted the need, efforts, or desire to enact a "reinforcement" within students: "reinforce[ing] students' understandings," "reinforcing [their] critical thinking," or designing "mutually reinforcing activities" were all examples that appeared in the statements. Overall, this did not constitute an overwhelming majority of the instances, but it was significant enough amongst the teaching statements using CRAFT metaphors (at 
least $20 \%$ of statements, balanced relatively evenly between fluents and initiates) to note the presence of such a metaphorization.

\section{Seeing and Writing}

As we've worked in reverse through the highest occurring metaphors, we now come to the most highly used metaphor in all of the teaching statements. Metaphors of visualization were prevalent across the board, proportionally appearing in both initiates' and fluents' statements more than any other metaphor. These metaphors included several different variations, and were applied by both groups in almost equal ratios to all of the five common components (students, writing, teaching, teachers, and classrooms). These metaphors included instances of "bringing [certain topics] into focus," "observing a topic" and "viewing writing," or students "viewing themselves as authorities." One of the most common uses of this metaphor came in terms of "reflection." While some might contest the metaphoricity of this term, special care was taken to distinguish between phrases like "I have students write reflections on their writing" and "[the result] is a reflection of student success," to separate more "deadened" uses of the term from others in which "reflection" is a more embedded metaphoric description of visualization, of "seeing the reflection." Similarly, most instances of "focus" were included as metaphoric, totaling 35 instances: while some might see this as another arguably "dead" metaphor, the operative element in most uses of "focus" is the (often unspoken) notion of the teacher as a "lens," bringing elements, ideas, and goals "into focus."

Of course, one of the very most frequent metaphoric uses in this context was directly associated with the idea of "seeing": "I help students see how...," "[students] are able to see writing in action," "I guide students to view themselves as authorities." This 
raises an important point, though - the conceptual metaphor SEEING-IS-KNOWING (since that is chiefly being emphasized by such metaphoric usage) is hardly a novel or revolutionary metaphor, and is by no means only used in Rhetoric and Composition. ${ }^{14}$ What is notable, however, about the presence of this metaphor in the teaching statements is the lack of overt discussion on the metaphor of visualization in the scholarship of the field. While most other metaphors that appeared in the statements, such as WRITING-ISPROCESS or the (much less occurring) metaphor WRITING-IS-CONVERSATION, are also prevalent in scholarship within the field, the metaphor of sight in its application to teaching writing is rarely an explicit point of disciplinary conversations.

A very common implementation of the VISUALIZATION metaphor seen in the teaching statements emphasized the need to make certain things "visible" or "apparent" to students, to inspire recognition in students. This idea of "awareness" occurred at a basic level, in stating a desire to "help students see/view" certain things, but it also developed into a further metaphorization that became its own force within the statements, wherein the insight was made the forefront of the description, as a way to not only view writing, but as a way to view and critically understand the world. In $66 \%$ of the teaching statements, again equally between initiates and fluents, teachers spoke of "lift[ing] the curtain" for students so that they can see, or seeking to "open students' eyes" and having "knowledge thaw before their eyes." Perhaps more so than in any other category, the metaphors associated with SEEING-IS-KNOWING represented the pedagogical enterprise of critical and social awareness that characterizes composition courses as much as the teaching of writing does. 


\section{Frequency and Application of Metaphors}

One of the original points of interest when beginning this study was to discover not only what metaphors were often used by initiates and fluents within the discipline of Rhetoric and Composition, but also what differences there were in the frequency of use between the two groups. At the beginning, I had expected that the examination would result in the confirmation of the hypothesis that initiates were, as a rule, more likely to use a single conceptual metaphor to frame the multiple aspects of their teacherly identity. I imagined that the use of metaphors associated with WRITING-IS-GROWTH to represent the initiate teacher as, perhaps, a "gardener teacher" would then lead to metaphoric associations and commonplaces categorically depicting students in terms of "growth potential" and classrooms as sites of nurturance. Conversely, I expected to observe a larger level of metaphorical variance within the fluents' teaching statements, assuming that they were more comfortable with a "mixed metaphorical" identity. What I found, however, in the body of teaching statements, was closer to the opposite.

Table 2: Individual frequency of metaphor use

\begin{tabular}{|c|c|c|c|c|}
\hline \multirow[t]{2}{*}{$\begin{array}{l}\text { PARTICIPANT } \\
\text { CLASS }\end{array}$} & \multicolumn{4}{|c|}{ PARTICIPANTS' METAPHOR USE PER TEACHING STATEMENT } \\
\hline & $\begin{array}{l}\text { Average } \\
\text { number of } \\
\text { unique } \\
\text { metaphors }\end{array}$ & $\begin{array}{l}\text { Most frequent } \\
\text { number of } \\
\text { conceptual } \\
\text { metaphors }\end{array}$ & $\begin{array}{l}\text { Percentage of } \\
\text { statements with } \\
\text { "overlapping" } \\
\text { conceptual } \\
\text { metaphors* }\end{array}$ & $\begin{array}{l}\text { Percentage of } \\
\text { statements with }+4 \\
\text { "overlapping" } \\
\text { conceptual } \\
\text { metaphors* }\end{array}$ \\
\hline Initiates $(\mathrm{n}=25)$ & 30.20 & 6 & $80 \%$ & $52 \%$ \\
\hline Fluents $(n=25)$ & 20.64 & 4 & $60 \%$ & $12 \%$ \\
\hline
\end{tabular}

* When calculating the "overlap" of metaphors, the "Other" category was excluded, since by nature many of the metaphors in that category were used infrequently, regardless of where applied.

As Table 2 indicates, the frequency by which participants used metaphors in their teaching statements was rather high, regardless of class. However, initiates were in fact more likely to employ a substantially larger set of metaphors, both in terms of unique 
instances of metaphoric language and in terms of multiple conceptual metaphors within a single statement. While my original thought had been that fluents would employ multiple distinctly separate conceptual metaphors, so that one metaphor might conceptualize the student while another conceptualizes the teacher, it was much more common to see "overlap," in that conceptual metaphors would be used in multiple arenas at the same time as others. On top of that, it was decidedly less common to see fluents do this at all, as opposed to a high occurrence rate amongst initiates.

Also, as one might wonder what role the page length of the teaching statements played in the number of metaphors used, I found it to be quite negligible. With the exception of two fluent statements whose lengths were one paragraph and eight pages, respectively, and four initiate statements whose lengths were between 4-5 pages each, all of the statements from both initiates and fluents stayed within the range of 1-3 pages. The pages were formatted (if not originally by the participant, by myself upon collection) to single spacing with one-inch margins. While there were a few statements from fluents which were part of their promotion/tenure documentation and were thus much longer due to the inclusion of non-relevant material regarding research and administration details that did not pertain to their teaching, these sections were not factored into the study, thus bringing their statements about teaching well within the 1-3 page range.

While these results did not confirm the initial hypothesis, another pattern became apparent. As the table shows, initiates were indeed much more likely to "mix" their metaphors, but not in a way that the metaphors represented the same identity. Instead, the data suggests that the metaphoric identities become, as the table description implies, overlapped on top of each other, making one uniform identity unlikely and in fact 
undesirable. On the other hand, the fluents' markedly lower uses in all categories suggests the slightly more focused identity being applied to the multiple categories (although not entirely uniform, clearly).

As an example of this overlap, one representative initiate's teaching statement used metaphoric instances that called on ten different conceptual metaphor categories (slightly more than the average), and overlapped six of these to describe different components of students, teaching, the teacher, writing, and the classroom. The writer metaphorizes students as "lifelong learners," using a common JOURNEY metaphor in the teaching statements to indicate the students' learning processes extending beyond the classroom and into the journey of life itself. Additionally, the writer directs the focus inward, identifying their own status as teacher-as-learner: "I will learn from my students and $[\ldots]$ I, too, will enter a classroom knowing I will be a little different when I finish it." Not only is the teacherly identity itself expressed here as being intimately connected with the act of learning, the classroom becomes metaphorized as a dynamic gateway that invariably pushes students and teacher forward along a path of what the writer calls a "mind altering" learning process. The teacher/writer also applies multiple metaphors of COMMUNITY and VOICE to students, the classroom, and writing/learning itself. There is a desire stated to have "students [...] view themselves as citizens of a larger populace" who "should strive to look beyond themselves" while "not losing sense of their own voice as they examine others" positions." Not only are metaphors of COMMUNITY used to reimagine the classroom as a democratic communal space for training in citizenship, the students' beliefs and values become their voices. Embedded in these metaphorizations is a further conceptual framework of VisUALIZATION. The students are to "view 
themselves" as members of this community, while not losing their other senses (values). Critical and social awareness is thus extended into the realm of visual apparency. The metaphoric instances the writer uses do not stand separate from each other, but instead overlap and work together to create the larger vision of the teacher and their pedagogical ideals. This sort of metaphoric engagement was quite common in the statements, rather than a binaric idea that pits "one metaphor" against "mixed metaphors," as the original hypothesis maintained. $^{15}$

\section{Discussion}

\section{Metaphorizing the Teacherly Identity}

When beginning this study, there were several assumptions and expectations that I had regarding how the metaphoric identities of teachers would be constructed. To begin with, I did expect to see a much different picture when it came to the levels of metaphoric frequency, in regards to how many conceptual metaphors would be used by the two groups of participants and how often those metaphors would appear in each statement. The metaphorization of teacherly identity within the teaching statements is in fact much more of a refined and subtle process than my initial expectations led me to believe. Whereas many of my previous conversations with different teachers had resulted in an idea that the teacher metaphors would appear in the form of "I see myself as [metaphor]," the ways that many teachers actually represented themselves and their identities displayed intricate and engaged levels of interaction that as a rule avoided simply stating, "I am a guide in the classroom." In fact, there were a handful of statements in which the teacher/writers explicitly stated that they did not want to make any such restrictive metaphoric assertion. One such writer said in his statement, 
I can't say that I have any particular "role" to play as an instructor; a good teacher must remain adaptable and adjust to the needs of the moment and the individual learner. In classes and in conferences with students, I have found myself playing the part of a coach, a guide, a tutor, a reference librarian, a technical consultant, a counselor, a lecturer, a taskmaster, a colleague, a devil's advocate, and a sympathetic audience.

And, in fact, this specific participant invoked at least ten different conceptual metaphors throughout the statement, many of them being even different from the ones listed in the above quote. On the other hand, there were some statements in which the writer/teacher explicitly argued that there would be no metaphoric role provided (as opposed to the adaptable one described above). This was often done in conjunction with claims by the writer/teacher that he or she were not influenced by current scholarship as much as by personal teaching experiences: "I do not allow research findings to dictate my teaching methods-I rely more on my own teaching experiences" (author's emphasis). ${ }^{16}$ In both cases, though, the teacher/writers emphasized the value of adaptability that was fundamental to their own teaching identity. This was in turn also the key value they wanted to impart to their students regarding writing: that such acts were indeed adaptable and contingent on the situations in which they arise. Many of the statements echoed both of these sentiments (although not usually as explicitly).

Another assumption regarding teaching statements that comes into question after exploring this data reflects on the advice-oriented structural rubrics that are found so often in print and online, for teachers seeking guidance in writing their teaching statements. In many of these texts, the use of metaphors is not highly acknowledged or emphasized. Granted, Chism suggests that a conceptual metaphor may help to provide a stimulating framework for a teaching statement - the implication, however, is again that the writer of the statement will be consciously using a single metaphor to frame the entire 
statement. Schönwetter et al. recommend the use of metaphor as a productive "building block" for organization, but, unlike Chism's endorsement, they warn against using a metaphor too extensively: "The critical incident or metaphor should be short and should be a starting point or summary point, rather than the focus of the teaching philosophy statement content" (94). ${ }^{17}$ While Schönwetter et al. do not really explain their reasoning for advising against a fleshed out use of metaphors, perhaps their concern is with the "figurative" nature that is commonly associated with metaphor. They may be worried that if a writer relies too much on metaphors, the academic (read: "serious") qualities of the professional (albeit occluded) genre of teaching statement might be sacrificed. On the other hand, Brian Coppola advises the use of a "guiding metaphor," but with the caveat that the teacher/writer must consider the implied metaphoric extensions of his or her teaching styles:

Are students empty vessels into which instructors pour well-organized information? Are students members of the learning team in which instructors are the coaches? In any case, be prepared to add a sentence or two of explanation about your metaphor so that readers get a sense of what you mean. (449)

While this appears to be good advice (especially if, in the wake of Freirian scholarship, one planned to metaphorize composition students as empty vessels), the emphasis of Coppola's point is really in the implied and unspoken statement, "If you're going to use a metaphor, make sure you do it right."

Coppola's advice predicates on the same notion as Chism and Schönwetter et al.'s: that the metaphors are going to be consciously and selectively chosen. However, the typical advice for teaching statements as exemplified in these three texts does not accurately reflect what often happens in statements of teaching philosophy. As seen in 
this study (and disproving my original expectation), the use of a single conceptual metaphor to frame all aspects of the statement is not common, or at all likely. Equally, contra Schönwetter et al. and Coppola, metaphors appear quite frequently and often quite independent of full elucidation. They are not being employed, in most cases, uncritically, but they are equally not always being made such a central point in the teaching statements that they need to be individually and explicitly addressed.

Neither the overall trends of metaphoric inherence nor the differences between the two groups of participants, then, exactly met expectations. However, the patterns that still developed from analyzing their uses of metaphors were highly illuminative. The fact that initiates were more likely, by far, to use both more conceptual metaphors and more metaphoric instances reflects a very high level of metaphoric engagement and interactivity that I would argue matches the initiate's status as entrant into the discipline and disciplinary conversations. The reason that my original hypothesis had been that initiates would use a single metaphor to describe multiple areas of their teaching philosophy was centered around the assumption that initiates, being newer to the scholarly conversations of the field, would be in a position of discovery, much like students first learning the writing process, but also in a position where they would feel pressure to present themselves as "fully coherent" - having a unified identity that shows their comfort and confidence as teachers.

There is at least a degree of conversation in the scholarship that suggests that this assumption is shared by others. As previously mentioned, Kristine Johnson's essay "The Millennial Teacher" depicts a graduate student, an initiate, searching for a unifying metaphor, one that "seems to bring everything into focus" (11). By the end of her essay, 
Johnson has certainly displayed sufficient interactive exploration and metaphoric engagement, but her final judgment is that she is well established within the boundaries of a single metaphor (inspired by Elbow's WRITING-IS-GROWING) and so she signs off by identifying herself as a "specialty violet gardener" (22). While I do not dismiss Johnson's exploration and consideration of several metaphors before settling on TEACHER-AS-

GARDENER, I do find it telling that she uses many of the same metaphors as seen in these teaching statements, with as much variety, even as she is consciously associating herself with one singular conceptual metaphor. ${ }^{18}$ In another example, Peter Elbow himself seems to be speaking out against a perceived pressure to choose a single metaphor with which to identify one's teaching, when he speaks of the problems of "binary thinking":

Yet we seem to be stuck having to occupy only one point along the continuum that students know so well - from being 'tough teachers' to being 'easy teachers.' We often vacillate: 'This term, it's no more Mr. Nice Guy.' But really skilled teachers somehow find ways to occupy more than one point - to do justice to these opposites in all their irreconcilability. ("Uses" 74)

In both of these examples, the discussions center on how or why different teachers make their way towards a singular metaphoric understanding of their own teaching, while the examples garnered from this study seem to show that it's very rare for anyone to truly use only one way to metaphorize themselves, even if they don't fully acknowledge it.

While the initiates did not tend to use a single conceptual metaphor, ${ }^{19} \mathrm{I}$ do think that their use of metaphors still indicated perhaps a more accurate characteristic of interactivity, in the sense of their overlapping use of metaphors. By employing the many different metaphors, in many different contexts, these teacher/writers were able to "try on" many different metaphoric voices, in the same way that so many of them said they encourage their students to, and just like as Johnson does explicitly in her essay (although 
she still feels that she has centered in on a single metaphor). This also agrees with Tim Linzey's argument, as discussed in detail in Chapter 1, in that the earlier stages of a metaphor's "lifespan" inspire a higher level of discovery and exploration amongst discourse communities. While some (rather, many) of these metaphors have been around for quite a while, the metaphors become revitalized and readied for new explorations and applications with each new generation of initiates.

One other particular note of distinction between the two groups came in the form of "citation." In some cases, the writers of statements felt it necessary to include with a metaphor an acknowledgement that "gave credit" to a particular scholar who had also used that metaphor. This was most common in the statements of initiates - over half of the initiates' statements included "citations" for various metaphors, while only $24 \%$ of the fluents participated in this practice. It could be argued that this is simply due to the graduate student condition of feeling expected to display knowledge of the field, but I would suggest that it goes further than that. Ken Hyland, in examining the occluded genre of dissertation acknowledgements, suggests that the "name dropping" that goes on in many acknowledgements, often seen as simply self-promoting and vain, actually is more relevant than people give credit. He states that acknowledgements

often play a metadiscursive role in being physically set apart from the main social and textual product [the dissertation] yet function to both facilitate the construction of this product and to comment on it. They point inward to the text and its author and outward to the factors which help construct them both. (244)

In the same way that these dissertation acknowledgements are physically set apart from the main text they comment on, while at the same time facilitating its production, the teaching statement exists in a "metatemporal" position in relation to the act of teaching. 
The teacher is providing a reflection on his or her teaching practices, as these practices have been enacted in the past, while projecting forward to anticipate how his or her pedagogical philosophy will influence future teaching experiences. In this metatemporal position, the convergence of internal and external influences and philosophies become manifest.

Additionally, just as the acknowledgement provides an inside perspective on the author while addressing the external influences on the author and text, one of the main motivating factors of the teaching statement is to provide an inward look at a teacher's pedagogical identity while acknowledging the disciplinary conversations that have shaped that identity. The teacher, writing about their teaching philosophy, often strives to create a teaching statement that shows their uniqueness and individual style $a s$ a teacher, apart from the larger community, but also their awareness and enactment of the ideals that arise from the disciplinary conversations as a whole (Chism I; Goodyear \& Allchin 5). Hyland notes that the dissertation acknowledgement serves as a sort of academic "gift-giving," in an effort to represent the writer as "academically connected": someone "with a life beyond the page in whom readers may be interested" (246). Equally, the teaching statement represents the teacherly identity as being "pedagogically connected": existing as part of the larger network or conversations of the discipline that indicates both influences and indebtedness to various pedagogical concepts. The metaphors being employed in this context, then, become the connection itself, and by citing the scholarly personages who also use those metaphors, the writer of the teaching statement is able to show their own ability to enact that interactive connectivity between personal philosophy and academic inclusion. Metaphorically speaking, they are able to show that they too are 
part of the conversation, not just simply that they know the conversation. This appears more often in the statements of initiates, which stands to reason, as they are often in the position of having to discover their "pedagogical connections" while simultaneously representing themselves as already having mapped out those connections by the time of writing a statement of teaching philosophy.

\section{Prevailing Metaphoric Sentiments}

It is perhaps unsurprising to see that many of the discipline's metaphors, prevalent in the scholarship of the past decades, made strong appearances within the teaching statements of both initiates and fluents. One of the research interests at the outset of this study was to see exactly how prevalent these metaphors were in teaching statements, and the results seem to reflect their strong positioning and influence in not only the literature of the field but also in the ways that teachers seek to represent themselves as personally invested members of the community. There were, of course, some surprising outcomes, including the relatively low frequency of the metaphors of COMMUNITY and CONVERSATION (both appearing in only $30-40 \%$ of teaching statements). While these two metaphors, as discussed in previous chapters, are used to frame the methods by which composition teachers associate with each other in telling stories and pooling experiences, their use when applied to students was rare, mainly used to describe the ideal environment that the teacher seeks to create in the classroom: a democratic space, where social responsibility and multiple voices are sponsored and valued.

\section{The Family of Process}

The most prevailing metaphors continue, for the most part, to be "the old standbys," revolving around conceptualizations of WRITING-IS-PROCESS that have long 
been a part of the disciplinary conversations. However, most of these metaphors have yet to become stagnant in how they are applied to the individual teaching experience. There were still multiple ways that teachers employed all of these metaphors in inventive and thoughtful ways to frame and shape their experiences and pedagogical imperatives. The one exception that stood out severely was the often cursory reference to "writing processes," calling up WRITING-IS-PROCESS but usually without much more interactive metaphoric engagement than that. This evidence indicates a confirmation of Tim Linzey's idea of "metaphoric assumption." At this stage, Linzey argues, the metaphor is no longer a force of discovery or high interactivity but instead carries a high level of "cognitive significance" within the discourse community, allowing it to be easily recognized and connected to previous conversations due to its proliferation (202). For the metaphor of PROCESS, there certainly seemed to be a level of "trustworthiness" associated with its appearance within the statements, in that the teacher/writer did not have to be worried about whether the reader would need further explanation of the metaphoric association. The downside of this is that these uses of WRITING-IS-PROCESS as an explicit metaphoric appearance did not display a very high level of interactive engagement, which dangerously places the metaphor into a "black box" within which the exploration of both its benefits and risks is not interrogated. In fact, in some of the cases wherein PROCESS was simply invoked with little engagement, the other prevailing metaphors of those statements seemed to paint a picture that seemed very contradictory to the typical ideals that are associated with WRITING-IS-PROCESS as a concept: the teachers became "facilitators" of the process, determining the direction and pace of movement through the process through the "structuring [of] major writing projects" that "guid[ed] students 
through the process" as dictated by the teacher. In essence, PROCESS itself is reformulated as a tool by which the teacher, as one statement put it, can ensure the proper "acquisition of specific skills" by his or her students, as they create "the final product."

Another interesting point, regarding PROCESS metaphors, was the relative lack of metaphors connecting to cognitivist metaphors of the process. There were a handful of statements that referred to the development of "thinking processes," and there were two distinct examples in which the process of writing was described as a "nonlinear process" or a "recursive process," seeming to call upon the various metaphoric applications by scholars such as Flower and Hayes, but little engagement beyond this occurred - in fact, there were an equal number of statements that warned against "overcomputerizing" the process of writing, at the danger that this would "make the composing process algorithmic."

Beyond merely seeing how many times each metaphor was used, a driving interest for this study was to identify how these metaphors reflected the teacherly identities both used by and available to teachers within the field of Rhetoric and Composition. As stated earlier, the explicit acknowledgement or application of a teacherly metaphor was rarer than originally expected, as most statements did not include comments of "I see myself as..." More often, however, the appearance of and engagement with these prevalent metaphors began to form images of the teacherly identity that actually crossed over the statements, reflecting their common benefits as well as risks.

In the case of the conceptual metaphor WRITING-IS-PROCESS, the most coherent shapings of metaphoric teacherly identity came by way of its antecedents, such as in 
WRITING/LEARNING-IS-JOURNEY or WRITING-IS-CRAFT. In metaphors of JOURNEY, for example, I would point to two different identities being metaphorically assumed by the teacher. The first is that of TEACHER-IS-GUIDE. This metaphor was one of the few metaphoric identities that did get explicitly acknowledged to any degree. Not only were there occasions when the metaphor was consciously invoked ("I see myself as a guide to my students"), but many statements contained metaphors that fed into the overall concept of guidance. The teacher metaphorically leads the students through new, sometimes rough, terrain - the guide may have a bit more experience and authority at hand, but still must travel the same trail as the guided students, and so the experience becomes a shared event. In one notable case, an initiate described his previous experience in the Peace Corps, teaching in the war-torn Republic of Georgia. During his stay, he lived in the same areas, on the same roads, as his students, and the learning that occurred during this time was most effective because of how both the daily journey to school and the daily journey of education were so equally shared, as the teacher "walk[ed] the same road as my students."

At the same time, one of the dangers that can become inherent to the metaphor of TEACHER-IS-GUIDE is the trend of passivity associated with students in several statements. In these cases, the teacher was not sharing an exploration with the students: instead the students "needed guidance," and were "mystified by the route" of writing. In these examples, the guiding takes a more directive approach: the teacher takes the wheel, "steering conversation" for students who otherwise might simply go into the "auto-pilot mode they assume when writing." A pertinent point becomes clear when seeing these applications of the GUIDE/JOURNEY metaphor, wherein the student becomes a passive 
agent that must be led along, guided, steered in the right direction: while some of the teacher/writers may have been consciously framing students as hapless, or wandering lost, most uses of the GUIDE/JOURNEY metaphor do not intend to disenfranchise the student. However, when a metaphor is used even with the best of intentions, one must be careful of the baggage, the other metaphoric commonplaces, that come along with the invocation of a metaphor. As discussed in Chapter 1, metaphor theory shows us that there are no explicitly "bad" metaphors - however, without a level of self-awareness when employing these metaphors, it can be quite easy for metaphors (such as TEACHER-AsGUDE or WRITING-As-JOURNEY), left unattended, to "take over" the teacher/writer's original purpose and begin to shape the perception of the student, the teacher, and even writing itself as something much different than what the writer intended.

\section{The Craft(ed/y) Teacher}

Metaphors invoking the idea of WRITING-IS-CRAFT were not only highly common, but were also usually quite direct in their application of the metaphor to literal notions of writing, teaching, and the student/teacher relationship. I believe that this happens for two distinct reasons. The first is that there seems to be a strong trend in the statements that recalls many of the same ideals first brought up by Donald Murray regarding the metaphoric association of writing with the practices of carpentry. Teachers spoke of "collecting resources," "manipulating material," and "building framework" when talking about the act of writing. However, what seemed more salient as a discussion point of this study is how the CRAFT metaphor indicated a particular metaphoric teaching identity. A strong majority of teachers described their methods and efforts in the classroom through these metaphors of construction, design, and implementation. 
Teachers may not be consciously metaphorizing themselves as carpenters, per se, but I would suggest that through these metaphorizations, teachers and students alike become "craftsmen" (or, a more equable term, "artisans"). One statement, in fact, make this connection explicit, as the teacher stated how she endeavored to create a collaborative environment in which she and her students worked "together, as craftspeople."

This metaphoric identity, perhaps best identified as TEACHER-AS-CRAFTSPERSON, offers certain generative associations for the teacher and student to draw on in that collaborative environment for learning - the teacher's role, as CRAFTSPERSON, is to teach the student how to actively appropriate the skills and tools necessary for future craftwork. However, it is also dangerously close to TEACHER-IS-MASTER, which I do believe also became integrated into some metaphoric instances of CRAFT, in statements when the relationship became more reliant on and driven by the power dynamics between teacher and student. In this iteration of the CRAFT metaphor, not only is the teacher clearly and intently in a position of power and knowledge, the student is clearly placed into the subservient role of "apprentice," there to learn the craft and profession only as dictated by the "master." Some statements reflected an awareness of this precarious position between CRAFTSPERSON and MASTER, as seen in one teacher's statement, where she noted her efforts to minimize any sort of "reliance on a master teacher." However, other cases showed teachers addressing the need to "reinforce [students'] critical thinking," provide students with "tools to synthesize and apply material," or "equip [...] students for future composing tasks" according to the skills held chiefly by the teacher, who will be able to evaluate how well "they have mastered the ability to write well." This creates a marked teacherly identity of MASTER while framing the student as a subservient, uninitiated 
apprentice, as opposed to the collaborative teaching and learning experience envisioned by teachers employing the metaphor of CRAFTSPERSON, exemplified by one teacher's comment on creating a classroom that is "more like a true workshop where we engage each other and the material as writers."

Another metaphor that stems from these instances is TEACHER-As-ARCHTECT. The architectural metaphor comes up quite frequently to not only depict the teacher as someone who helps students learn a craft but also as someone who carefully and skillfully creates the design by which that learning will take place. References to "scaffolded interaction" (which at least one initiate cited from James Gee), and the "structure" and "construction" of courses and writing assignments were common. This metaphor of the teacher as architecturally-minded might actually provide a better "container" for the CRAFT metaphor than the distinction I just offered between CRAFTSPERSON and MASTER. There were instances wherein the teacher described his or her efforts to produce an "architectured" space for learning, interaction, and writing these metaphors, such as the Gee-inspired "scaffolded interaction," do emphasize the efforts to create and build a conducive learning environment for students. However, on the other side, there were, as noted, several instances of metaphoric descriptions of the necessity to reinforce, build, or even repair students, through their actions, education, or perceptions. Problematically, this metaphoric application invariably shapes the student as a passive object, receiving the designs and structures being dictated by the teacher. The teacher is providing that structure, those designs, in a calculated way and the student is therefore seen as being uncalculating, by nature needing that structure: as one writer put it, the "scaffolding [will] eventually be removed," conjuring up notions of the training 
wheels coming off of a child's bike. Perhaps some students do need that scaffolding, but the discussions of "structured assignment prompts" seemed restrictive when placed against other more interactive discussions in a small handful of statements that valued the deconstruction of the craft - "dismantling ideas," "breaking down" writing, and stressing the "limitations of these tools."

\section{Teacherly Ways of Seeing}

Wanting to have our students "see something new" is hardly a revolutionary idea, nor is it a particularly uncommon or unfair sentiment. Perhaps it comes as no surprise, then, that SEEING-IS-KNOWING, a conceptual metaphor so integrated into general expressions of human language, would appear as frequently as it did in the teaching statements of this study. What I find striking, however, about the use of this metaphor is that it does clearly create a couple different metaphors of the teacher that are rarely addressed in disciplinary scholarship. One of the teacher metaphors that is generated through the use of VISUALIZATION metaphors is that of TEACHER-AS-LENS. While there were some references to the use of "texts as lenses," the prevailing metaphoric application of this idea of lenses, of providing students with new ways to "read" the world, came through what the teacher could offer. The statements often explained the activities and material of courses as being "focused" around certain goals, objectives, and ideals. ${ }^{20}$ Teachers spoke out against the valuing of "the limited lens of grades" or relying on "hidden practices" of writing, and stated the importance of "making writing the focus," ensuring that "the process [...] becomes visible" or "apparent," thus allowing students "to see" these practices as functional as well as approachable. 
In addition to the teacher acting as a lens for students, providing them with "clear vision" of writing and learning, another metaphoric identity apparent in these metaphoric instances frames the teacher as specifically offering multiple perspectives. Beyond the lens, the metaphor then becomes TEACHER-AS-PRISM. In $44 \%$ of all VISUALIZATION metaphors, this emphasis on "seeing other perspectives" was key. Teachers talked of giving students the opportunity to "access perspectives that lie outside their experience," "shift perspectives," and "view a variety of perspectives." This metaphor stands as a particularly interesting and productive teacherly identity, which also associates with many of the other ideals of the field. JOURNEY metaphors of "multiple pathways," CONVERSATION metaphors of "multiple voices," and other examples of multiplicity all emphasize these same ideals, of allowing the student access to the other views, other perspectives, of life, writing, and social issues. In many statements, teacherly identities of TEACHER-As-PRISM were associated with these other metaphoric approaches, as part of the overlapping that occurred so often. In some of the most developed cases, the metaphors of VISUALIZATION fully worked in tandem with these other metaphors, thus creating a coherent and integrated image of the teaching, learning, and writing relationships that went beyond even the notion of overlap, as seen in the following conclusion to one teacher/writer's statement:

Each of my students will find a different combination of lenses useful, and each of them will focus on different parts of the landscape. And I point out the mountains and the greenery, but they respond by pointing out things I am not able to see on my own, enriching my experience and informing my teaching into the future. And they take the knowledge needed to use the lenses, and maybe a couple of photographs, and they continue down the road to the next class, their careers, and the rest of their lives, as I take my place in the crowd of people who wave at them from their rearview mirror. And the next time they encounter a scenic stop, they already know how to use the equipment and they don't need a guide. So they keep using those 
skills, and though they will trade up to even more complex and useful ways of seeing the world, I think they will remember the vision we shared.

Not only is the teacher offering "lenses" for seeing the world, but the metaphors of JOURNEY, COMMUNITY, DISCOVERY, and TEACHER-AS-LEARNER all come together in this (quite poetic) depiction of the student-teacher relationship, indicating not only the learning that will occur in the course, but how students will continue this learning further on, as they journey through life beyond the classroom.

While these two metaphoric identities for the teacher, shaped by the metaphoric interactivity exhibited in relation to VISUALIZATION as a conceptual framework for the learning that takes place in the composition classroom, seem to have positive and engaging ideals capable of framing effective teaching styles and identifications, there was also an unsettling trend in several uses of VISUALIZATION. Naturally, if the teacherly identity inspires sight, the opposite is blindness. There were instances where the students were indeed depicted as being blind, thus needing a "helper guide" in the form of the teacher to "show them the light." Or, more to the point, the student is not so much totally blind but instead equipped with "blinders" keeping them from seeing the truth of the world, or only able to see it in a particular way. When this metaphorization occurred, the teacher becomes more like a TEACHER-As-CORRECTIVE-LENS. As stated in the results, this became quite apparent in multiple metaphoric associations with the idea of "awareness" - the student is depicted as being unaware, and often by association uncritical, blinded, and resistant to true vision. Students, in this metaphorization, "must attain a proper focus," because they "fail to see" what is available to them and "must learn to see" the world around them with corrected "critical insight." This idea of "failing to see" the world correctly is a dangerous pitfall of VISUALIZATION metaphors - I would 
not argue that (most) teachers are intentionally depicting their students as uncritically blinded, but as the commonplaces come into play through the engaged metaphoric interactivity of both TEACHER-AS-LENS and TEACHER-AS-PRISM, it becomes incredibly important to not forget the metaphoric extensions that accompany the conceptual metaphor.

\section{Conclusion}

The teaching statement is indeed a personal and social document at the same time, and the ways in which the teacherly identity is metaphorically depicted in these statements goes beyond the simple structures advised by much of the published work that considers the genre. The statements examined as part of this study expose many insights regarding the prolific nature not only of specific disciplinary metaphors of Rhetoric and Composition but also of the overall dominance of metaphoric language in application to all aspects of teaching philosophies. Statements of teaching philosophy are perhaps the most indicative sets of documents within the field to see the actual interactive use of metaphors that spans both the published scholarship of the field and the personal experiential perspectives of individual teachers. By looking at these statements, we see that those metaphors that have been intrinsic to the scholarship of the field for decades, like PROCESS, continue to have personally relevant and appealing merit for teachers as they apply the conversations of the field to their own classrooms and students. Additionally, there are dominant metaphors, like VISUALIZATION, whose appearances are hardly as much "new" as they are "unacknowledged" in those same disciplinary conversations produced through the scholarship. 
Certain metaphors appear to be prevalent, and others discovered, but there are also other trends that reaffirm the need to consciously consider our metaphoric associations. In each of the discussed metaphors, there are beneficial and insightful metaphoric extensions that enable certain types of learning and writing. However, there are also dangerous pitfalls that, without critical consideration, can implicate both the teacher and student in an unproductive relationship. Many of these metaphors have the capacity for depicting the student through passivity: the TEACHER-AS-ARCHITECT, for example, can force a shaping of the student as a passive structure, an object that must needs be "reinforced" or "fixed," and both the TEACHER-AS-GUIDE and TEACHER-AsLENS potentially frames the student through "blindness," as incapable of seeing correctly or productively without the guiding, correcting vision of the teacher. This metaphorization is often contradictory to many of the disciplinary ideals that seek to conceptualize the student as an active and authoritative agent of writing and learning. In fact, one of the patterns that emerged from the "catchall" category of "Other" centered around the notion of student "engagement": beyond the idea of students "engaging in texts" (thus "interacting" with them), students were depicted as needing to be engaged needing to be, perhaps, "activated" from an inactive, passive state. This trend spanned many of the metaphors, with the notion of "unengaged" or "passive" students appearing in at least $47 \%$ of the teaching statements.

While this study only offers a limited view on the genre of teaching statements (although collected from a variety of sources and perspectives within the Rhetoric and Composition community), it does indicate the further necessity for metaphoric awareness within the disciplinary conversations and considerations of the teaching and activity of 
writing. One of the most valuable observations to be made from this study, also, is the confirmation of the high level of metaphoric interaction that occurs on a personal level by members of the community. While there are instances of personal metaphors, as well as uncritical invocations of disciplinary metaphors, the strong majority of teachers/writers exhibited an active use of multiple metaphors that drew from several conversations and were applied to several different aspects of their own experience. 


\section{Notes}

'It should be noted that there have been critiques of the teacher narrative that assert that the true underlying objective of such narratives is to achieve that same goal: to establish and represent a positive teacherly identity (Convery; Gallagher \& Gray).

${ }^{2}$ Perlman, et al. certainly note that the field of psychology requires teaching, stating that "instruction takes almost two thirds (64\%) of faculty time" (146). However, their call is for this to be recognized and emphasized more universally by departments in the hiring process, something that one could argue is already a recognized concern of hiring committees within Rhetoric and Composition.

${ }^{3}$ While it could be argued that teacher narratives are also not always public, or at least publicized/shed, the practice of publicly sharing the teacherly experience by way of a teacher narrative is quite common within the field of Rhetoric and Composition - in the form of a published essay or as part of a workshop environment. In these ways, the teacher narrative becomes a quite public document, satisfying one of the major goals of the genre, which is to generate conversation on the specific, contextual application of the pedagogical ideals of the field.

${ }^{4}$ It's probably not too much of a surprise that many studies of this vein have focused on the occluded genres specifically generated by initiate members of academia, such as graduate students, as they apply for degree programs, enter the job market, and complete their dissertations. The aspect of professional development that is emphasized in Swales's vision of occlusion is highly sensitive to the ways that the academic identity is carefully considered and constructed in these documents - just as the genres themselves are liminally part of both public and private discourses, the initiate is often at a transitional moment of entering into a more public identity.

${ }^{5}$ Indeed, even Swales's example study of an occluded genre, in which he examines the submission letter that accompanies articles submitted for publication, draws its data from a single pool, the submission files for the journal English for Specific Purposes.

6 "Before and after," so to speak: as a graduate student and several years later as a professor.

${ }^{7}$ While this one, particularly, represented an interesting take on the genre of the teaching statement by presenting the philosophy multimodally, it proved infeasible for textual analysis alongside the other statements.

${ }^{8}$ Some participants also commented on the amount of time they had taught and studied Rhetoric and Composition in their teaching statements, which helped to identify what their status was at the time of writing the statement.

"One thing that must be acknowledged is the inherent subjectivity of the coding process. While every effort was made to identify the different metaphors being used, some metaphors could be interpreted differently. As an example, with "“try[ing] on' different writing voices," another entirely separate conceptual metaphor that could be seen is WRITING-IS-PERFORMANCE, emphasizing the performative role of writing identities.

${ }^{10}$ Metaphoric expressions within the "Other" category accounted for the remaining 335 unique instances.

"The very notion of "growing" is itself inherently complex, due to multiple and divergent implications that could be associated with the concept of "growth." What particular "objects of growing" students might be metaphorized as, or what metaphoric setting of growth the classroom would be placed in, could vary wildly - as noted in Chapter 2, Elbow's original iteration of WRITING-IS-GROWING as a metaphor for writing includes metaphoric extensions relating to plant/garden growth (attending to the intellectual nutrition of writerly ability), organism evolution (single-celled "ideas" developing into complex arguments), and body growth (the growing size of research and paper development). 
${ }^{12}$ This was an interesting occurrence, as it gave one of the few instances of how individuals of this study might themselves be influencing the metaphoric perceptions of other teachers. In this case, two of the other participants in this study were graduate students who, upon investigation, were from the same school and part of the training course mentioned $-21 \%$ and $26 \%$ of their metaphoric instances, respectively were tied to the concept of CRAFT.

${ }^{13}$ Awareness of "rhetorical construction" and "social construction" were often tied very closely together, even at times conflated entirely.

${ }^{14}$ In fact, the Latin word for "to see" was video.

${ }^{15}$ It is possible, however, to consider that the high use of metaphor that was found in initiates' teaching statements might still be because of their inexperience in terms of "indicisiveness," or the effort to try to answer/represent as many pedagogical identities as possible in order to "cover their bases." I think looking at this as an effort of discovery, of "trying on" identities, while more generous, might also overlook these efforts to appeal to as many audience members as possible. However, it is worth noting that the fluents' statements, as they were often parts of more "refined" job documents (for promotion or tenure) did not appear to reflect this same effort to appeal to multiple identity-bases - they instead spent more time explaining the practical (or, literal?) elements of their metaphoric activities and identities, such as the direct effects on their students as seen through evaluations, responses, and advisory work (typical categories within such portfolios).

${ }^{16}$ This individual, who began their statement with the given quote, went on to use 42 metaphors that were very reflective of dominant and prevalent metaphors that appear in the scholarship and conversations of the field.

${ }^{17}$ Schönwetter et al.'s rubric for a successful teaching statement, however, incongruously includes criteria to evaluate the quality of a statement's metaphor based on how well it links to multiple components within the statement, which would indicate a metaphor's usefulness beyond a "starting" or "summary" point.

${ }^{18}$ Johnson even notes her own use of architectural metaphors, "framing" her teaching, but then quickly moves on.

${ }^{19}$ There were absolutely no teaching statements that only had one conceptual metaphor. Two statements both had the lowest number, three conceptual metaphors, and both had six unique metaphoric instances. One was from an initiate, the other was from a fluent, and they were both less than half a page long, which would account for the lower number of metaphors. It is notable that even the shortest statements still contained multiple metaphors.

${ }^{20}$ Again, as stated in the results section, while some might question the metaphoricity of "focus" due to its commonality in general communication, I would point out the ways that this focus is being perceived of as being the clarification of vision, the emphasis that brings these goals into focus 


\section{CONCLUSION}

\section{UNBOXING THE TEACHING METAPHORS}

I have no quarrel with the use of metaphors (if they are good ones) in talking about metaphor. But it may be as well to use several, lest we are misled by the adventitious charms of our favorites.

Max Black, Models and Metaphors

Ever since Aristotle first identified metaphora as a figurative trope within poetic and rhetorical discourse, writers have weighed in on the value of metaphor, to varying levels of both support and condemnation. I have seen this project as the opportunity to synthesize these varying perspectives on metaphor, for the purpose of examining the teacherly identity within Rhetoric and Composition. Additionally, I believe my analysis of metaphor is congruent with other studies that have endeavored to turn an inward eye on the discipline, to understand not only the nature of our disciplinary subject (writing and rhetoric), but also the nature of how that subject is taught. This project has not sought to simply tabulate a grand list of metaphors for writing and teaching, judging the "good" and "bad" metaphors in order to advise their usage. Nor have I intended to use metaphor simply as a vehicle for talking about other topics altogether - as I have argued at different points in the previous chapters, one cannot extract metaphor from the discipline of Rhetoric and Composition. In her 1994 essay "Reading the Writing Process," Lisa Ede asked, "Can we be more conscious of, and more explicit about, the models and metaphors that animate our research and the narratives that construct us as researchers and teachers?" (41). Ede's call for a greater awareness of the metaphoricity of Rhetoric and 
Composition was a motivating factor initially for my own research in this subject, and a guiding question for this dissertation.

My dissertation's study of metaphor and identity within the field of Rhetoric and Composition answers Ede's call by addressing specific metaphoric conceptual systems that are inherent to the discipline, alongside a developed understanding of the inner workings of metaphor itself. Theories of metaphor are often placed at odds with each other, as they often view metaphoric activity working on different levels. However, discussions of both tension and similarity, figurative language and literality, and the conceptuality of metaphor are all vital to a fully fleshed out comprehension of metaphor that informs this study and any other potential studies that seek to further explore the subject. Philip Eubanks, in "Understanding Metaphors for Writing," spotlights this necessity: "It is not enough that we recognize, in a general way, the substantive ramifications of metaphor, not if we misunderstand the particular metaphors we encounter" (93). As Eubanks notes the "misunderstanding" of particular metaphors, I would add to that the necessity to avoid overlooking those metaphors that we take for granted, as integrated, "black-boxed" elements of the theoretical and pedagogical ideals within the discipline. These black-boxed metaphors, such as PROCESS, STORY, or CONVERSATION, have traveled alongside the discipline as it has grown and developed, but their metaphoric lives are hardly over. I believe that research into these metaphors, and others like them, will help readers and teachers better identify their own metaphoric engagement, in a way that goes beyond an assumption that the metaphors by which they describe writing and teaching are simply figurative devices. 
As teachers enter into the conversations of the field, and even after many years of teacherly experience, it is not uncommon for them to identify with certain metaphors for their teaching style: the "teacher as gardener," the "inspirational evangelist," or even (for better or worse) the "Dead Poets' Society teacher." However, while they may be aware of these explicit metaphors that they've chosen to describe their pedagogical philosophies and identities, do these metaphors always align with the other metaphors that define the discipline, shaping and influencing their teacherly identity? In Chapter IV, for example, teachers on occasion did invoke explicit metaphors for how they viewed themselves in the classroom (as well as metaphors they wanted to distance themselves from). In these cases, however, the actual metaphoricity of their represented teacherly identity extended well beyond that concrete metaphoric identity which was offered up front. The more subtle influences of metaphors such as Process, ARChitecture, GuidanCE, and VISUALIZATION were present. In such cases, the shaping influence of these underlying metaphors made itself known in how not only their teacherly identity was constructed, but also how that teacherly identity was structured against the identity of the student writer.

As found in my study, teachers do tend to invoke multiple, varied metaphors, especially when considering the contextual variance within which the teacherly identity must operate. This is yet another aspect of parallelism between a study of metaphor and a study of the teacherly identity: as with metaphor, there are both similarities and tensions that exist between the multiple figurations of a teacher's identity. As I.A. Richards states, however, "there are very few metaphors in which disparities between tenor and vehicle are not as much operative as the similarities. [...] The peculiar modification of the tenor 
which the vehicle brings about is even more the work of their unlikenesses than of their likenesses" (127). When the metaphoric intersections of the teacherly identity are made apparent, the resulting awareness of similarity and tension does not mean that the teacher must necessarily resist the dynamic relationship they inhabit with the metaphors at play in their identity construction. Instead, the engaged awareness of the tensions between the teacherly metaphors become the grounds by which the teacher's identity becomes more established, more internally persuasive.

In Mikhail Bakhtin's explanation of heteroglossia, he places a high value on the "critical interanimation" that comes when one recognizes how the multiple ideologicallycharged languages (or, in our discussion, the metaphors) of one's identity stand in tension with each other. At this moment of recognition, "the inviolability and predetermined quality of these languages [comes] to an end, and the necessity of actively choosing one's orientation among them [begins]" (Dialogic 296). Likewise, a critical awareness of the metaphoricity of the individual teacherly identity as it extends well beyond a singular teacherly identity brings any tensions or conflicts to the fore, and imbues the teacher with a stronger reflective agency over their placement within those metaphors. As initiates become part of the conversations within Rhetoric and Composition, their exposure to the many perspectives, pedagogies, and metaphors within the field becomes fundamental to their own identity construction. By making our own metaphoric, critical interanimation more explicit, we allow these initiates the opportunity to engage with the conceptual metaphors of the discipline more capably, so that they not only have a stronger role in the shaping of their own teacherly identity, but also so that they can have a recognized, active role in the future iterations and shapings of those conceptual metaphors. 
This has clear merit when considering the initiate entering the conversations and community of Rhetoric and Composition. However, it is equally valuable for the more experienced fluents of the field, as it can be deceptively easy to accept the metaphors of the field as "black boxes," concepts that have long since been "figured out" and stably integrated into the disciplinary identity. It is equally problematic when a recognition of unwelcome metaphoric associations is accompanied by an attempt to discard or exert control over a metaphor. Ann Berthoff, while critiquing metaphorizations of PROCESS as a computer process, states that "any analogy can be faulty or misleading if it is carried too far, of course, but some are more dangerously unstable than others" (6). While such statements, made by others as well, are disquieting to me even simply for their distrustful perspective of metaphor at large, I take more issue at the moment with the caution Berthoff warns towards the instability of metaphor, and her subsequent attempt to halt its use. As I have previously argued, there are no "bad" metaphors; I would not even revise this to say that "unstable" metaphors are "bad." In fact, as Robert Frost states, "all metaphor breaks down somewhere. That is the beauty of it" (723). It is in this instability that we are exposed to the tensive formation of the discipline. Berthoff asserts that metaphors are chiefly valuable "as speculative instruments," offering "ways of seeing the implications of theory" (7). I would argue against this, however, by pointing out that by relegating the role of the metaphor to that of an instrument, a tool, for showing how theory is performed ignores metaphor's own role in the creation (or shaping) of theory. As I have expressed in this project, the (continued) role of metaphors such as PROCESS, CONVERSATION, and STORY do more than simply show us where we've been as a discipline: they also continue to shape the teacherly identities of both established and new 
participants within the discipline. We can identify the instabilities, the tensions, exposed by metaphor, but we are better served to consider how those tensions can be productively employed rather than attempting to dissolve the metaphor entirely.

As stated earlier, this study has not attempted to create a "master list" of metaphors within Rhetoric and Composition. Lakoff and Johnson point out that the pool of conceptual metaphors in human language is hardly finite in size, and I would similarly suggest that an exhaustive accounting of the metaphors teachers use to describe their teacherly identities would be difficult to accomplish, nor is it entirely necessary. Beyond the genre of teacher narratives and teaching statements, however, further analysis of how these metaphors are expressed in other public, as well as occluded, pedagogical and scholarly genres would enrich the understanding of metaphor's activity within Rhetoric and Composition. The electronic listservs and other forums wherein members of the composition community converge (physically as well as digitally) contain multiple discussions that engage heavily with metaphors of the field, as members both express discomfort with certain metaphors and offer helpful (re)visions of metaphoric notions. ${ }^{1}$ Syllabi and other course documents (paper topics, in-class writing prompts, etc.), as well as teaching handbooks, readers, and guides, could also be examined to analyze the metaphoric identities being implied, suggested, or simply assumed as teachers establish their roles within the actual classroom. However, the metaphors of the teacherly identity are hardly one-way in their development and transmission; they are also reciprocated and responded to by students in the classroom (an element that I have left largely unattended in this project). Therefore, this study could be expanded in the future to include the student perspective and role in the construction of teacherly identity. 
I believe this dissertation's study of metaphoric identity can be expanded not only to include a closer examination of the metaphorized student identity, but also to consider how the teacherly identity is metaphorized through the metaphor of TEACHER itself. One of the tensions that often appears when considering the role of the teacher in Rhetoric and Composition is how the teacherly identity reflects the difference between the "real" teacher, in the classroom, and the ideal, idealized vision of what it means to be a TEACHER. This involves more than just the scholarly and pedagogical conversations of the field - intrinsic to the metaphoric TEACHER are views of teacherly identity as seen in popular media and culture, as well as in the expectations of the teacher that a student has upon entering the course. ${ }^{2}$ When reading accounts in teacher narratives that on occasion relate the shock experienced when a classroom experience "goes wrong" due to the student-teacher relationship, I am reminded that these expectations and ideals create a metaphoric role that perhaps may be unattainable, where the tensions between "teacher" and TEACHER become intractably difficult to ameliorate. By acknowledging and addressing the TEACHER-AS-TEACHER metaphor more directly, I believe we may be able to not only smooth the transition for initiates beginning to teach, but also better understand how some metaphoric teacherly identities are shaped before we even have a chance to engage them ourselves.

Metaphors become part of how we live (and teach) by their continued use and evolution, to such a degree that their presence becomes an inherent way by which we conduct our future teaching lives. New members of the Rhetoric and Composition community bring with them new metaphoric meaning, but they are also potentially prefigured, predetermined, if we do not maintain a critical, interactive awareness of the 
metaphors that shape and are shaped by our teacherly experience. And, even though individual teachers may reject or resist certain metaphors as they relate their own teacherly experiences and identities, the collective disciplinary identity is still influenced by these metaphors. Lakoff and Johnson aptly titled their book Metaphors We Live By, and I believe that it is equally apt to see the conceptual metaphors of Rhetoric and Composition as those metaphors we teach by. However, these metaphors are hardly static (or even stable) entities that we can treat as "black boxes" that no longer require transparency or engagement. As Lakoff and Johnson argue, "to operate only in terms of a consistent set of metaphors is to hide many aspects of reality" (221). It is through the shifting, shaping metaphors of Rhetoric and Composition that we can see the potential realities of teacherly identity. 


\section{Notes}

${ }^{1}$ My research request, for example, was sent to the WPA-L listserv in reply to a discussion on militaristic metaphors like "drill sergeants" and "boot camps" being used to describe the writing teacher and classroom/workshop.

${ }^{2}$ Anecdotally, the student expectation of what it means to be a teacher is well described by a "review" given to a fellow graduate student teacher on a popular website where teachers are rated by their students. In this case, the reviewer/rater warned future students of this teacher by saying, "Beware! [The teacher's name] is not really a professor! She is a graduate student!" 


\section{REFERENCES}

Aristotle. Poetics. Ed. Stephen Halliwell. Trans. Stephen Halliwell. Cambridge, MA: Harvard UP, 1995.

--. Rhetoric. Ed. E. Capps, T.E. Page, \& W.H.D. Rouse. Trans. John Herry Freese. NY: G.P. Putnam's Sons, 1926.

Arrington, Phillip K. "Tropes of the Composing Process." College English 48.4 (1986): 325-38.

Bakhtin, Mikhail. Problems of Dostoevsky's Poetics. Ed. Caryl Emerson. Trans. Caryl Emerson. Minneapolis, MN: U of Minnesota P, 1984.

---. The Dialogic Imagination. Ed. Michael Holquist. Trans. Michael Holquist \& Caryl Emerson. Austin: U of Texas P, 1981.

Ballif, Michelle. "What Is It That the Audience Wants? Or, Notes toward a Listening with a Transgendered Ear for (Mis)Understanding." JAC: A Journal of Composition Theory 19.1 (1999): 51-70.

Ballif, Michelle, D. Diane Davis, and Roxanne Mountford. "Negotiating the Differend: A Feminist Trilogue." JAC: A Journal of Composition Theory 20.3 (2000): 583-625.

Bell, Diana Calhoun, and Becky Nugent. "Sites of Resistance." Radical Pedagogy 3.3 (2001). 6 Jul $2009<\mathrm{http}: / /$ radicalpedagogy.icaap.org/content/issue3_3/3bellandnugent.html>.

Belzer, Alisa. "Blundering Toward Critical Pedagogy: True Tales from the Adult Literacy Classroom." New Directions for Adult and Continuing Education 102 (2004): 5-13.

Berthoff, Ann E. The Making of Meaning: Metaphors, Models, and Maxims for Writing Teachers. Montclair, NJ: Boynton/Cook, 1981.

Bishop, Wendy. "A Rhetoric of Teacher-Talk - Or How to Make More Out of Lore." Under Construction: Working at the Intersections of Composition Theory, Research, and Practice. Ed. Christine Farris \& Christopher M. Anson. Logan: Utah State UP, 1998. 217-33.

Bizzell, Patricia. "Cognition, Convention, and Certainty." PRE/TEXT 3.3 (1982): 213-43. 
Black, Max. Models and Metaphors: Studies in Language and Philosophy. Ithaca, NY: Cornell UP, 1962.

---. "More about Metaphor." Metaphor and Thought. 2nd ed. Ed. Andrew Ortony. NY: Cambridge UP, 1993. 19-41.

Bleakley, Alan. "Writing with Invisible Ink: Narrative, Confessionalism and Reflective Practice." Reflective Practice 1.1 (2000): 11-24.

Bloom, Lynn. "Hearing Our Own Voices: Life-Saving Stories." Writing Ourselves Into the Story: Unheard Voices from Composition Studies. Ed. Sheryl I. Fontaine \& Susan Hunter. Carbondale, IL: Southern Illinois UP, 1993. 89-102.

---. "Subverting the Academic Master Plot." Narration as Knowledge: Tales of the Teaching Life. Ed. Joseph Trimmer. Portsmouth, NH: Boynton/Cook, 1997. 11626.

Brandt, Deborah. Literacy as Involvement: The Acts of Writers, Readers, and Texts. Carbondale: Southern Illinois UP, 1990.

Bruffee, Kenneth A. "Collaborative Learning and the 'Conversation of Mankind'." College English 46.7 (1984): 635-52.

Bruner, Jerome. Actual Minds, Possible Worlds. Cambridge, MA: Harvard UP, 1986.

Burke, Kenneth. The Philosophy of Literary Form: Studies in Symbolic Action. Berkeley: $\mathrm{U}$ of California P, 1974.

Carroll, Lee Ann. "Pomo Blues: Stories from First-Year Composition." College English 59.8 (1997): 916-33.

Chism, Nancy V.N. "Developing a Philosophy of Teaching Statement." Ed. Kay H. Gillespie. Essays on Teaching Excellence: Toward the Best in the Academy. 9.3 (1998): 1-2.

Coe, Richard M. "An Apology for Form; Or, Who Took the Form out of the Process?" College English 49.1 (1987): 13-28.

Coles, Robert. The Call of Stories: Teaching and the Moral Imagination. Boston: Houghton Mifflin Harcourt, 1989.

Connors, Robert J. "Composition History and Disciplinarity." History, Reflection, and Narrative: The Professionalization of Composition, 1963-1983. Ed. Mary Rosner, Beth Boehm, \& Debra Journet. Stamford, CT: Ablex, 1999. 3-21.

---. "Robert J. Connors Responds." College English 58.8 (1996): 968-74. 
---. "Teaching and Learning as a Man." College English 58.2 (1996): 137-57.

Convery, Andy. "Listening to Teachers' Stories: Are We Sitting Too Comfortably?" International Journal of Qualitative Studies in Education 12.2 (1999): 131-46.

Coppola, Brian P. "Writing a Statement of Teaching Philosophy." Journal of College Science Teaching 31.7 (2002): 448-54.

Culley, Margo, and Catherine Portuges. Gendered Subjects: The Dynamics of Feminist Teaching. Boston: Routledge, 1985.

Cummings, Robert E. "Student-Teacher Conferencing and the Graduate Instructor: Searching for Balance and Style in Conferencing Pedagogy." In Our Own Voice: Graduate Students Teach Writing. Ed. Tina Lavonne Good \& Leanne B. Warshauer. Boston: Allyn \& Bacon, 2000. 212-20.

D’Angelo, Frank. "Professing Rhetoric and Composition: A Personal Odyssey." History, Reflection, and Narrative: The Professionalization of Composition, 1963-1983. Ed. Mary Rosner, Beth Boehm, \& Debra Journet. Stamford, CT: Ablex, 1999. 269-81.

Davidson, Donald. "What Metaphors Mean." On Metaphor. 2nd ed. Ed. Sheldon Sacks. Chicago: U of Chicago P, 1979. 29-45.

Davidson, Jeanne R., and Carole Ann Crateau. "Intersections: Teaching Research through a Rhetorical Lens." Research Strategies 16.4 (1998): 245-57.

Deletiner, Carole. "Negotiating the Negotiated Curriculum." In Our Own Voice: Graduate Students Teach Writing. Ed. Tina Lavonne Good \& Leanne B. Warshauer. Boston: Allyn \& Bacon, 2000. 95-104.

Derrida, Jacques. "White Mythology: Metaphor in the Text of Philosophy." Margins of Philosophy. Trans. Alan Bass. Chicago: U of Chicago P, 1982. 207-71.

Ede, Lisa. "Reading the Writing Process." Taking Stock: The Writing Process Movement in the '90s. Ed. Lad Tobin \& Thomas Newkirk. Portsmouth, NH: Boynton/Cook, 1994. 31-44.

Elbaz-Luwisch, Freema. "Research on Teachers' Knowledge: The Evolution of a Discourse." Journal of Curriculum Studies 23.1 (1991): 1-19.

-... "Writing as Inquiry: Storying the Teaching Self in Writing Workshops." Curriculum Inquiry 32.4 (2002): 403-28. 
Elbow, Peter. "Reflections on Academic Discourse: How It Relates to Freshmen and Colleagues." College English 53.2 (1991): 135-55.

.... "The Uses of Binary Thinking." JAC: A Journal of Composition Theory 13.1 (1993): $51-78$.

---. Writing with Power: Techniques for Mastering the Writing Process. New York: Oxford University Press, 1981.

--.. Writing without Teachers. NY: Oxford UP, 1973.

Emig, Janet A. The Composing Processes of Twelfth Graders. Urbana, IL: NCTE, 1971.

Enos, Theresa. "Road Rhetoric - Recollecting, Recomposing, Remaneuvering." Living Rhetoric and Composition: Stories of the Discipline. Ed. Duane H. Roen, Stuart C. Brown, \& Theresa Enos. Mahwah, NJ: Lawrence Erlbaum Associates, 1999. 75-86.

Eubanks, Philip. "Understanding Metaphors for Writing: In Defense of the Conduit Metaphor." College Composition and Communication 53.1 (2001): 92-118.

Faigley, Lester. "Competing Theories of Process: A Critique and a Proposal." College English 48.6 (1986): 527-42.

Flower, Linda. "Taking Thought: The Role of Conscious Processing in the Making of Meaning." Thinking, Reasoning, and Writing. Ed. Elaine P Maimon, Barbara F Nodine, \& Finbarr W O'Connor. NY: Longman, 1989. 185-212.

Flower, Linda, and John R. Hayes. "A Cognitive Process Theory of Writing." College Composition and Communication 32.4 (1981): 365-87.

---. "The Cognition of Discovery: Defining a Rhetorical Problem." College Composition and Communication 31.1 (1980): 21-32.

Freire, Paolo. Pedagogy of the Oppressed. 30th Anniversary Edition. Trans. Myra Bergman Ramos. NY: Continuum International Publishing Group, 2003.

Frost, Robert. Collected Poems, Prose \& Plays. 4th ed. NY: Library of America, 1995.

Fulkerson, Richard. "Composition Theory in the Eighties: Axiological Consensus and Paradigmatic Diversity." College Composition and Communication 41.4 (1990): 409-29.

Funk, Robert W. "Foreword." The Dark Interval: Towards a Theology of Story. Ed. John Dominic Crossan. Sonoma, CA: Polebridge Press, 1988. ix-xiv. 
Gallagher, Chris W., and Peter M. Gray. "Ambivalent Reflections: On Telling 'True' Stories of the Classroom." College Composition and Communication 52.4 (2001): $651-55$.

Gallagher, Chris W., Peter M. Gray, and Shari Stenberg. "Teacher Narratives as Interruptive: Toward Critical Colleagueship." symploke 10.1 (2002): 32-51.

Gebhardt, Richard C. "Editor's Column: Diversity in a Mainline Journal." College Composition and Communication 43.1 (1992): 7-10.

Geisler, Cheryl. "Toward a Sociocognitive Model of Literacy: Constructing Mental Models in a Philosophical Conversation." Textual Dynamics of the Professions: Historical and Contemporary Studies of Writing in Professional Communities. Ed. Charles Bazerman \& James Paradis. Madison, WI: U of Wisconsin P, 1991. 171-90.

Goodman, Nelson. Languages of Art: An Approach to a Theory of Symbols. Indianapolis: Bobbs-Merrill, 1968.

Goodyear, Gail E., and Douglas Allchin. "Statements of Teaching Philosophy." To Improve the Academy. Ed. Matthew Kaplan. Stillwater, OK: New Forum Press and the Professional and Organizational Development Network in Higher Education, 1998. 103-22.

Gorrell, Robert M. "How to Make Mulligan Stew: Process and Product Again." College Composition and Communication 34.3 (1983): 272-77.

Graham, Margaret Baker, and Patricia Goubil-Gambrell. "Hearing Voices in English Studies." JAC: A Journal of Composition Theory 15.1 (1995): 103-20.

Hairston, Maxine. "The Winds of Change: Thomas Kuhn and the Revolution in the Teaching of Writing." College Composition and Communication 33.1 (1982): 7688.

Halverson, Christine A. "Activity Theory and Distributed Cognition: Or What Does CSCW Need to DO with Theories?" Computer Supported Cooperative Work 11.1 (2002): 243-67.

Harlow, Roxanna. “'Race Doesn't Matter, but...': The Effect of Race on Professors' Experiences and Emotion Management in the Undergraduate College Classroom." Social Psychology Quarterly 66.4 (2003): 348-63.

Hashimoto, I. "Voice as Juice: Some Reservations about Evangelic Composition," College Composition and Communication 38.1 (1987): 70-80. 
Haswell, Richard H, and Min-Zhan Lu, eds. Comp Tales: An Introduction to College Composition through Its Stories. NY: Longman, 2000.

Hays, Janice. "Intellectual Parenting and a Developmental Feminist Pedagogy of Writing." Feminine Principles and Women's Experience in American Composition and Rhetoric. Ed. Louise Wetherbee Phelps \& Janet A Emig. Pittsburgh, PA: U of Pittsburgh P, 1995. 153-90.

--. "Models of Intellectual Development and Writing: A Response to Myra Kogen et al." Journal of Basic Writing 6.1 (1987): 11-27.

Hesse, Douglas D. "2005 CCCC Chair's Address: Who Owns Writing?." College Composition and Communication 57.2 (2005): 335-57.

Hill, Carolyn. Writing from the Margins: Power and Pedagogy for Teachers of Composition. NY: Oxford UP, 1990.

Hill, Carolyn Ericksen. Writing from the Margins: Power and Pedagogy for Teachers of Composition. NY: Oxford UP, 1990.

Hinman, Lawrence M. "Nietzsche, Metaphor, and Truth." Philosophy and Phenomenological Research 43.2 (1982): 179-99.

Holbrook, Sue Ellen. "Women's Work: The Feminizing of Composition." Rhetoric Review 9.2 (1991): 201-29.

Hollan, James, Edwin Hutchins, and David Kirsh. "Distributed Cognition: Toward a New Foundation for Human-Computer Interaction Research." ACM Transactions on Computer-Human Interaction 7.2 (2000): 174-96.

Hyland, Ken. "Dissertation Acknowledgements: The Anatomy of a Cinderella Genre." Written Communication 20.3 (2003): 242-68.

Jalongo, Mary Renck, Joan P. Isenberg, and Gloria Gerbracht. Teachers 'Stories: From Personal Narrative to Professional Insight. San Francisco: Jossey-Bass Publishers, 1995.

Johnson, Kristine. "The Millennial Teacher: Metaphors for a New Generation." Pedagogy 6.1 (2006): 7-24.

Johnson, Mark. The Body in the Mind: The Bodily Basis of Meaning, Imagination, and Reason. Chicago: U of Chicago P, 1987.

Keller, Evelyn Fox. Refiguring Life: Metaphors of Twentieth-Century Biology. NY: Columbia UP, 1995. 
Kent, Thomas. Paralogic Rhetoric: A Theory of Communicative Interaction. Lewisburg: Bucknell UP, 1993.

Kinneavy, James L. "The Process of Writing: A Philosophical Base in Hermeneutics." Composition Theory for the Postmodern Classroom. Ed. Gary A Olson \& Sidney I Dobrin. Albany, NY: SUNY Press, 1994. 7-15.

Klein, Deborah. "Iago Lives in the Panopticon; Or, Teaching Resistance, Granting Respect." College English 62.2 (1999): 169-91.

Kövecses, Zoltán. Metaphor in Culture: Universality and Variation. Cambridge, UK: Cambridge UP, 2005.

Lakoff, George. "Metaphor, Morality, and Politics, Or, Why Conservatives Have Left Liberals in the Dust." Social Research 62.2 (1995): 177-213.

Lakoff, George, and Mark Johnson. Metaphors We Live By. Chicago: U of Chicago P, 1980.

Latour, Bruno. Science in Action: How to Follow Scientists and Engineers Through Society. Cambridge, MA: Harvard UP, 1987.

Lensmire, Timothy J. "The Teacher as Dostoevskian Novelist." Research in the Teaching of English 31.3 (1997): 367-92.

Lewiecki-Wilson, Cynthia. "Reflecting on the (Re-?) Turn to Story: Personal Narratives and Pedagogy." College Composition and Communication 51.1 (1999): 96-109.

Lindemann, Erika. A Rhetoric for Writing Teachers. 3rd ed. NY: Oxford UP, 1995.

Linzey, Tim. "Toward a Life-Span Account of Metaphor.” Metaphor \& Symbol 12.3 (1997): 189-204.

Locke, John. An Essay Concerning Human Understanding. Ed. Alexander C. Fraser. NY: Dover Publications, 1959.

Lu, Min-Zhan. "From Silence to Words: Writing as Struggle." College English 49.4 (1987): 437-48.

Lunsford, Andrea. "Collaboration, Control, and the Idea of a Writing Center." Writing Center Journal 12.1 (1991): 3-10.

de Man, Paul. "The Epistemology of Metaphor." On Metaphor. 2nd ed. Ed. Sheldon Sacks. Chicago: U of Chicago P, 1979. 11-28. 
Mansfield, Margaret A. "Real World Writing and the English Curriculum." College Composition and Communication 44.1 (1993): 69-83.

Mayes, Clifford. "The Teacher as an Archetype of Spirit." Journal of Curriculum Studies 34.6 (2002): 699-718.

McGann, Patrick, and Gesa E. Kirsch. "Two Comments on 'Teaching and Learning as a Man'." College English 58.8 (1996): 964-68.

McMillen, Paula S., and Eric Hill. "Why Teach 'Research as a Conversation' in Freshman Composition Courses? A Metaphor to Help Librarians and Composition Instructors Develop a Shared Model." Research Strategies 20.1-2 (2004): 3-22.

Morgan, Kathryn Pauly. "The Perils and Paradoxes of the Bearded Mothers." The Gender Question in Education. Ed. Ann Diller et al. Boulder, CO: Westview Press, 1996. 124-34.

Murphy, Christina. "Breaking the Print Barrier: Entering the Professional Conversation." Publishing in Rhetoric and Composition. Ed. Gary A. Olson \& Todd W. Taylor. Albany, NY: SUNY Press, 1997. 5-18.

Murray, Donald M. A Writer Teaches Writing: A Practical Method of Teaching Composition. Boston: Houghton Mifflin, 1968.

---. "Teach Writing as a Process Not Product REPRINT." Cross-Talk in Comp Theory. 2nd ed. Urbana, IL: NCTE, 2003. 3-6.

---. "Writing as Process: How Writing Finds Its Own Meaning." Eight Approaches to Teaching Composition. Ed. Timothy R. Donovan \& Ben W. McClelland. Urbana, IL: NCTE, 1980. 3-20.

Neaderhiser, Stephen, and Joanna Wolfe. "Between Technological Endorsement and Resistance: The State of Online Writing Centers." Writing Center Journal 29.1 (2009): 49-77.

Nietzsche, Friedrich. "On Truth and Falsity in their Extramoral Sense." Essays on Metaphor. Ed. Warren A. Shibles. Whitewater, WI: Language Press, 1972. 1-14.

North, Stephen. The Making of Knowledge in Composition: Portrait of an Emerging Field. Upper Montclair, NJ: Boynton/Cook, 1987.

Olson, Gary A. "Publishing Scholarship in Rhetoric and Composition: Joining the Conversation." Publishing in Rhetoric and Composition. Ed. Gary A. Olson \& Todd W. Taylor. Albany, NY: SUNY Press, 1997. 19-33. 
-a. "Toward a Post-Process Composition: Abandoning the Rhetoric of Assertion." PostProcess Theory: Beyond the Writing-Process Paradigm. Ed. Thomas Kent. Carbondale, IL: Southern Illinois UP, 1999. 7-15.

Orner, Mimi, Janet L. Miller, and Elizabeth Ellsworth. "Excessive Moments and Educational Discourses That Try to Contain Them." Educational Theory 46.1 (1996): 71-91.

Ortony, Andrew. "Metaphor, Language, and Thought." Metaphor and Thought. 2nd ed. Ed. Andrew Ortony. NY: Cambridge UP, 1993. 1-16.

Orwell, George. "Politics and the English Language." Shooting an Elephant, and Other Essays. London: Secker and Warburg, 1950. 84-101.

Payne, Michelle. "Rend(er)ing Women's Authority in the Writing Classroom." Taking Stock: The Writing Process Movement in the '90s. Ed. Lad Tobin \& Thomas Newkirk. Portsmouth, NH: Boynton/Cook, 1994. 97-111.

Perl, Sondra. "The Composing Processes of Unskilled College Writers." Research in the Teaching of English 13.4 (1979): 317-36.

Perlman, Baron et al. "Applicants for a Faculty Position Do Not Emphasize Teaching." Teaching of Psychology 23.2 (1996): 103-04.

Petraglia, Joseph. "Writing as an Unnatural Act." Reconceiving Writing, Rethinking Writing Instruction. Ed. Joseph Petraglia. Mahwah NJ: Lawrence Erlbaum Associates, 1995. 79-100.

Plato. Gorgias. Trans. W. R. M. Lamb. Cambridge, MA: Harvard UP, 1914.

Podis, JoAnne, and Leonard Podis. "Pedagogical In Loco Parentis: Reflecting on Power and Parental Authority in the Writing Classroom." College English 70.2 (2007): $121-43$.

Powell, Douglas Reichert. "The Story of the Story Is the Story." Blundering for a Change: Errors \& Expectations in Critical Pedagogy. Ed. John Paul Tassoni \& William H. Thelin. Portsmouth, NH: Boynton/Cook, 2000. 9-23.

Pratt, Mary Louise. "Arts of the Contact Zone." Profession 91. NY: MLA, 1991. 33-40.

Price, Margaret. "Beyond 'Gotcha!': Situating Plagiarism in Policy and Pedagogy." College Composition and Communication 54.1 (2002): 88-115.

Pullman, George. "Stepping Yet Again into the Same Current." Post-Process Theory: Beyond the Writing-Process Paradigm. Ed. Thomas Kent. Carbondale, IL: Southern Illinois UP, 1999. 16-29. 
Quintilian. Institutio Oratoria. London: W. Heinemann, 1921.

Radman, Zdravko. "Difficulties With Diagnosing the Death of a Metaphor." Metaphor \& Symbol 12.2 (1997): 149-57.

Rankin, Elizabeth. "From Simple to Complex: Ideas of Order in Assignment Sequences." JAC: A Journal of Composition Theory 10.1 (1990): 126-35.

-... Seeing Yourself as a Teacher: Conversations with Five New Teachers in a University Writing Program. Urbana, IL: NCTE, 1994.

Reichert, Pegeen. "A Contributing Listener and Other Composition Wives: Reading and Writing the Feminine Metaphors in Composition Studies." JAC: A Journal of Composition Theory 16.1 (1996): 141-57.

Reid, Stephen, ed. Purpose and Process: A Reader for Writers. 4th ed. Upper Saddle River, NJ: Prentice Hall, 2001.

Richards, I. A. The Philosophy of Rhetoric. NY: Oxford UP, 1936.

Ricœur, Paul. The Rule of Metaphor: Multi-Disciplinary Studies of the Creation of Meaning in Language. Trans. Robert Czerny, Kathleen McLaughlin, \& John Costello, SJ. Toronto: U of Toronto P, 1981.

Ritchie, Joy S., and David E. Wilson. Teacher Narrative as Critical Inquiry: Rewriting the Script. NY: Teachers College Press, 2000.

Ronald, Kate. "How to Tell a True Teaching Story." College English 62.2 (1999): 25564.

Rupert, Avis Winifred. "The Real Worlds of Teaching and Doing Writing." The English Journal 90.5 (2001): 141-42.

Samraj, Betty, and Lenore Monk. "The Statement of Purpose in Graduate Program Applications: Genre Structure and Disciplinary Variation." English for Specific Purposes 27.2 (2008): 193-211.

Schell, Eileen. "Feminist (Un)motherhood: Reigning Rhetorics of Mothering Inside and Outside of Academe." JAC: A Journal of Composition Theory 22.3 (2002): 40413.

---. "Reading Student Silences: Working Through Issues of Speaking and Silence in Teaching Women's Autobiography." Concerns 26.3-4 (1999): 102-18. 
Schönwetter, Dieter J. et al. "Teaching Philosophies Reconsidered: A Conceptual Model for the Development and Evaluation of Teaching Philosophy Statements." International Journal for Academic Development 7.1 (2002): 83-97.

Searle, John R. "Metaphor." Metaphor and Thought. 2nd ed. Ed. Andrew Ortony. NY: Cambridge UP, 1993. 83-111.

Shaw, Philip, and Akiko Okamura. "The Letter of Submission: Avoiding the Promotional Genre." IEEE Transactions on Professional Communication 41.4 (1998): 274-76.

Shen, Fan. "The Classroom and the Wider Culture: Identity as a Key to Learning English Composition." College Composition and Communication 40.4 (1989): 459-66.

Shor, Ira. When Students Have Power: Negotiating Authority in a Critical Pedagogy. Chicago: U of Chicago P, 1996.

Silk, Michael. "Metaphor and Metonymy: Aristotle, Jakobson, Ricoeur, and Others." Metaphor, Allegory, and the Classical Tradition: Ancient Thought and Modern Revisions. Ed. G. R. Boys-Stones. NY: Oxford UP, 2003. 115-49.

Stock, Patricia. "The Function of Anecdote in Teacher Research." English Education 25.3 (1993): 173-87.

---. "Toward a Theory of Genre in Teacher Research: Contributions from a Reflective Practitioner." English Education 33.2 (2001): 100-14.

Swales, John. "Occluded Genres in the Academy: The Case of the Submission Letter." Academic Writing: Intercultural and Textual Issues. Ed. Eija Ventola \& Anna Mauranen. Philadelphia: John Benjamins Publishing Co, 1996. 45-58.

Tassoni, John Paul, and William H. Thelin. "Blundering the Hero Narrative: The Critical Teacher in Classroom Representations." Blundering for a Change: Errors \& Expectations in Critical Pedagogy. Ed. John Paul Tassoni \& William H. Thelin. Portsmouth, NH: Boynton/Cook, 2000. 1-8.

Taylor, Marcy, and Jennifer L. Holberg. "'Tales of Neglect and Sadism': Disciplinarity and the Figuring of the Graduate Student in Composition." College Composition and Communication 50.4 (1999): 607-25.

Tobin, Lad. "Bridging Gaps: Analyzing Our Students' Metaphors for Composing." College Composition and Communication 40.4 (1989): 444-58.

---. "Process Pedagogy." A Guide to Composition Pedagogies. Ed. Gary Tate, Amy Rupiper, \& Kurty Schick. NY: Oxford UP, 2001. 1-18. 
---. "Reading Students, Reading Ourselves: Revising the Teacher's Role in the Writing Class." College English 53.3 (1991): 333-48.

---. Writing Relationships: What Really Happens in the Composition Class. Portsmouth, NH: Boynton/Cook, 1993.

Tomlinson, Barbara. "Cooking, Mining, Gardening, Hunting: Metaphorical Stories Writers Tell About Their Composing Processes." Metaphor and Symbolic Activity I.1 (1986): 57-79.

Trimbur, John. "Consensus and Difference in Collaborative Learning." College English $51.6(1989): 602-16$.

Trimmer, Joseph. "Introduction." Narration as Knowledge: Tales of the Teaching Life. Ed. Joseph Trimmer. Portsmouth, NH: Boynton/Cook, 1997. ix-xv.

Villanueva, Victor. "The Givens in Our Conversations: The Writing Process." Cross-Talk in Comp Theory. 2nd ed. Ed. Victor Villanueva. Urbana, IL: NCTE, 2003. 1-2.

Voss, Ralph F. “Janet Emig's The Composing Processes of Twelfth Graders: A Reassessment." College Composition and Communication 34.3 (1983): 278-83.

Wandless, Bill. "The Scarlet Letters: Toward a More Reflective Method of Grading Process Writing." In Our Own Voice: Graduate Students Teach Writing. Boston: Allyn \& Bacon, 2000. 275-82.

Welch, Nancy. "Resisting the Faith: Conversion, Resistance, and the Training of Teachers." College English 55.4 (1993): 387-401.

---. "Telling Tales about Teaching Writing." College English 59.8 (1997): 939-45.

White, Hayden. "The Value of Narrativity in the Representation of Reality." Critical Inquiry 7.1 (1980): 5-27.

Williams, Bronwyn. "Heroes, Rebels, and Victims: Student Identities in Literacy Narratives." Journal of Adolescent \& Adult Literacy 47.4 (2003): 342-45.

Yagelski, Robert P. "It's (My) Story, but I'm (Not) Sticking to It." College Composition and Communication 52.4 (2001): 655-58.

---. "The Ambivalence of Reflection: Critical Pedagogies, Identity, and the Writing Teacher." College Composition and Communication 51.1 (1999); 32-50. 


\section{APPENDIX A:}

\section{IRB APPROVAL DOCUMENTATION}

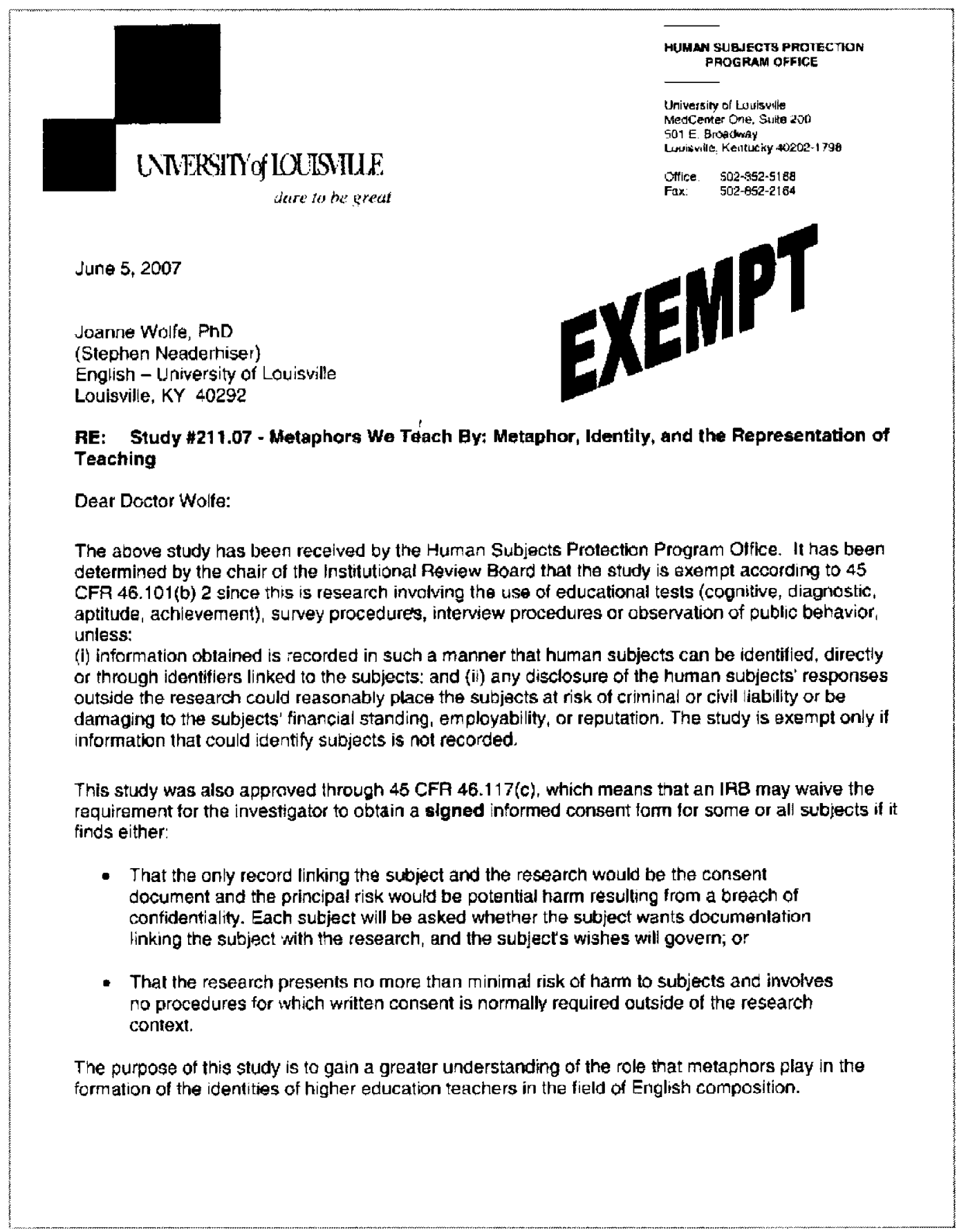


Site Approval

If this study will take place at an affiliated research institulion, such as Jewish Hospitalst Mary's Hospital, Norton Healthcars, or University of Louisville Hospital, site approval by the affiliated institution must be given before the research may begin.

Please advise if there is any change in the protocol so that the IFB may cetermine if the study still meets the exemption criteria. Best wishes for a successful study. Please send all inquires and electronic revised/requested items to our office emall address at hsppofo louisville.edu.

Sincerely,

Pxo in aused

Peter M. Quesada, Ph.D., Vice Chair

Social/Behavioral/Educational Institulional Review Board

PMQinik 


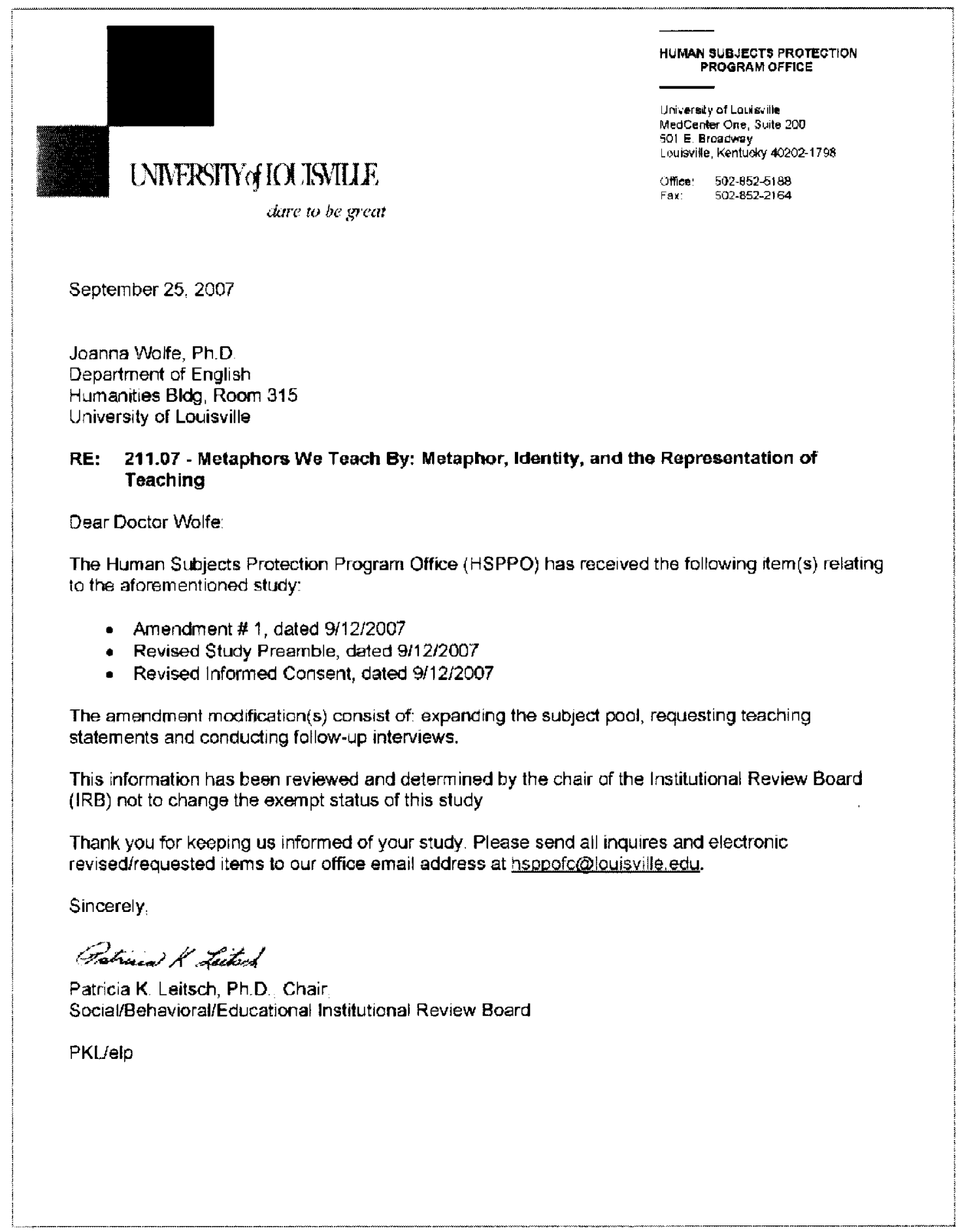




\section{APPENDIX B: INFORMED CONSENT PREAMBLE}

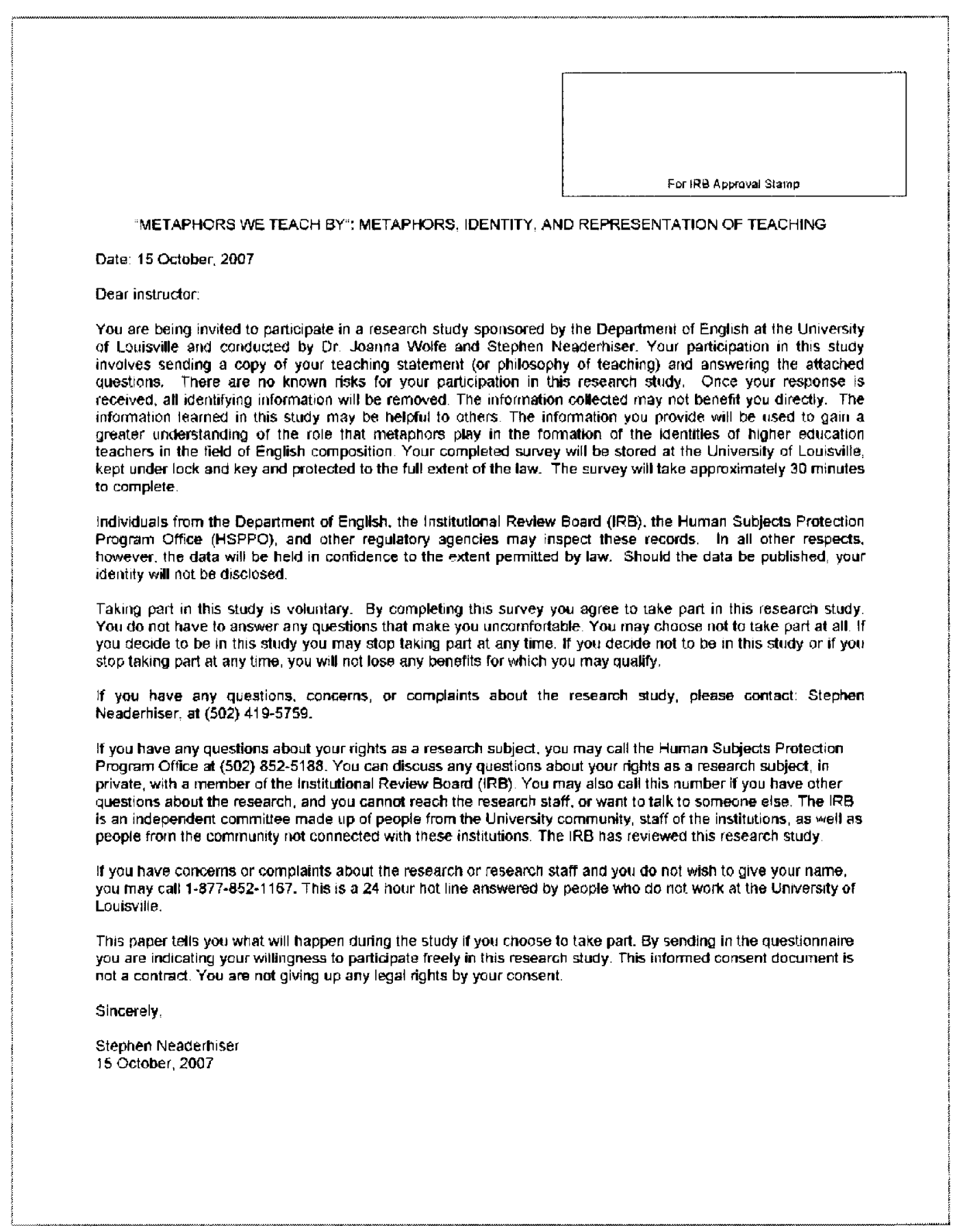




\section{APPENDIX C: \\ RECRUITMENT EMAIL FOR STUDY PARTICIPATION}

Subject Line: Study Request

"Metaphor, Identity, and the Representation of Teaching"

Request for Survey and Teaching Philosophies

We are Joanna Wolfe, $\mathrm{PhD}$, a faculty member in the English Department at the University of Louisville, and Stephen Neaderhiser, a graduate student in the $\mathrm{PhD}$ program at the University of Louisville. We are conducting a research project that explores the ways composition teachers describe their teaching styles, methods, and experiences. To this end, we are conducting a survey and collecting teaching statements from composition instructors. We hope to learn about how teachers of composition perceive and express different metaphoric roles for teaching in their own personal teaching experiences and learning communities.

If you are a composition instructor who is interested in participating in this study, we invite you to complete the attached survey, and send it to Stephen at senead01@louisville.edu. We would also like to receive a copy of your pre-existing teaching statement, such as one needed to apply for a teaching position (if you have one available). We will be reading these responses to discover what threads of similarity exist amongst the ways teachers represent their teaching styles and experiences. In addition, we may contact you in the future for a possible interview during which we would discuss your responses.

You may email your survey and teaching statement to Stephen, at senead01@louisville.edu. Feel free either to attach the file to your email, or copy/paste your response and statement directly into the email. If you do not have a teaching statement, we would still highly value your response to the survey.

All information that would specifically identify you will be removed immediately when we receive your materials. This study is voluntary, and you may discontinue your participation at any time. Attached to this announcement should be the informed consent document, informing you of your rights and expectations in accordance with the study. Thank you for your time, and if you have any questions regarding participating in this survey, please contact Stephen at senead01@louisville.edu.

Sincerely,

Joanna Wolfe

Stephen Neaderhiser

senead01@louisville.edu 


\section{APPENDIX D: SURVEY QUESTIONS ACCOMPANYING TEACHING STATEMENT REQUEST}

Certain figurative or metaphorical tropes find their ways into how we as compositionists discuss our teaching, the field of composition, and our relationship to the academic institution. One example of this is the "teacher-as-parent" metaphor, which emerges in discussions of the nurturant classroom, or, as Kathryn Pauly Morgan (1996) points out, in the comparison of the "emotionally distant father figure" of literature studies to the feminized "mother figure" of composition within English departments. I am interested in learning of the ways that metaphors for teaching in composition are exhibited not only in the scholarship, but also within individual teachers' discourse and communities. Thus, I would like to ask for your input in this.

- What focus or field is your work in (Rhet/Comp, English Literature, etc.)?

- [If a graduate student] How far along are you in your graduate work?

- How many years of teaching experience do you have?

- How would you describe your teaching style, in general?

- When considering your description of your teaching, relationship with your students, and/or position in the English department, what roles (if any) do you find yourself adhering to? How so?

- What would you see as being some of the dominant or prevailing metaphors within the field of composition?

- Are there certain metaphors for teaching that you find being used often in your local teaching community or institution? Do you find these metaphors to be unique to your community, and why (or why not)?

- Of the metaphors you perceive, in scholarship or in your own personal experience, are there any that you feel are particularly productive ways to think about teaching? Why? Are there ones you find to be unproductive in any way? 


\section{CURRICULUM VITAE}

NAME: $\quad$ Stephen Edwin Neaderhiser

ADDRESS: Bingham Humanities, Rm. 315

Department of English

University of Louisville

Louisville, KY 40292

DOB: $\quad$ Manhattan, KS - July 28, 1978

EDUCATION: $\quad$ Ph.D., Rhetoric and Composition

University of Louisville

2004-2009

M.A., English

University of Kansas

2002-2004

B.A., English

University of Kansas

1996-2002

TEACHING

EXPERIENCE: $\quad$ Assistant Professor, Department of English, Kent State University - Stark, North Canton, OH (starting 08/2009)

Graduate Teaching Assistant, Department of English, University of Louisville, Louisville, KY (08/2004-08/2009)

Graduate Teaching Assistant, Department of English, University of Kansas, Lawrence, KS (08/2003-05/2004)

PUBLICATIONS: "Between Technological Endorsement and Resistance: The State of Online Writing Centers," co-authored with Joanna Wolfe.

Writing Center Journal 29.1 (Spring 2009). 49-77.

"Click YES to Continue': The Course Syllabus as an End-User Licensing Agreement," co-authored with Christopher Alexander. In process. 
CONFERENCES: "What Role(s) Recitation? - A Dialogue Concerning Recitation and Literacy," with Christopher Alexander. Conference on Expanding Literacy Studies. Ohio State University. Columbus, $\mathrm{OH}$, April 2009.

"Explorations through Time and Space: Technology and the Chronotope in the Composition Classroom." Thomas R. Watson Conference on Rhetoric and Composition. Louisville, KY, October 2008.

"Oh, What a Beautiful Yesterday: Disentangling the 'Uncle Remus' Stories from the Briar Patch." Kentucky Philological Association. Barbourville, KY, March 2007.

"“What I Learned at School Today': Complicating the Notion of the Teacher Narrative." Thomas R. Watson Conference on Rhetoric and Composition. Louisville, KY, October 2006.

"Panel on Improving the WCRP Survey." East Central Writing Centers Association. Alliance, OH, March 2006.

"Transformative Consumptions and Consuming Transformants: Dr. Jekyll and Mr. Hyde's Potential in the (Real) Victorian World." Kentucky Philological Association. Bowling Green, KY, March 2006.

ADMINISTRATIVE EXPERIENCE: $\quad$ Assistant Director, Writing Centers Research Project, University of Louisville, Louisville, KY (8/2005 - 7/2007)

Graduate Coordinator, "The Lebowski Cult: An Academic Symposium." Louisville, KY, September 2006.

GRADUATE COURSEWORK UofL:

Teaching College Composition (B. Williams)

The Rhetoric of Science (M. Rosner) Popular Culture and Literacy (B. Williams) Research Methods in Composition (D. Journet) Seminar in Rhetorical Studies: Narrative Theory (D. Journet) Human Computer Interaction (J. Wolfe) Seminar in Rhetorical Studies: Literacy (D. Brandt) Composition Theory and Practice (K. Kopelson) Queer Theory (K. Kopelson)

19th Century British Lit: Fantastic Metamorphoses (S. Griffin) 
20th Century Lit: Globalization, Migrations, Diasporas (E. Willey) The Civil War and American Culture (S. Ryan)

GRADUATE COURSEWORK $\mathrm{KU}$ :
Advanced Composition Theory (F. Farmer)

Feminism and Composition (F. Farmer and A. Devitt)

Independent Study: The Rhetorical Tradition (F. Farmer)

History of the English Language (J. Hartman)

Advanced English Grammar (J. Hartman)

Bakhtinian Theory (F. Farmer)

Renaissance Poetry (M. Swann)

The Slave Narrative (M. Caminero-Santangelo)

TECHNOLOGICAL

LITERACIES: Proficient in multimodal (audio, video, and graphic) technologies and software

Extensive knowledge of web page development (Front Page,

HTML)

Programming knowledge in ColdFusion, Visual Basic

Proficient in MS Office, Photoshop, Adobe software suite,

CorelDRAW graphics suite

FOREIGN

LANGUAGE: $\quad$ Proficient in French, German

PROFESSIONAL

ASSOCIATIONS: Member, National Council of Teachers of English

Member, Modern Language Association

Member, English Graduate Organization (EGO), University of

Louisville

ACTIVITIES: $\quad$ Graduate Coordinator, Intramural Reading Group (IRG),

University of Louisville

Coordinator, Social Graduate Student Listserv (ID), University of

Louisville

PROFESSIONAL

INTERESTS: $\quad$ Business Writing

Technical Writing

Composition

Science and Technology Studies

Popular Culture Studies

Bakhtinian Theory

Metaphor Theory

Computers and Composition 